\title{
Hyperscales: Analysis, Historical Uses, and Possible Applications in Contemporary Music Composition
}

\author{
Douglas Wayne Brown \\ West Virginia University, douglas.brown@mail.wvu.edu
}

Follow this and additional works at: https://researchrepository.wvu.edu/etd

Part of the Composition Commons

\section{Recommended Citation \\ Brown, Douglas Wayne, "Hyperscales: Analysis, Historical Uses, and Possible Applications in Contemporary Music Composition" (2019). Graduate Theses, Dissertations, and Problem Reports. 7406. https://researchrepository.wvu.edu/etd/7406}

This Problem/Project Report is protected by copyright and/or related rights. It has been brought to you by the The Research Repository @WVU with permission from the rights-holder(s). You are free to use this Problem/Project Report in any way that is permitted by the copyright and related rights legislation that applies to your use. For other uses you must obtain permission from the rights-holder(s) directly, unless additional rights are indicated by a Creative Commons license in the record and/ or on the work itself. This Problem/Project Report has been accepted for inclusion in WVU Graduate Theses, Dissertations, and Problem Reports collection by an authorized administrator of The Research Repository @ WVU. For more information, please contact researchrepository@mail.wvu.edu. 


\title{
Hyperscales:
}

\section{Analysis, Historical Uses, and Possible Applications in Contemporary Music Composition}

\section{Douglas Brown}

\section{A Research Document submitted to the}

College of Creative Arts

at

West Virginia University

in partial fulfillment of the requirements for the degree of

Doctor of Musical Arts

in

Composition

\author{
David Taddie, Ph.D., Chair \\ Matthew Heap, Ph.D. \\ Travis Stimeling, Ph.D. \\ Andrea Priester Houde, M.M. \\ Jules Malarcher, Ph.D. \\ School of Music
}

\section{Morgantown, West Virginia}

2019

Keywords: hyperscale, pitch organization, Adonai malakh, Dastgāh e-Māhur, znamenny chant, Algerian scale, Jacques Ibert, Joel Hoffman, 6-8-2-4-5-8, pitch field, Slonimsky

(C) Copyright 2019 Douglas Brown 


\title{
ABSTRACT \\ Hyperscales: \\ Analysis, Historical Uses, and Possible Applications in Contemporary Music Composition
}

\author{
Douglas Brown
}

This paper introduces the hyperscale, defines terminology that is new or potentially ambiguous, examines historical scales which may be a hyperscale or not (with examples when available), introduces two synthetic hyperscales created by the author, tells the story behind their creation through an analysis of an original piece by the author that uses both scales, compares the scale characteristics and composition techniques used in the piece with those of another piece written by a contemporary composer, and finally offers some concluding thoughts on the future of the hyperscale in art music. Because relatively little scholarship exists for this topic, this paper serves as both an introduction and an analysis of various approaches in the creation of hyperscales and of the use of existing hyperscales. 


\section{Table of Contents}

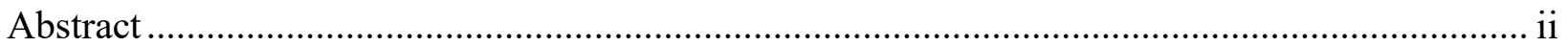

Chapter 1. Introduction: Thinking Beyond One Octave ................................................................

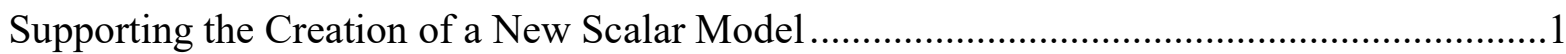

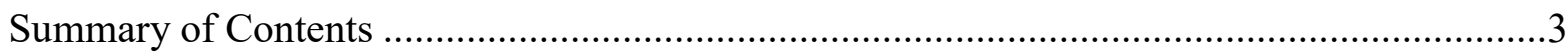

Chapter 2. The Concept of Scalar Expansion Beyond One Octave ...................................................

Identification of a Hyperscale ............................................................................................

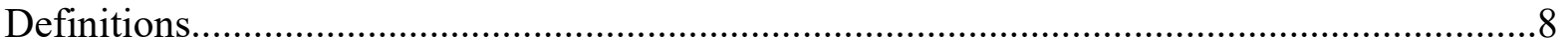

More on Octave Displacement...........................................................................................

Major and Minor Hyperscales ......................................................................................12

Chapter 3. Hyperscalar and Hyperscale-like Paradigms in History ...............................................20

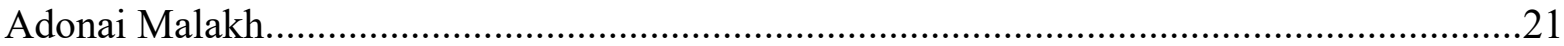

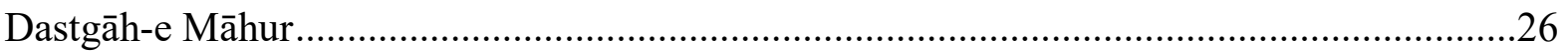

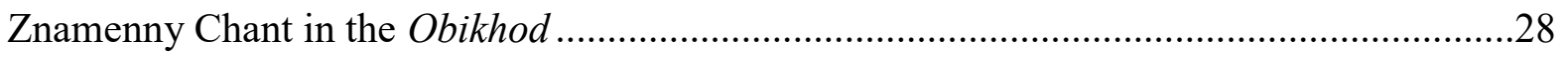

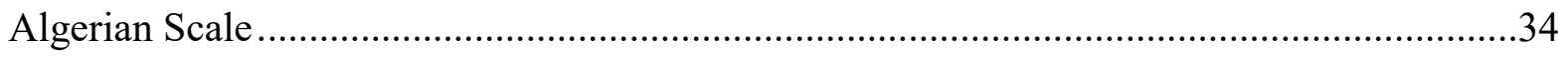

Contemporary Scales: Joel Hoffman ................................................................................42

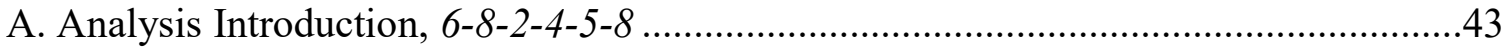

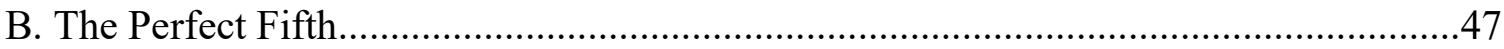

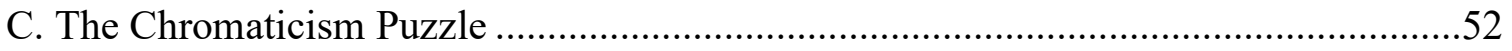

D. Solving the Puzzle and Confirming the Intervals ........................................................53

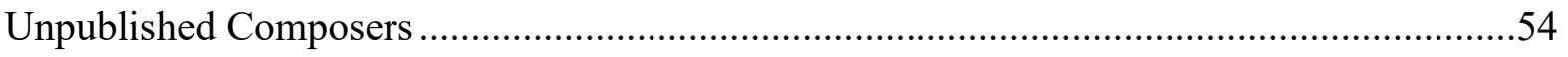

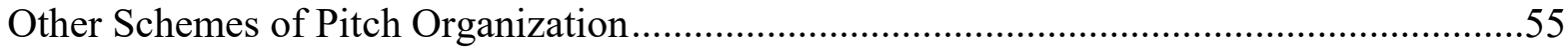

A. Process Composition .............................................................................................55

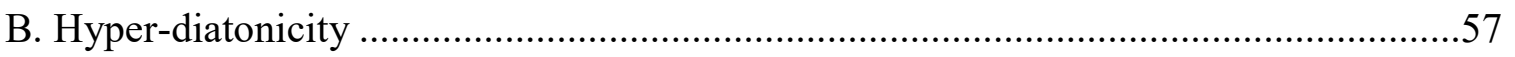

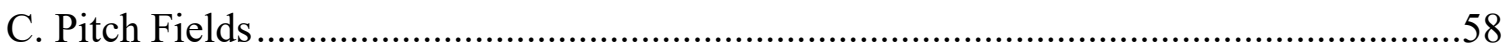


Chapter 4. Creation of a Practical Piece for Performance, Streetwise

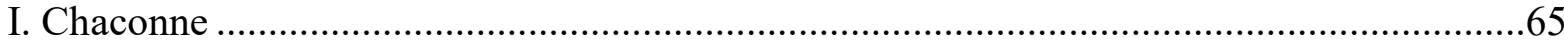

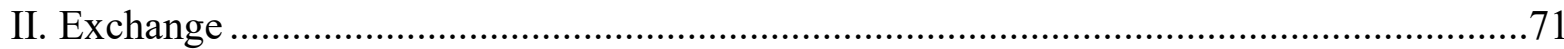

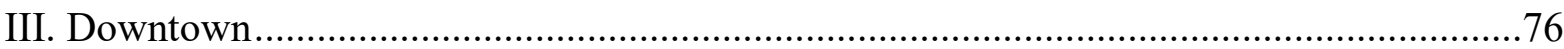

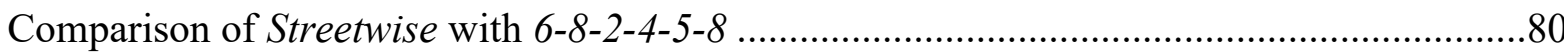

Chapter 5. Final Thoughts: Observations about the Future Development of the Hyperscale ........82

Challenges of Harmony within the Cycle of Functions ..........................................................82

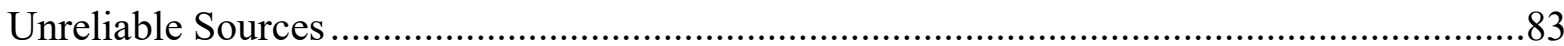

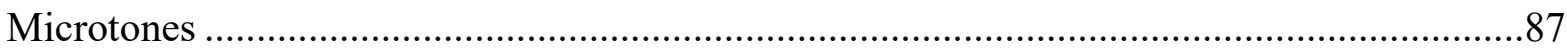

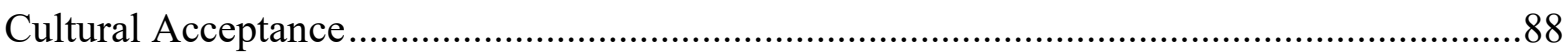

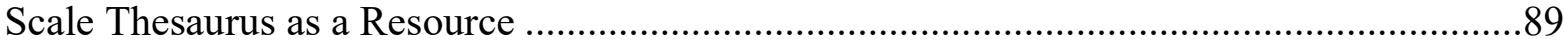

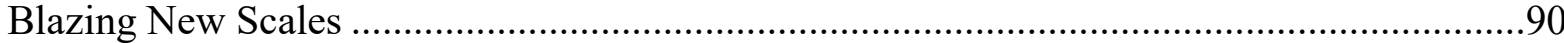

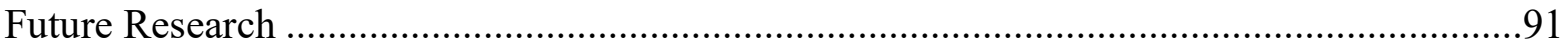

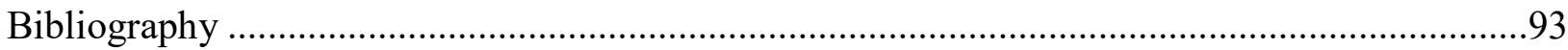

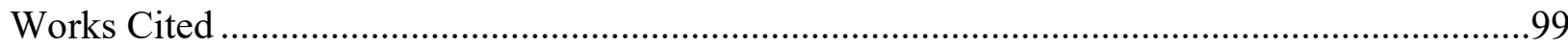

Appendix: Streetwise Study Score .......................................................................................103 


\section{Chapter 1. Introduction: Thinking Beyond One Octave}

The seed for this paper was planted over eight years ago, in the spring of 2011 , with a simple problem for a composition that was solved by an equally simple solution. The work that I was writing, a piece for horn and saxophone double quartet, had a melodic cadence in its introduction that I believed was overly plain for the expressive mood and series of chromatic modulations present in the first movement. The natural tendency of the melody in this place was to ascend by step to tonic - La-Ti-Do - but I thought this to be too obvious and decided that ending on Do did not evoke a suitable mood for the movement. ${ }^{1}$ After experimenting with the melody in different ways, I came up with a solution by having the melody end not on tonic but on the next half step above by ascending a whole step from Ti to Di, the raised 8th scale degree an augmented octave above the lower tonic. The "missed resolution" that I was hoping for, however, resulted in the effect of a secondary dominant. I followed by sequencing this new whole-step motive throughout the first movement to obfuscate the tonic, which I believe turned out well. Birthed from this moment came a method of pitch organization which became the hyperscale - fundamentally, a scale that exceeds the span of one octave, which is explained in more detail starting on p. 7.

\section{Supporting the Creation of a New Scalar Model}

While this sequence turned out not to define the primary character of the double-quartet piece, my mind began pondering the use of the missed-Do concept in future compositions -

1. http://www.jstor.org.www.libproxy.wvu.edu/stable/24045329. This paper uses a solfége system with movable Do, always places Do in the (lower) tonic position, and uses a similar system to one found at the following source. Pitches in this paper are labeled on the ascending major scale thus: [lowered-original-raised, respectively] De-Do-Di, Ra-Re-Ri, Me-Mi-Ma, Fe-Fa-Fi, Se-Sol-Si, Le-La-Li, Te-Ti-Ta. Steve Larson. "The Value of Cognitive Models in Evaluating Solfege Systems.” Indiana Theory Review 14, no. 2 (1993): 98. 
possibly as the foundation of a synthetic scale that a composer could successfully mislead the listener, away from the leading-tone-to-tonic melodic tendency while leaning toward semblance of structure and necessary order. Since the tonic pitches on either end of the one-octave scale are significant for two important qualities - one, the property of the higher pitch has a wavelength that is one-half the length of the lower; and two, this pair marks the outer boundaries that contain the other pitches as a defined set - important to me was that this new hyperscale, a term that I coined at this moment, could retain these strong attributes common to one-octave scales.

I also sought justification for the creation of a new scale. Because a hyperscale does not satisfy the first attribute above of a one-octave scale - by ending exactly one octave higher than the starting pitch - a new work using the new hyperscale would need to subconsciously satisfy the question of why the scale stops and starts where it does. Its purpose would also need to incorporate my desire to give the impression that the upper tonic was approached but overshot, as I attempted in the double quartet. Creating a half step between the sixth and seventh scale degrees $-\mathrm{La}$ to $\mathrm{Ti}-$ of the major scale through lowering the leading tone $-\mathrm{Ti}$ becomes $\mathrm{Te}-$ now creates a whole step up to Do, which does not create any room to miss the tonic, except for perhaps going up another half step to Di. However, my preference is to avoid the three-half step, avoiding an interval in the scale that sounds exotic and cliché to me. I eventually decided on applying more closely the technique I used in the double quartet by keeping the seventh scale degree on Ti but continuing the ascent by whole step until encountering another note used in the scale previously to signal the end of the hyperscale - just as encountering tonic (or the key center) in any one-octave scale signals its own completion. As a result, the new scale passes through the raised eighth, Di, and raised ninth, $\mathrm{Ri}$, on its way to the raised tenth scale degree, $\mathrm{Ma},-$ that is, a raised scale-degree three but one octave higher - which is the enharmonic 
equivalent to the unraised fourth scale degree, Fa, taken one octave higher that appears earlier and, therefore, the end of the scale. (See Figure 2 on p. 12 and the accompanying text.)

Thus, by ending on a repeated pitch, this new major hyperscale satisfies the concern of the properties of the starting and ending notes of the scale. Although the lowest note of the scale, tonic, no longer has the first partial (one octave) above, in the way this scale is used the second and third partials (octave + fifth, two octaves) are still present.

\section{$\underline{\text { Summary of Contents }}$}

Because the hyperscale is a relatively unknown tool in the composer's arsenal for writing music in a postmodern, postminimal setting with great, untapped potential, this paper is a survey that approaches the hyperscale from the three perspectives of music theory, history, and composition. The next chapter, devoted to the theory of the hyperscale in general, begins with identifying its properties, definitions of terminology that are either new or require clarity, and delineation of the two new scales - major hyperscale and minor hyperscale - as created by the author. This chapter contains two tables that show the possible triads and seventh chords that are directly created or implied by the "triads" in the major and minor hyperscales and two more tables that cross-reference the complete set of possible chords by chord symbol and those used in Roman-numeral analysis using $\mathrm{F}$ in the tonic position as an example.

The third chapter focuses on the history of the hyperscale. Very few examples of this device exist in pre-Modern music, but those that do represent a broad cross-section of global culture. The Adonai malakh, dastgāh-e Māhur, and znamenny chant scales are virtually identical, though historically they function differently and were developed independently of each other. Scholarship on this "family" of hyperscale is very limited, and examples in print are 
difficult to find. Existing pieces that are identified by English-language academia are generally unclear or are currently out of print, thus presenting an opportunity for others to fill in the holes with future research.

During his travels through the Mediterranean, French composer Jacques Ibert discovered a hyperscale, the Algerian scale, which he cleverly exploited in the second movement of Escales, for chamber ensemble. A thorough analysis of the work included here focuses on Ibert's apparent familiarity of the Algerian scale through careful scoring of the pitch collection via his treatment of the oboe melody and harmony in each supporting instrument.

Retired Cincinnati Conservatory of Music professor and composer Joel Hoffman currently collaborates with musicians - composers and performers, alike - in China. A composition colleague named Gao Weijie independently conceived of artificial scales that exceed or fall short of the span of one octave. ${ }^{2}$ Gao's influence appears to have affected Hoffman profoundly through some of his own compositions, and this paper examines one such work that makes significant use of the hyperscale: $6-8-2-4-5-8$. This chamber piece commissioned by Eighth Blackbird introduces an original hyperscale in the vein of tertian and quintal harmony.

This chapter also briefly touches on three other techniques that are not necessarily hyperscalar but important to this study as near misses: the process-composition style of Karlheinz Stockhausen, the hyper-diatonicity of Stefan Wolpe, and pitch fields, most notably used by Luciano Berio. The first of these compositional methods uses pitches that exceed the normal octave but has no defined set and uses non-discrete pitches. The second uses added pitches inside a scale but does not employ them in a manner outside the one-octave scale. The

2. Joel Hoffman. “6-8-2-4-5-8.” E-mail message to author. February 21, 2019. 
final method examined uses a series of discrete pitches that exceed one octave though are not always scalar in nature.

This paper is designed to highlight the theoretical and historical approaches with new methods of pitch organization via use of a hyperscale, either through construction of a new scale or from an existing scale. Thus, the goal of this work is to be informative, thought-provoking, and - ultimately - helpful to the composer to use an idea found here for future writing. Chapter Four demonstrates practical application of major and minor hyperscales in a piece I composed, consisting of an analysis of the hyperscalar characteristics of a piece for tuba and piano, titled Streetwise.

The first movement of Streetwise employs the major hyperscale alternating with the minor-major scale. ${ }^{3}$ The analysis shows how the hyperscale creates a unique "cycle of functions" of sorts, how modulation is created through various techniques, and how the movement attempts to ease the common listener from tertian harmony into a new listening paradigm. Here also begins an account of a compositional puzzle built on a quintal chord that is threaded through movements one and two as a veiled remark on the relationship between the two hyperscales I use and the typical major and minor scales used historically in music composition.

The second movement features both the major and minor hyperscales. Here I created another cycle of functions, manipulated into several variations that are summarized by Table 6 within the chapter, to show how these two hyperscales are as harmonically flexible as a oneoctave scale. The interplay between major and minor hyperscales is analyzed in depth: simultaneous chords from both scales built on the same scale degree, obfuscation of major and

3. A minor-major scale, also known as jazz harmonic minor, has degree three at a minor interval above tonic and the sixth and seventh degrees at major intervals above tonic. In C, this scale is C-D-Eb-F-G-A-B-C. Middlebrook. Scales \& Modes, 88. 
minor (similar to what can be found in one-octave pieces), further exploration of modulation techniques, and the conclusion to the aforementioned puzzle.

Movement three is a display of different ways to tonicize the minor hyperscale through modalization, an analysis of the use of the three tritones that naturally occur in the minor hyperscale, and a compositional experiment of how much I could dissolve the integrity of both the major and minor hyperscales while keeping a semblance of their form. The piece ends with another nod to the quintal chord. Large tables in this chapter provide a synopsis of the key analysis of each movement, plus show the possible variants of the complete cycle of functions that this author encountered in both forms of the hyperscales.

Following the analysis, similarities and differences in Streetwise are compared to Hoffman's 6-8-2-4-5-8 to demonstrate how a hyperscale may operate with different characteristics and yet remain viable, the largest difference being that my work focuses on harmonic output while Hoffman's gravitates toward important intervals and chromatic pitches.

Chapter Five concludes the paper by presenting challenges that the composer may encounter while creating new hyperscales or using existing ones. From music theory (function, harmony, microtones, pre-existing scales), to current cultural challenges (legitimacy, unfamiliar culture), to further academic implications (reliability of sources, future research possibilities), this list is by no means exhaustive, but the number of sections in this chapter suggest that the enterprising composer has many matters to consider and explore in terms of pitch organization. 


\section{Chapter 2. The Concept of Scalar Expansion Beyond One Octave}

\section{$\underline{\text { Identification of a Hyperscale }}$}

After finding few results in an extensive search for scales that exceed one octave, I chose to coin the term "hyperscale" in order to distinguish scales with the characteristics outlined below from other forms of pitch organization, such as "pitch fields" (see p. 59). As far as I know, no other term exists to adequately distinguish such a scale, thus this term with be used throughout the document.

Most scales in the Western tradition, by rule, do not exceed one octave. When an ascending scale starting on tonic reaches the pitch at half its wavelength - which is also regarded as tonic - the scale ends, and while these scales may be performed further upward (or downward) and onward, the scale is fundamentally the same, only echoed within a different octave. In its most fundamental meaning, a hyperscale is a series of notes intended as a scalar representation of a pitch collection that exceeds one octave. The major scale, with the wellknown pattern of whole-whole-half-whole-whole-whole-half, has the distinct quality of an uneven intervallic pattern creating exactly one octave. Had this pattern, by chance, made the scale exceed one octave, it would qualify as a hyperscale. This paper is concerned with scales and a select number of other properties of pitch that surpass the span of one octave that have the potential to be hyperscales, occasionally comparing these properties to the familiar one-octave scale.

Beyond its basic denotation of exceeding an octave, a hyperscale is repeated in more than one instance with the same interval series, whether overlapping, contiguous, or with a gap containing extrascalar pitches (see pp. 14-15 and accompanying Figure 7). Pitches that are distinct from one octave to another as a rule (made to be broken, of course) usually do not 
combine through octave displacement to create a chromatic-like run, but rather should stand out in context. E.g., a scale with $\mathrm{E}$ and $\mathrm{F} \#$ in one octave and $\mathrm{Eb}$ and $\mathrm{F}$ in another octave would sparingly ever be used to create a sequence containing $\mathrm{E} b, \mathrm{E}, \mathrm{F}$, and $\mathrm{F} \#$ together in the same octave in order to preserve the integrity of the scale. (See pp. $33 \mathrm{ff} ., 42 \mathrm{ff}$., and $60 \mathrm{ff}$. for analyses of pieces that subscribe to this principle.)

\section{$\underline{\text { Definitions }}$}

tonic - the lowest pitch in a scale that represents the tonal center, although there may be lower pitches in the scale (see subprimary pitches, below). Tonic is, of course, the highest pitch in the scale that does not contain a secondary octave (see below), per its usual practice in a one-octave scale.

hypertonic - the uppermost note in a hyperscale, marking the end of the scale. This pitch may or may not be repeated lower in the scale; in chapter four I report the importance of this property to me. Pitches between hypertonic and the next higher tonic may be displaced pitches (see octave displacement, below) from pitches in the scale or not diatonic to the scale.

primary octave $(')$ - the lowest octave in the hyperscale that includes the lower tonic pitch and higher, through - but not including - the pitch (if any) one perfect octave higher than the lower tonic. Notation of a pitch in the primary octave is indicated by its letter name followed by a single prime stroke; e.g., $\mathrm{D}$ in the primary octave written as $\mathrm{D}^{\prime}$. The primary octave may not contain the lowest pitches in the scale; see subprimary pitches, below. 


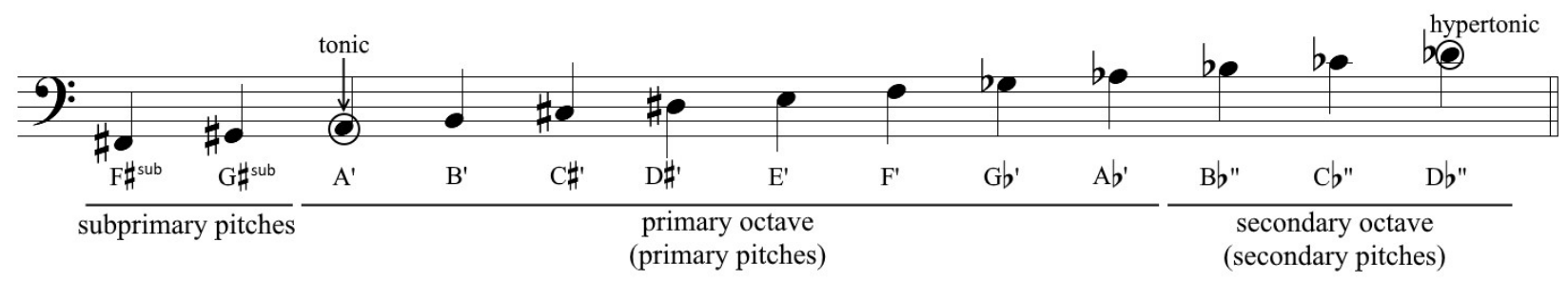

Figure 1. Example of a derived hyperscale, containing subprimary pitches, primary pitches in the primary octave, and secondary pitches in the secondary octave. Note that $\mathrm{Ab}$ is in the primary octave since it is lower than A $\mathrm{A}$.

subprimary pitches ${ }^{(\mathrm{sub})}$ - pitches in a hyperscale that fall below the lowest tonic of the scale and, therefore, below the primary octave; e.g., $\mathrm{G} \#$ in the scale below a tonic A and does not appear higher in the scale - written as $G \sharp$ sub. The number and range of subprimary pitches is technically unlimited.

secondary octave (") - the pitches in a hyperscale which are above the pitches of the primary octave, including the pitch one perfect or augmented octave greater than tonic, if existent; e.g., $\mathrm{B} b$ in the secondary octave written as $\mathrm{B} b "$. Patterns extended into further octaves, such as tertiary ("'), quaternary ("'I'), etc., within a single hyperscale are possible.

octave displacement, often shortened to displacement - the use of pitches in a hyperscale outside of their assigned octave. In the example scale above (Figure 1), if tonic in one instance is located at $\mathrm{A}_{2}, \mathrm{~A} b^{\prime \prime}$ is typically located at $\mathrm{A} b_{3}$, using this pitch at, for example, $\mathrm{A} b_{2}$ (in the primary octave) is octave displacement. 
The term octave displacement may also be used to identify octave transposition outside of the assigned octave, either permanently or for a short period; e.g., the last measure of Streetwise, III. "Downtown" in the right-hand of the piano (see analysis in chapter 4 on pp. 8081 ). Octave displacement is described further in the next section of this paper.

instance - one pitch set of intervallic patterns used in the formation of a complete hyperscale. This term is used in places where octave would normally be used in discussion of a typical oneoctave scale. This paper may also use the word instance in its customary denotation.

octave designation - middle $\mathrm{C}$ equals $\mathrm{C}_{4}$. The diatonic half step lower is $\mathrm{B}_{3}$.

In this paper, keys using the major or minor hyperscale are sometimes abbreviated using the uppercase or lowercase letter, respectively, for the tonic plus "HYP" in small caps; e.g., C Major Hyperscale is abbreviated as CHYP, and C Minor Hyperscale as снYP. In analysis figures, HYP is abbreviated further to a single " $\mathrm{H}$ " followed by a colon, consistent with current analysis practice (as in $\mathrm{CH}_{\mathrm{H}}$ or $\mathrm{CH}:$ ).

\section{$\underline{\text { More on Octave Displacement }}$}

Pitch sets exceeding one octave through displacement do not necessarily make a hyperscale. The two scales historically used chiefly in Western music, major and minor; those that preceded them, church modes; plus most every other scale - but not all - in common use worldwide, past and present, are irregular in structure. A steady sequence of whole- and halfstep patterns - a la transpositionally and sequentially combinatorial pitch sets - is not considered 
for the purpose of this paper (aside from the chromatic scale) a scale, in the traditional sense. ${ }^{4}$ One common set with the sequential property that exceeds one octave to which musicians can relate is the Circle of Fifths. While the argument could be made that each pitch eventually comes around the circle and comprises the current chromatic scale, composing a piece of music that restrains each pitch to its derivative octave becomes a greater novelty over being an exercise in musical skill. Considering the unwieldy nature of such a piece, $\mathrm{C}_{1}-\mathrm{G}_{1}-\mathrm{D}_{2}-\mathrm{A}_{2}-\mathrm{E}_{3}-\mathrm{B}_{3}-\mathrm{F}_{4}-\mathrm{C}_{5}-$ $\mathrm{G}^{\#} 5-(\mathrm{D} \#) \mathrm{E} b_{6}-\mathrm{B} b_{6}-\mathrm{F}_{7}\left[-\mathrm{C}_{8}\right]$, the half-step chromatic scale contained within one octave makes more sense.

This is not to say that octave displacement has no place when using a hyperscale. Streetwise, my own piece presented in this paper, utilizes octave displacement sparingly in order to preserve the integrity of the hyperscale. Because audiences have not heard these new scales frequently enough, if at all, to be familiar with their sound, straying outside the boundaries of the scales too often - even through octave displacement - will destroy the integrity of the scale, consequently overcoming the integrity of the exotic sound for the listener. Common sense guidelines for octave designation, therefore, must be in place for the hyperscale to be effective. Jacques Ibert demonstrates clever displacement of pitches in a hyperscalar melody without losing this strength in his work Escales; an analysis demonstrating this flexible use of the Algerian scale is provided in Chapter Three, starting on p.33.

4. By this definition the chromatic scale is certainly applied in Modern settings as a scale, most notably in the twelve-tone row, though its origin is from the natural overtones. Perhaps the other most significant exceptions, though not all, to this rule today are the octatonic scale - with its whole-half-whole-half-whole-half-whole-half sequence of steps, rotatable into exactly three possible scales notated as $(0,1),(0,2)$, and $(1,2)$ - and the whole step scale, of which there are only two unique possibilities. Regularly-structured scales are commonly considered synthetic because the harmonic overtone series is not a factor in their derivation. Ben Johnston and Bob Gilmore. "Scalar Order as a Compositional Resource: 1962-63." In Maximum Clarity and Other Writings on Music, University of Illinois Press, 2006: 11-13. http://www.jstor.org/stable/10.5406/j.ctt1xcqj6.7. 


\section{Major and Minor Hyperscales}

The two new, complementary scales that I crafted - major hyperscale and minor hyperscale - are the focus of the analysis of Streetwise and are introduced here briefly with a few properties specific to these scales. The major hyperscale consists of the pattern whole-wholehalf-whole-whole-whole-whole-whole-whole, where the pitches in the key of C are C-D-E-F-GA-B-C\#-D\#-E\#(F). I considered many factors in the choices that I made in construction of this scale.

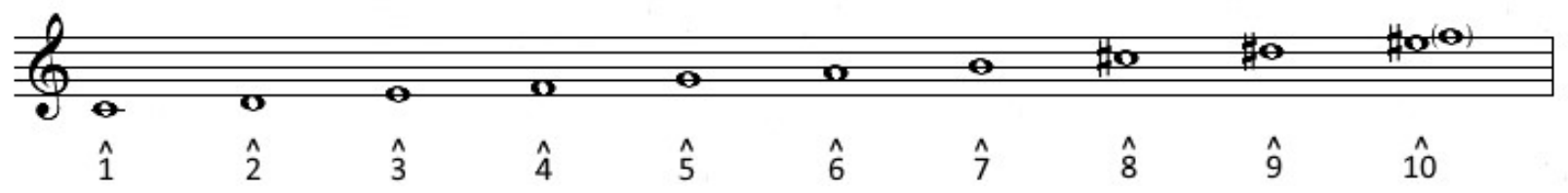

Figure 2. Major hyperscale and its scale degrees.

In the melodic idea presented in Chapter One (see pp. 1-2) that moves upward past the tonic, I was not satisfied at any time that I used pitches that were diatonic to the current key center. While my final solution was that use of chromatic pitches would be necessary for that piece, this sparked the idea in my mind of the possibility of a scale that included additional pitches above the tonic that were not repeated below, hence, the addition of diatonic pitches. I chose to use the major scale as a base, but instead of going up a half step from the leading tone to tonic, the scale would proceed by whole step, stopping when repeating a note that occurs previously, which in this case is the fourth scale degree. A typical scale contains unique pitches except for the upper and lower notes, so I decided that the new scale would need a similar rule in place and chose this as the basis for where the scale ends. Because the scale was created by replacing the last half-step interval with a continuous chain of whole steps to the end, the 
incidental result of the major hyperscale is that the upper six pitches are identical to the wholetone scale. The decision to end with a whole step and not a half step as the one-octave major scale does was a personal aesthetic choice.

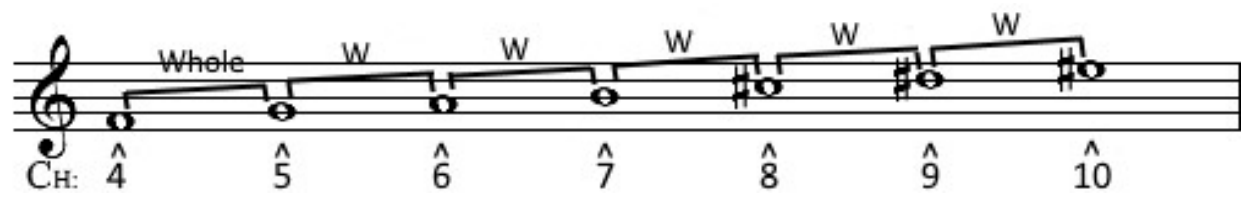

Figure 3. Whole-tone scale at the end of the major hyperscale.

The minor hyperscale is constructed using a similar tactic to the major form by changing the size of the last step in a natural minor scale - on this occasion, reduced to the size of a half step - and appending whole steps until arriving again at the previously used pitch at the third degree. The resulting scale has the pattern whole-half-whole-whole-half-whole-half-wholewhole. Because the minor hyperscale has two half steps where its major partner uses whole steps and has the same number of scale degrees, the minor's hypertonic is two chromatic half steps lower than the major form's hypertonic.

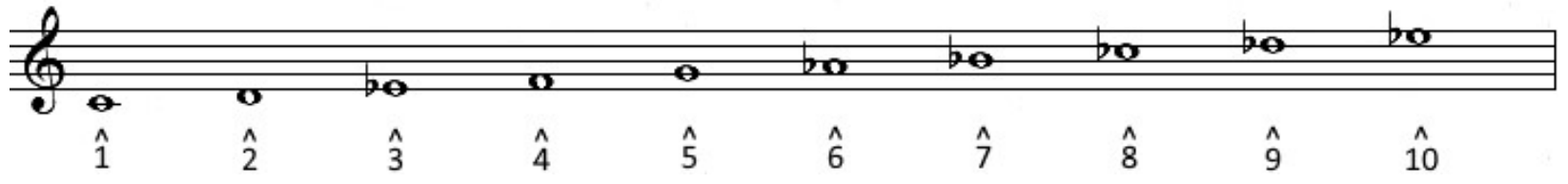

Figure 4. C Minor Hyperscale, as an example, and its scale degrees.

The major hyperscale contains three pitches one whole step apart above the perfect octave over tonic, which in C Major Hyperscale, for example, are $C \sharp ", D \sharp "$, and E\#". The minor hyperscale, however, only contains two pitches in the secondary octave; the lowered eighth scale 
degree falls in the primary octave, though the eighth, ninth, and tenth degrees are also one whole step apart. ${ }^{5}$ Because of the customary sound of one-octave scales, the lay listener is typically aware (at least subconsciously) that the respective raised and lowered eighth degrees fall above and below the perfect octave. "Missing" the perfect octave diatonically allows for new musical ideas for the composer to exploit; for example, scale degrees seven and eight of the major hyperscale reside a half step away from the upper tonic on either side. The analysis of Streetwise in chapter four demonstrates a resolution of these upper and lower leading tones.

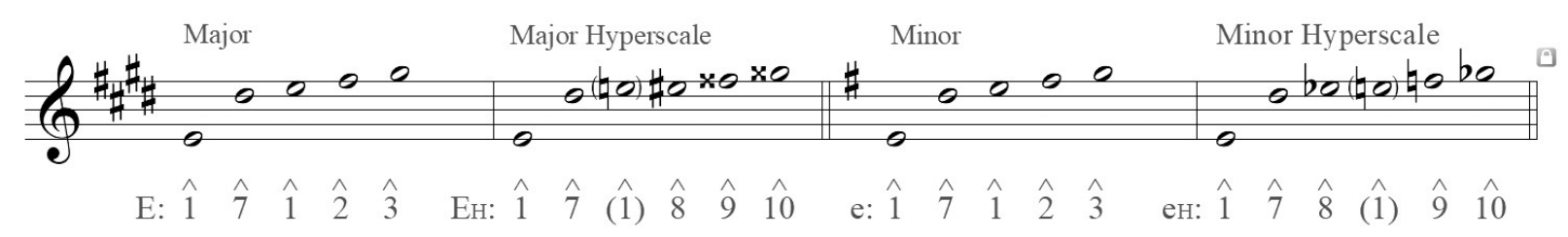

Figure 5. Comparison of altered pitches in major and minor hyperscales to parallel pitches in major and minor scales. Note the relative position of scale degree 1 (in parentheses), upper tonic of the one-octave scale, to its position next to scale degree 8 of each hyperscale.

A pronounced difference between standard scales and their hyperscale companions is the number of available diatonic triads. By nature, each of the major and minor scales contain seven tertian triads:

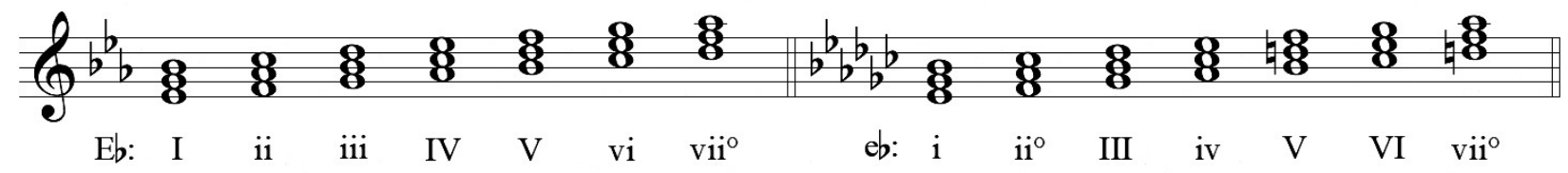

Figure 6. The seven diatonic triads of the Eb Major and Eb Minor scales.

5. The secondary octave begins at the point one perfect octave above tonic, such that a diatonic pitch that is of diminished octave interval falls on the primary octave. A hyperscale may or may not have pitches that rest below the tonic - in the subprimary octave - and has pitches in both primary and secondary octaves. Pitches may or may not fall in the tertiary octave. 
Since I wanted the scale to maintain a key center, I chose to use extrascalar pitches to fill in between each instance of the scales that I created. Therefore, if using B Minor Hyperscale, a tonic of $\mathrm{B}_{2}$ would have a hypertonic of $\mathrm{D}_{3}$, and the next higher series would begin on $\mathrm{B}_{4}$, ending on $\mathrm{D}_{5}$. The result of the latter method in deployment of a hyperscale with a range significantly less than two octaves is a large gap between the hypertonic of the lower instance and the tonic of the upper instance. (See Figure 7, below. Also see page 80 for a comparison between a work that uses this method and another that uses the hypertonic from one instance to create the tonic of the next instance.)

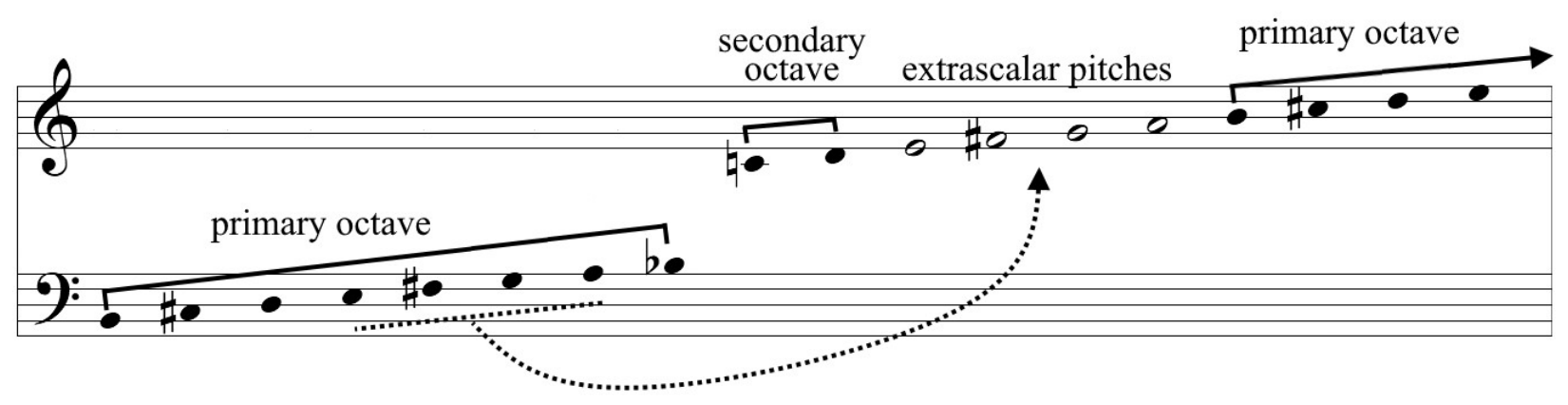

Figure 7. Origin and location of extrascalar pitches relative to the B Minor Hyperscale.

Inserting extrascalar pitches into the large gaps innated present between each instance of the major and minor hyperscales creates consistent overlapping triads in the primary and secondary octaves. I have identified fifteen chords - both triads and implied seventh chords created from the diatonic triads in various inversions in the major hyperscale and thirteen such chords in the minor hyperscale. (See Tables 1 through 4, which follow on the next pages. In each table, tonic lies in odd-numbered octaves; e.g., $\mathrm{F}_{1}, \mathrm{~F}_{3}, \mathrm{~F}_{5}$, etc.) 
Table 1. Possible Diatonic Triads and Implied Chords in Minor Hyperscale, using F Minor Hyperscale as an Example, with tonic on $\mathrm{F}_{2}$.

Root position in secondary octave above tonic
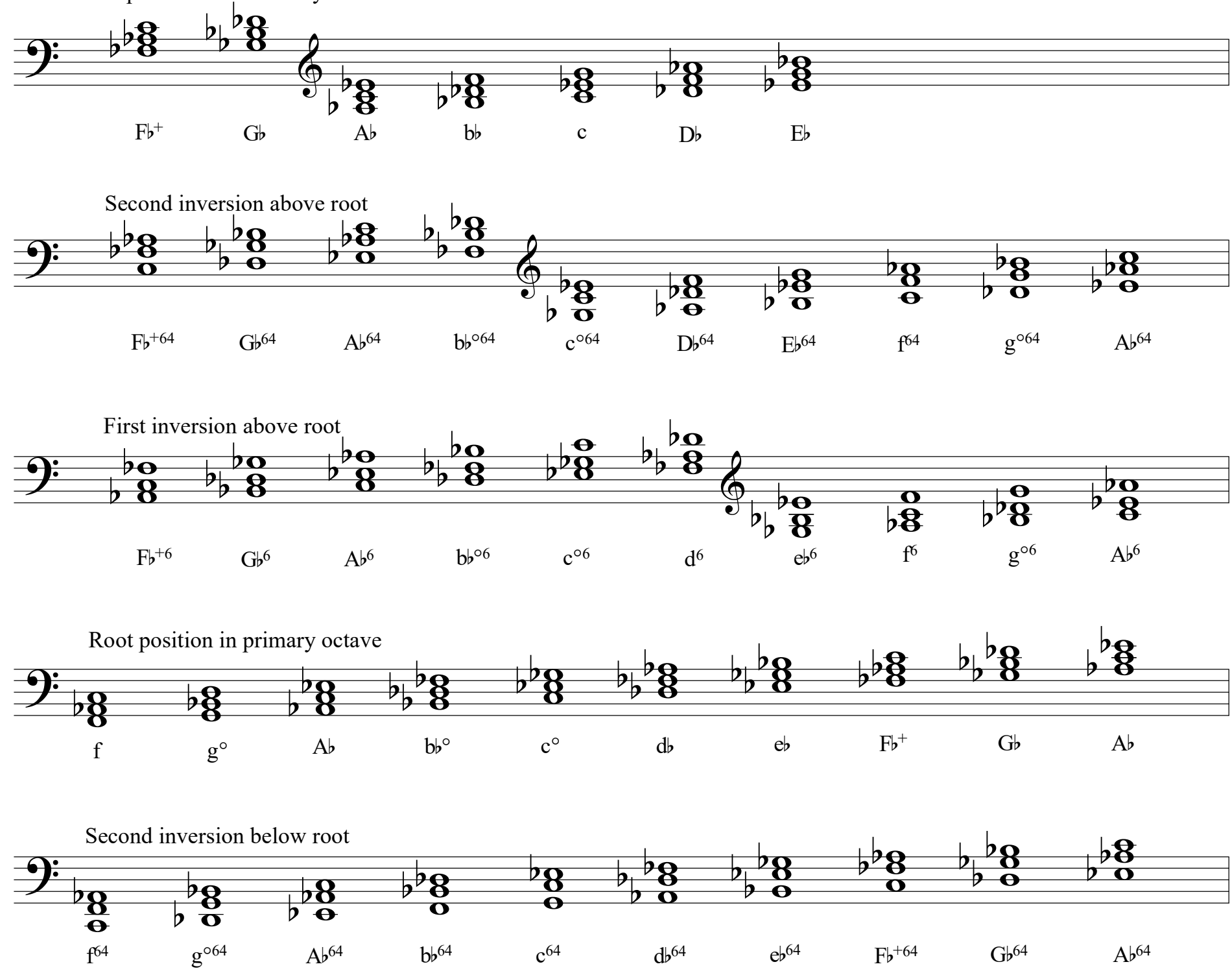

First inversion below root
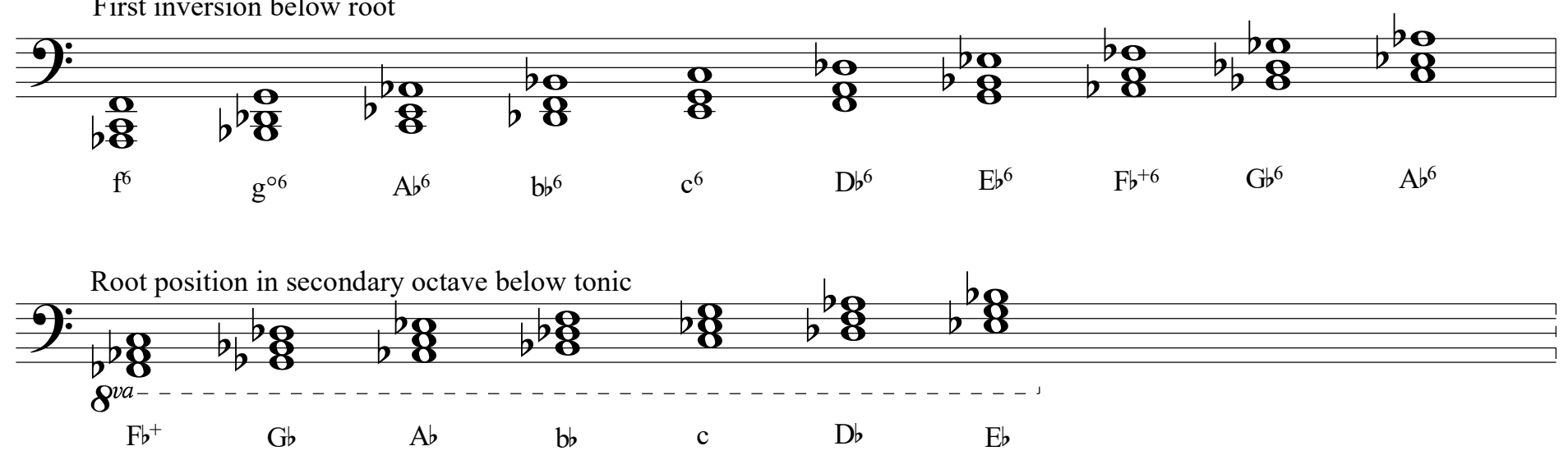
Table 2. Possible Diatonic Triads and Implied Chords in Major Hyperscale, using F Major Hyperscale as an Example, with tonic on F2. Implied chords are labeled inside brackets.

Root position in secondary octave above tonic

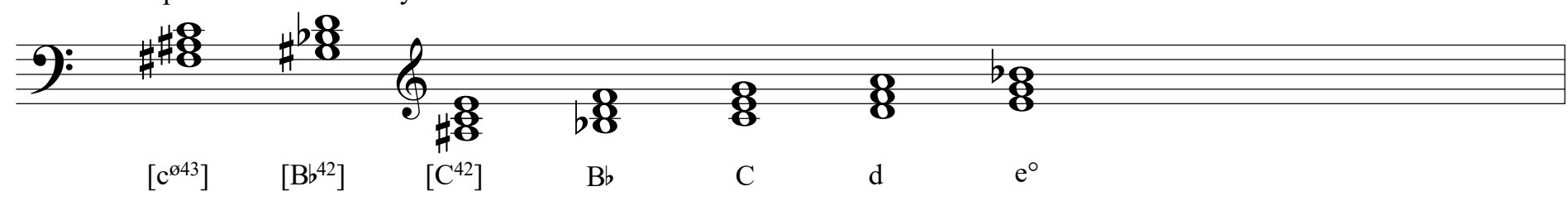

Second inversion above root
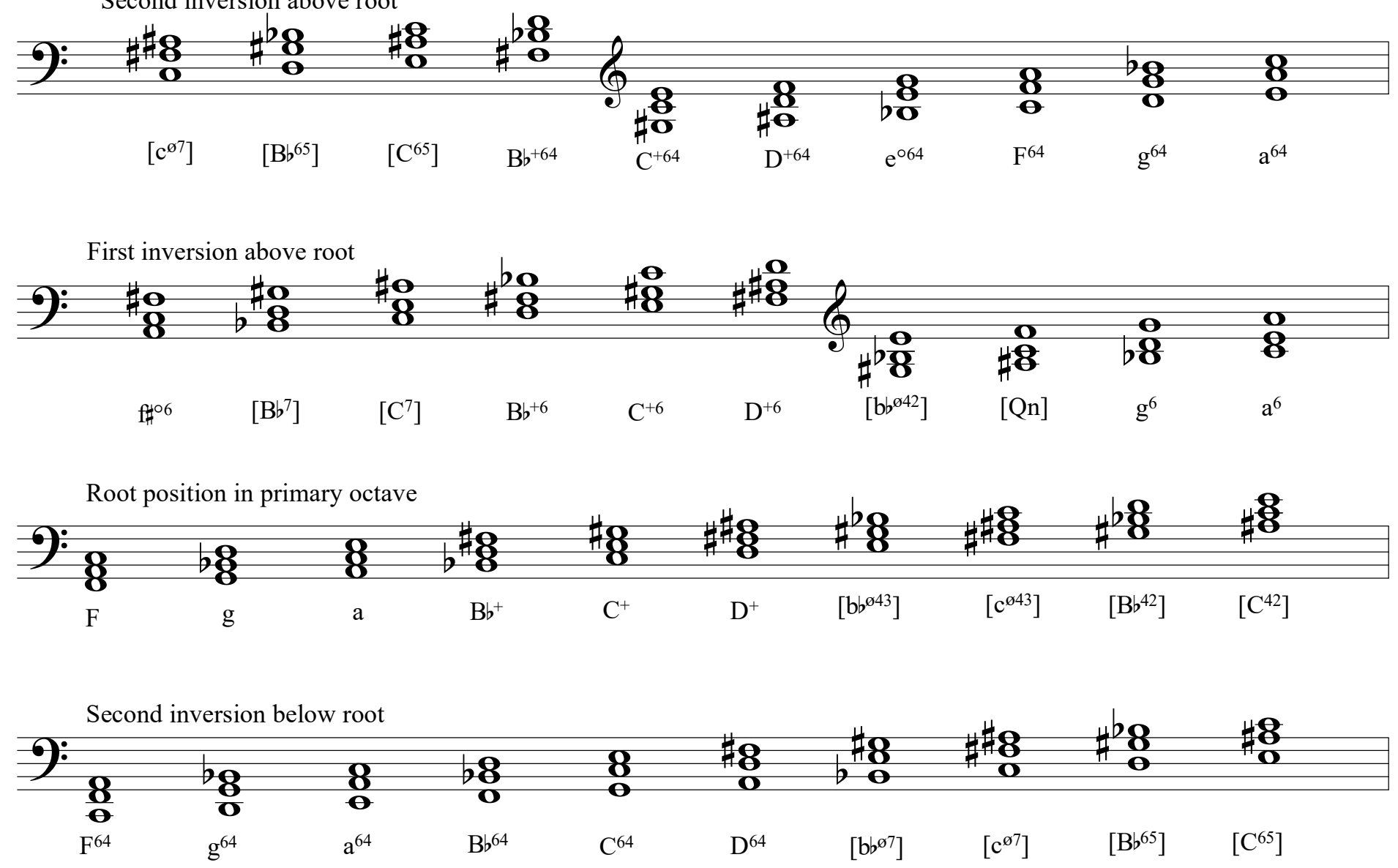

First inversion below root

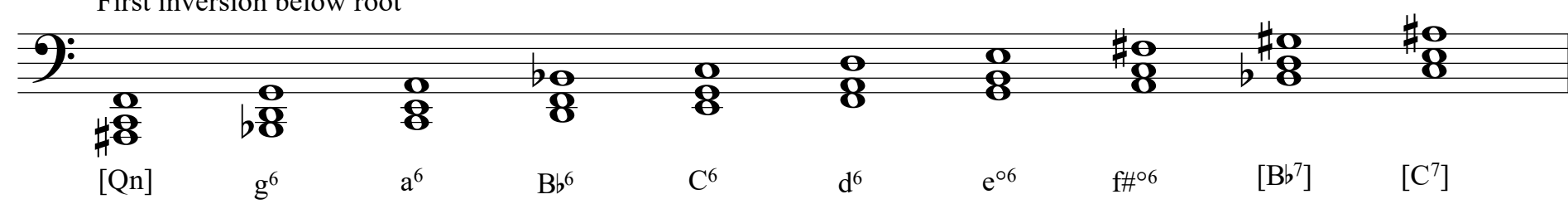

Root position in secondary octave below tonic

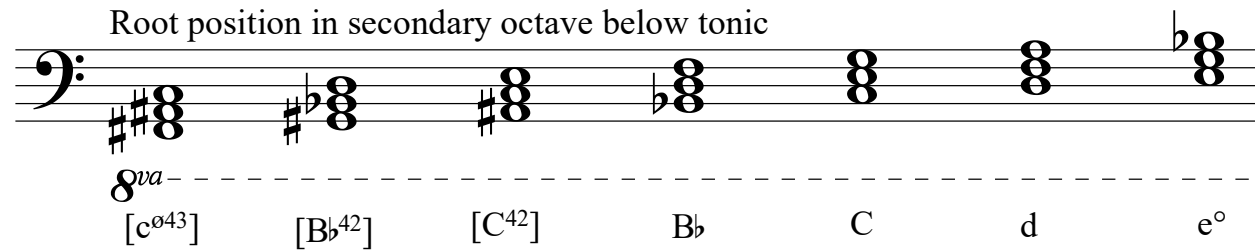




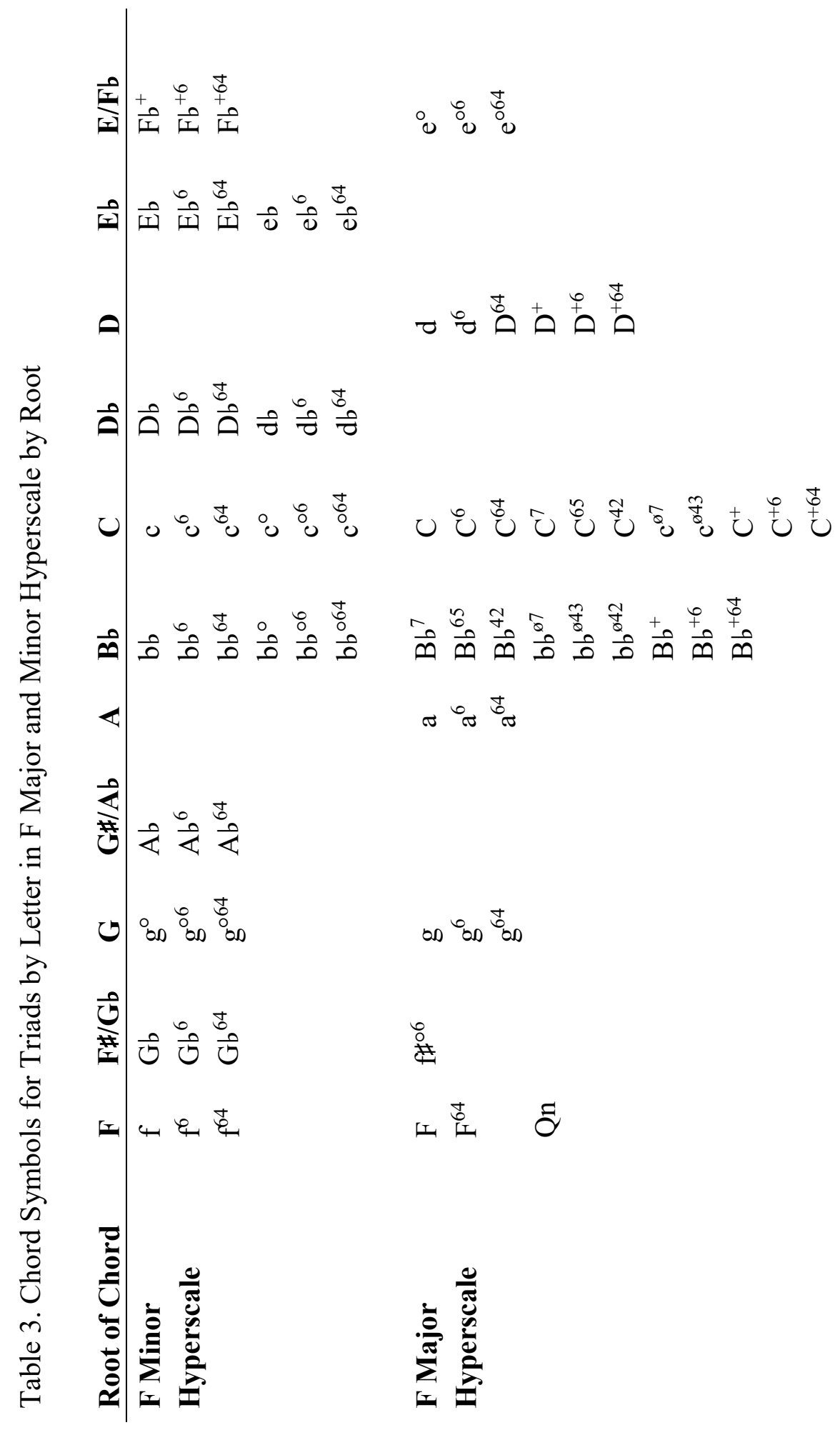




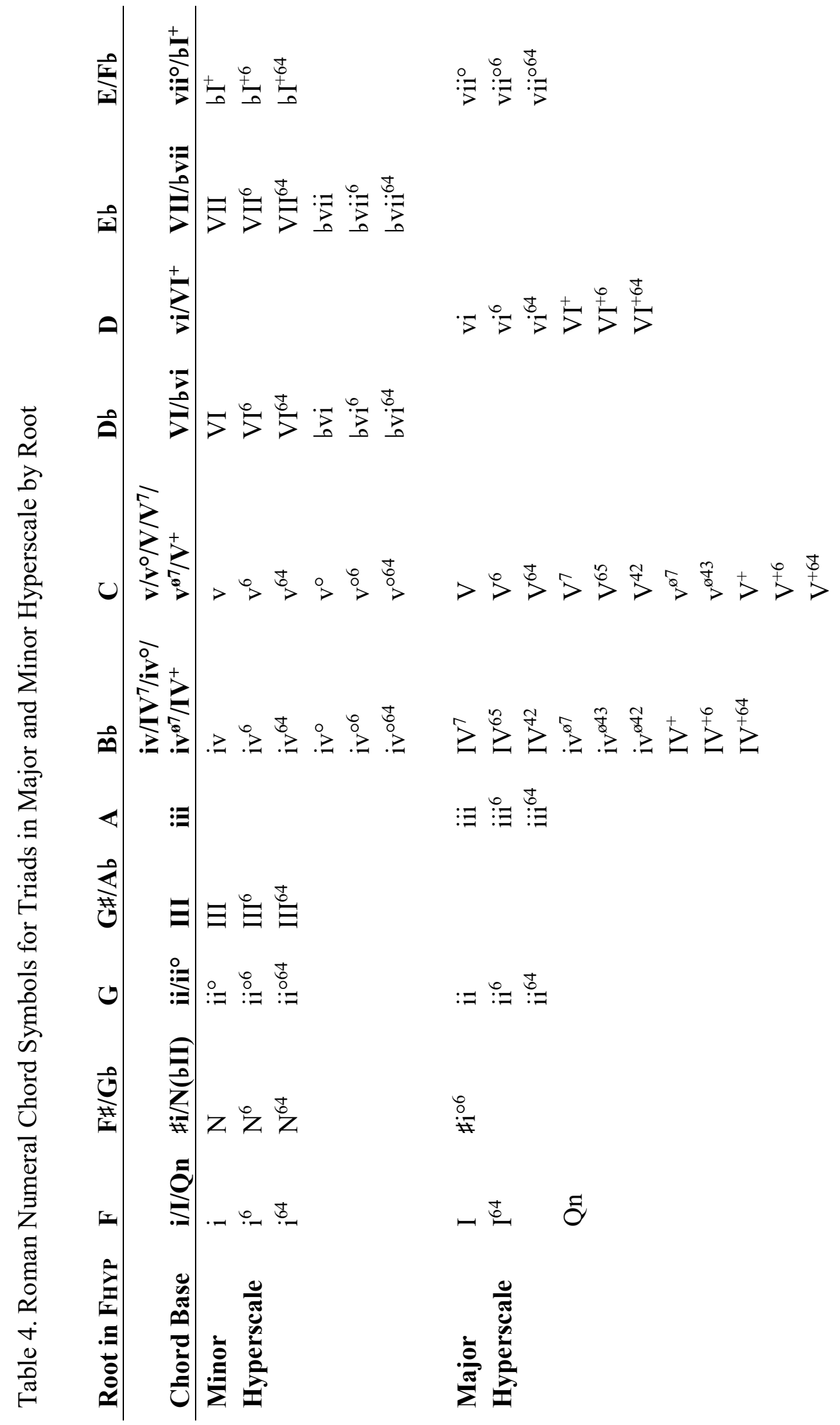


In major hyperscale, the lower pitches in intervals of a minor third in the primary octave change to a diminished third and sometimes imply a seventh chord with a missing third or fifth when this pitch is raised in the secondary octave, such as the triad built on the seventh scale degree in Figure 8, below. Though technically a triad, the interval of the diminished third behaves as a major second here, with implied pitches completing the chord.

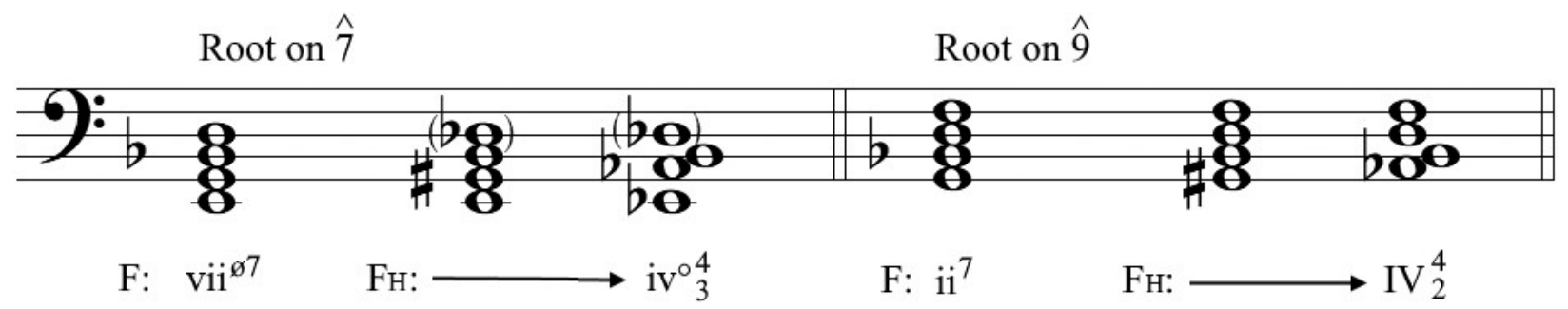

Figure 8. Supertonic and leading-tone seventh chords, converted from major scale to major hyperscale, functioning as subdominant sevenths. In this illustration, tonic $\left(\mathrm{F}^{\prime}\right)$ is located at $\mathrm{F}_{1}$ and $\mathrm{F}_{3}$, so that $\mathrm{F} \#$ " is at $\mathrm{F}_{2}$, and $\mathrm{G} \#$ " is at $\mathrm{G} \#_{2}$. The $\mathrm{Db} b_{3}$ in the first hyperscale example is an implied third that does not appear in the scale.

\section{Chapter 3. Hyperscalar and Hyperscale-like Paradigms in History}

Not intended to be complete source, this paper merely surveys the history of the hyperscale, so quite likely not every hyperscale is here. Sources searched include scale books, online databases and search engines, music journals and encyclopedias, and leads from colleagues, yet this search cannot be exhaustive. My hope is that this text motivates someone to look further, so I encourage additional investigation and discovery. The hyperscales that follow in this chapter cover a large array of time periods - ranging from the pre-medieval through the Common Practice Period to the twenty-first century - and are found in use across a wide variety of cultures. 


\section{$\underline{\text { Adonai Malakh }}$}

"Adonai malakh" " ("God is king") is the opening line to the 93rd Psalm of the Hebrew Torah (the Old Testament in Christian scripture). Unlike many of the psalms in Judeo-Christian scripture, the author of this song is unidentified. Historically, at the time this psalm was written, the nation of Israel may have been threatened militarily by its stronger neighbors, and so this poetry is intended by its author to encourage the kingdom's people to remember that the Lord God is still in control of all. ${ }^{7}$

1 The Lord reigns, He is clothed with majesty;

The Lord is clothed,

He has girded Himself with strength.

Surely the world is established, so that it cannot be moved.

2 Your throne is established from of old;

You are from everlasting.

3 The floods have lifted up, O Lord,

The floods have lifted up their voice;

The floods lift up their waves.

4 The Lord on high is mightier

Than the noise of many waters,

Than the mighty waves of the sea.

5 Your testimonies are very sure;

Holiness adorns Your house,

O Lord, forever. ${ }^{8}$

6. Both words in this term are not infrequently transliterated as "Adonay" and "malach" in English, with each spelling matching in different sources variously. The spelling "Adonai malakh" appears to be most common and is used throughout this paper for consistency.

7. Charles H. Spurgeon. "Psalm XCIII." The Treasury of David: Containing an Original Exposition of the Book of Psalms; A Collection of Illustrative Extracts from the Whole Range of Literature; A Series of Homiletical Hints upon Almost Every Verse; and Lists of Writers upon Each Psalm, 2nd ed. New York: Funk \& Wagnalls, 1885, 283.

8. Ps. 93, New King James Version (NKJV). 
The link between verse and music was almost inseparable in the ancient Hebrew tradition. Israel's most popular king, David, set the standard for the use of psalms ever since his role during his youth as court musician to the nation's first king, Saul, and the tradition of singing to verse in praise of God has been kept since - in temple rituals, celebrated rites, and synagogue observances. ${ }^{9}$ What is known today about the namesake scale taken from the traditional opening chant of this psalm is handed down through the tradition of Jewish worship called Ashkenazi, the broader Jewish musical prayer practice in the majority of Europe that initially began during the Middle Ages in today what is western Germany and eastern France, eventually spreading across a great portion of the continent. ${ }^{10}$

Cultural friction creates scholarly disagreement concerning research around the Adonai malakh scale. As with nearly every hyperscale I encountered during the research process for this document, peer-reviewed journal articles and published books available in the English language tends to possess an our-scale-is-different-from-all-other-scales argument, either as a postulate inside an informative article taking a grand view of their musical system or as an entire commentary offering a rebuttal to another article whose author claims that the structure of their scale of choice is the source of a rival's scale. For example, scholar of Jewish liturgy Joseph Levine believes that an Arabic scale, maqām kurdī, purported by other ethnomusicologists to be related to Hebrew music is not as connected to the same source that Ashkenazi derives from as other scholars would make it out to be. ${ }^{11}$ Whether the reader believes in the superiority of one

\footnotetext{
9. Don Harrán. “'Kehi Kinnor' by Samuel Archivolti (d. 1611): A Wedding Ode with Hidden Messages.” AJS Review 35, no. 2 (2011), 254. http://www.jstor.org/stable/41310618.

10. Boaz Tarsi. "Lower Extension of the Minor Scale in Ashkenazi Prayer Music." Indiana Theory Review 23 (2002): 153. http://www.jstor.org/stable/834350.

11. Joseph A. Levine. "Toward Defining the Jewish Prayer Modes with Particular Emphasis on the Adonay Malakh Mode.” Music Judaica 3, no. 1 (1980), 19, 21-23. http://www.jstor.org/stable/23687478.
} 
theory or another is beyond the scope of this paper; the important detail to this analysis is that the Adonai malakh scale is fundamentally different due to its quality as a hyperscale. For instance, while the maqām kurdī in Figure 9 below retains the same pitches through all octaves, the Adonai malakh scale in Figure 10 contains different pitches registrally, here crediting interlocking scales that create primary and secondary octaves in the formation of a hyperscale.

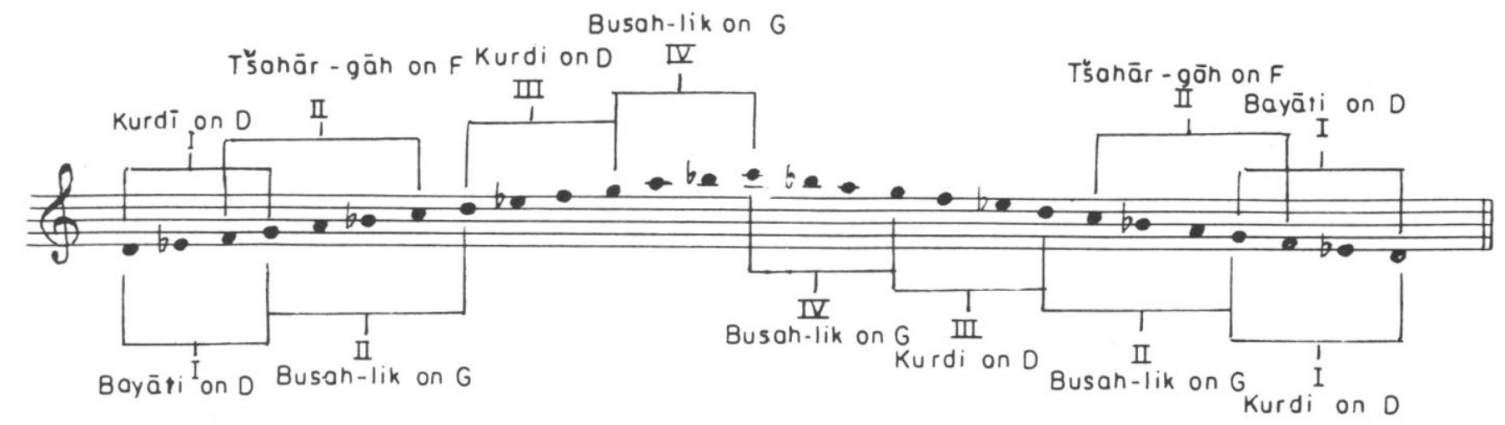

Figure 9. Arabic mode maqām kurdī. ${ }^{12}$

According to some musicologists studying Jewish music, worse still is the presupposition made by Western musicologists that the Adonai malakh scale is connected to any of the Greek tetrachord models that look for harmony, making the mistake of forcing the Adonai malakh scale into a mold within Western music theory. ${ }^{13}$ Because these traditional prayer modes are Eastern in origin, they thus have no relationship with the harmonic theory prevalent in the West. ${ }^{14}$

12. Levine, from "Toward Defining Prayer Modes," 22.

13. Deborah Kramer Netanel. The Kaddish: A Jewish Prayer in Western Art Music. PhD diss., University of Cincinnati, 2003. Ann Arbor: ProQuest, 4-6.

14. Boaz Tarsi. "Observations on Practices of 'Nusach' in America." Asian Music 33, no. 2 (2002), 177-78. http://www.jstor.org/stable/834350. 


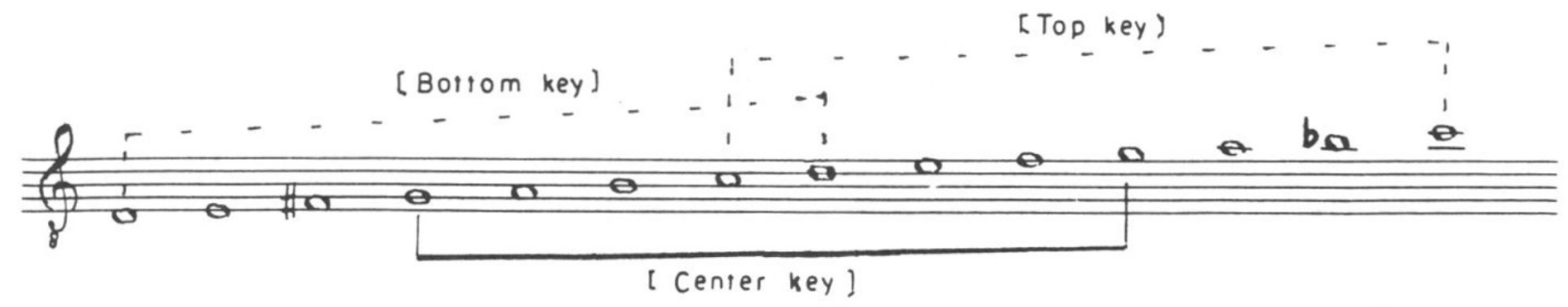

Figure 10. Hebrew mode Adonai malakh, with the hypothesis of the Greek tetrachordal concept applied. $^{15}$

The definition of mode is another instance where scholars of Jewish prayer song - as do others of various Eastern music - make a distinction from Western music. The Adonai malakh scale is one of three main modal scales in Ashkenazi Jewish prayer music. The source above in Figure 10 presents the comprised pitches as $\mathrm{D}_{4}-\mathrm{E}-\mathrm{F} \#-\mathrm{G}-\mathrm{A}-\mathrm{B}-\mathrm{C}_{5}-\mathrm{D}-\mathrm{E}-\mathrm{F}-\mathrm{G}-\mathrm{A}-\mathrm{B} b-\mathrm{C}_{6}$. Another source, below in Figure 11, indicates $\mathrm{C}_{4}-\mathrm{D}-\mathrm{E}-\mathrm{F}-\mathrm{G}-\mathrm{A}-\mathrm{B} b-\mathrm{C}_{5}-\mathrm{D}-\mathrm{E} b$ as the proper pitch collection. With the latter transposed up one whole step, the pitches are identical in both scales except that the former scale includes four additional scale degrees beyond what the latter includes.

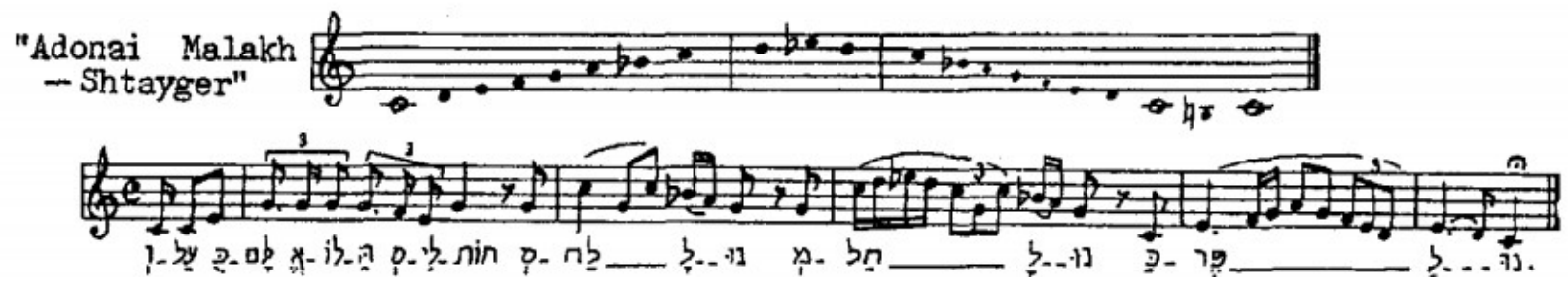

Figure 11. The Adonai malakh scale as practiced in the typical Ashkenazi synagogue with a sample service song. ${ }^{16}$

15. Levine, "Toward Defining Prayer Modes," 22.

16. Netanel. Kaddish, 6. 
Figure 11 is more consistent with other sources and is a more realistic reflection of the vocal range of the typical cantor. While Western modes are concerned with the rotation of a scale to a new tonal center, this pitch collection itself is not classified as a mode according to Ashkenazi scholars. Instead, modes in the Ashkenazi sense are not related scales so much as they are motive-like phrases (derived from well-known words, like in the psalm “Adonai malakh”) around which melodies are built. Composer of Ashkenazi song, Hugo Weisnall, clarifies the difference: "If a scale is thought of as an alphabet, a mode would be a word." 17 A prominent Ashkenazi scholar, Boaz Tarsi, writes,
"As mentioned, the musical term mode applies only in its most general all-inclusive definition, which relates to the wide variety of musical and extra-musical components. Indeed this seems to be one source of the confusion, contradictions, and ambiguous terminology that have beset clarifications of the modality of Ashkenazi Jewish music." 18

Levine further strengthens this premise by pointing out "that performers quote motives rather than scales." 19

As with the rest of the following hyperscale examples, very little scholarship for the Adonai malakh scale is in the English language; sources that do exist tend to not be in agreement with a standardized pitch collection or even a range. Furthermore, examples given of song or

17. Levine, "Toward Defining Prayer Modes," 15.

18. Tarsi, "Practices of 'Nusach'," 177-78.

19. Levine, "Toward Defining Prayer Modes," 24. 
chant often do not conform to the given scale, making further examination of the topic from a historical perspective difficult.

\section{Dastgāh-e Māhur}

The term dastgāh is one of several in Persian music that musicologists who report on the subject have a difficult time both defining in the English language and putting into precise terms of what it consists. The best description of a dastgāh is a suite of music that is often performed in public spaces, but most often for friends in the privacy of someone's home, and may also mean to be the performance of such a dastgāh as well. Like all dastgāh, the dastgāh-e Māhur ${ }^{20}$ consists of several modes, and as in the Adonai malakh, a mode in the Eastern sense - like the Indian raga - is more akin to a motif or a melodic phrase in the West. ${ }^{21}$ While some scholars state that Persian music is different from any other and provide a defense with a nationalistic bent, others are willing to point out that music from both sides of the world share many common characteristics before the end of the Middle Ages. ${ }^{22}$

With the same principal interval scheme as the Obikhod and Adonai malakh scales, the dastgāh-e Māhur scale starts on $\mathrm{G}_{3}$, containing all of the natural notes up to $\mathrm{A}_{4}$, and ends on $\mathrm{B}_{4}$ (see Figure 12, below). Two properties of this scale set it apart from the other two, however; the

20. Māhur is a small village of over one hundred people in current-day Iran. The phrase dastgāh-e Māhur translates from Persian into English as "music of Māhur." "Mahur, Iran." Wikipedia.; "Dastgāh e-Māhur." Google Translate. Note: As of the date of the completion of this paper, Google Translate no longer capably translates this phrase.

21. Mohsen Harajian. Ghazal as a Determining Factor of the Structure of the Iranian Dastgāh. PhD diss., University of Maryland College Park, 1999. Ann Arbor: UMI, 1999. ProQuest, 147; Hormoz Farhat. "Dastgāh-e Māhur." In The Dastgāh Concept in Persian Music. Cambridge Studies in Ethnomusicology. Cambridge: Cambridge University Press, 1990, 19.

22. Jean During, Zia Mirabdolbaghi, and Dariush Safvat. The Art of Persian Music. Washington, D.C.: Mage Publishers, 1991, 47. 
usual starting note ( $\bar{a} q \bar{a} z$, in Persian) is $\mathrm{C}_{4}$, joining one tetrachord below and two above, leaving no room for a secondary octave. The mode dictates a finalis, also on $\mathrm{C}_{4}$. In other words, a dastgāh mode that uses such a scale $\left(G^{\text {sub }}-A^{\text {sub }}-B^{\text {sub }}-C^{\prime}-D^{\prime}-E^{\prime}-F^{\prime}-G^{\prime}-A^{\prime}-B b^{\prime}\right)$ typically begins and ends on the same pitch, not-so-coincidentally what would be deemed as tonic in a hyperscale. ${ }^{23}$ The $\mathrm{B} \mathfrak{\natural}^{\text {sub }}$ and $\mathrm{B} b^{\prime}$ pitches are the distinguishing characteristics that qualify the dastgāh-e Māhur pitch set as a hyperscale.

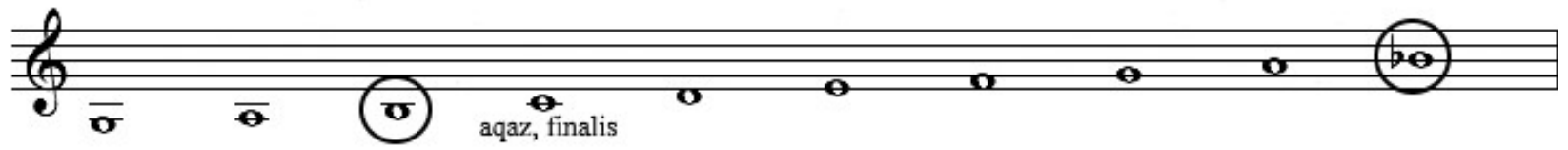

Figure 12. The dastgāh-e Māhur scale. ${ }^{24}$

The dastgāh-e Māhur is divided into twelve sections, similarly to a song cycle. Each section has a set of "rules" in performance that, like in Western jazz, are meant to be broken, but only if the performer understands the unwritten guidelines of the correct way to do so. Despite these handed-down rules, scholars sometimes disagree on the genuine properties of dastgāhs. One expert may say that only the twelve semitones as known in Western music are permissible, while another may state that certain quartertones may be substituted in an artistic manner, though not as chromatic embellishment but as substitution for another pitch in the scale. ${ }^{25}$

Though centuries old, the scale is still culturally significant. The dastgāh as an art form is currently experiencing a renaissance in Iran due to the Islamic Revolution of 1979 that resulted

23. Farhat, "Dastgāh-e Māhur”, 89.

24. Farhat, 89.

25. Jean During, Art of Persian Music, 47; Farhat. "Dastgāh-e Māhur,” 92-93. 
in laws banning Western popular music and encouraged traditional forms of local folk song. ${ }^{26}$ At the onset of the regime change, females were banned from recording any music in Iran, and all recordings, new and old, of music that did not follow a strict set of "suggested characteristics" were openly discouraged and sometimes destroyed. Most artists residing in the nation have become diligent not to stir the waters, resolving their problems by ceasing to record new albums, avoiding appearances in public concerts, and - in some cases - emigrating from Iran when possible to avoid imminent harm from authorities. ${ }^{27}$ Composers who borrow the dastgāh-e Māhur scale from the Persian culture for their own use may wish to consider taking extra care to learn the cultural background of this scale and comprehend the implications of its use for anything outside of the social norm in which dastgāh is normally performed, especially in the global political climate of this age. Chapter 5 contains further remarks on this sensitive topic (see pp. $88 \mathrm{ff}$.).

\section{Znamenny Chant in the Obikhod}

The Obikhod is a book of psalm settings and liturgical chants created for the Russian Orthodox monastery in Volokolamsk, near Moscow, by unknown editors around 1575. Around 1600, a monk named Ivan Shaidurov created a system of neumes for the Obikhod to facilitate the spread of znamenny chant through the Russian Orthodox church, building a classification of four

26. Arya (Ali) Bastani-Nezhad. "A Critical Study of the Iranian Teaching Textbooks on Iranian Classical Performance.” Journal of Historical Research in Music Education 35, no. 2 (2014), 143. http://www.jstor.org/stable/43664212.

27. Harajian, Ghazal as Determining Factor, 160-61. 
trichord registers that, after a half-century, fell out of favor. ${ }^{28}$ About two hundred years later, under a charge from Tsar Nicholas I, Russian composer Alexei Lvov (1799-1870) Shaidurov revived and codified znamenny chant in a new edition of the Obikhod. ${ }^{29}$ Before the Bolshevik Revolution restricted the efforts of the Orthodox church, the 1909 edition became the dominant chant book used across Russia and exterior regions stretching from Slovakia and Ukraine in Eastern Europe to geographic areas wrapped around the Black Sea, including Georgia and Armenia. ${ }^{30}$

According to one scholar, chant from the Greek Byzantine tradition became more chromatic while rites in the Russian tradition stayed more closely aligned with diatonicism, giving the Russian Orthodox Church the claim to greater authenticity in its roots of worship, even though the chant evolved markedly through the centuries in Russia. As a result, there are few similarities between Byzantine chant and what is found in the Obikhod. ${ }^{31}$

The scale itself is a sequential set of trichords with whole-step spacing, each set separated by a half step. From the beginning, those who wrote the chants conceived the registers of the original four trichords with labels for each set: low, sombre [sic], bright, and triple bright (see Figure 13, below). The rhythm is comparable to simple meter in the Western tradition:

28. Jeffery B. Wall. "The Influence of Znamenny Liturgical Chant on the Nineteenth-Century Russian Choral School: A Guide for Performance." The Choral Journal 50, no. 3 (2009), 23. http://www.jstor.org/stable/23559804.

29. Olga Dolskaya-Ackerly. "Aesthetics and National Identity in Russian Sacred Choral Music: A Past in Tradition and Present in Ruins." The Choral Journal 42, no. 5 (2001), 16. http://www.jstor.org/stable/23554005.

30. Joan L. Roccasalvo. “The Znamenny Chant.” The Musical Quarterly 74, no. 2 (1990), 217. http://www.jstor.org/stable/742190.

31. Wall, "The Influence of Znamenny Liturgical Chant," 23. 
"The melodies moved generally in relative half, quarter, and whole-note durations, with freedom to sustain half and whole notes slightly. The half note received the "beat," while whole notes usually occur at ends of phrases or lines. Eighth notes were rare in znamenny chant, and no beat was unduly stressed." 32

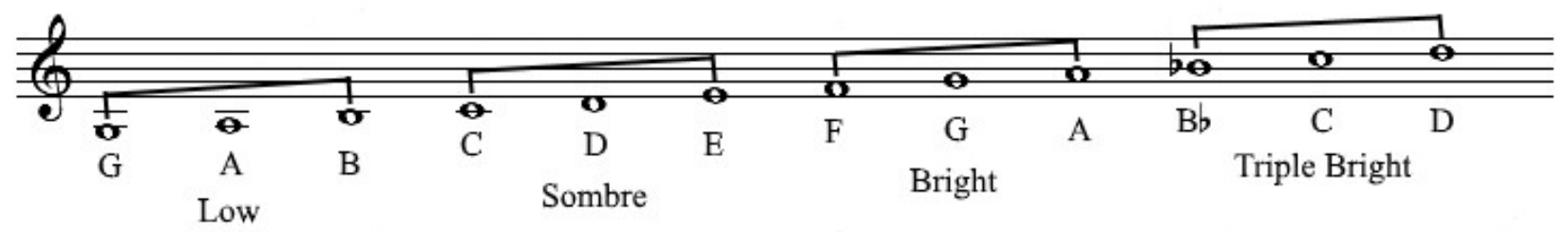

Figure 13. The four registers of znamenny chant in the scale of the Obikhod.

The number of trichords that can be strung together in znamenny chant is theoretically unlimited, from one to infinity; however, the typical number included in chant is four, which commonly encompasses the range from $\mathrm{G}_{3}$ to $\mathrm{D}_{5}$ to correspond the voice of the typical male cantor. Russian composers who have used this scale often build additional trichords below or above the original set of four; in practice, a composer can string together five octaves of trichords before repeating the pitch pattern. ${ }^{33}$

32. Wall, 23-24.

33. Wall, 23. 

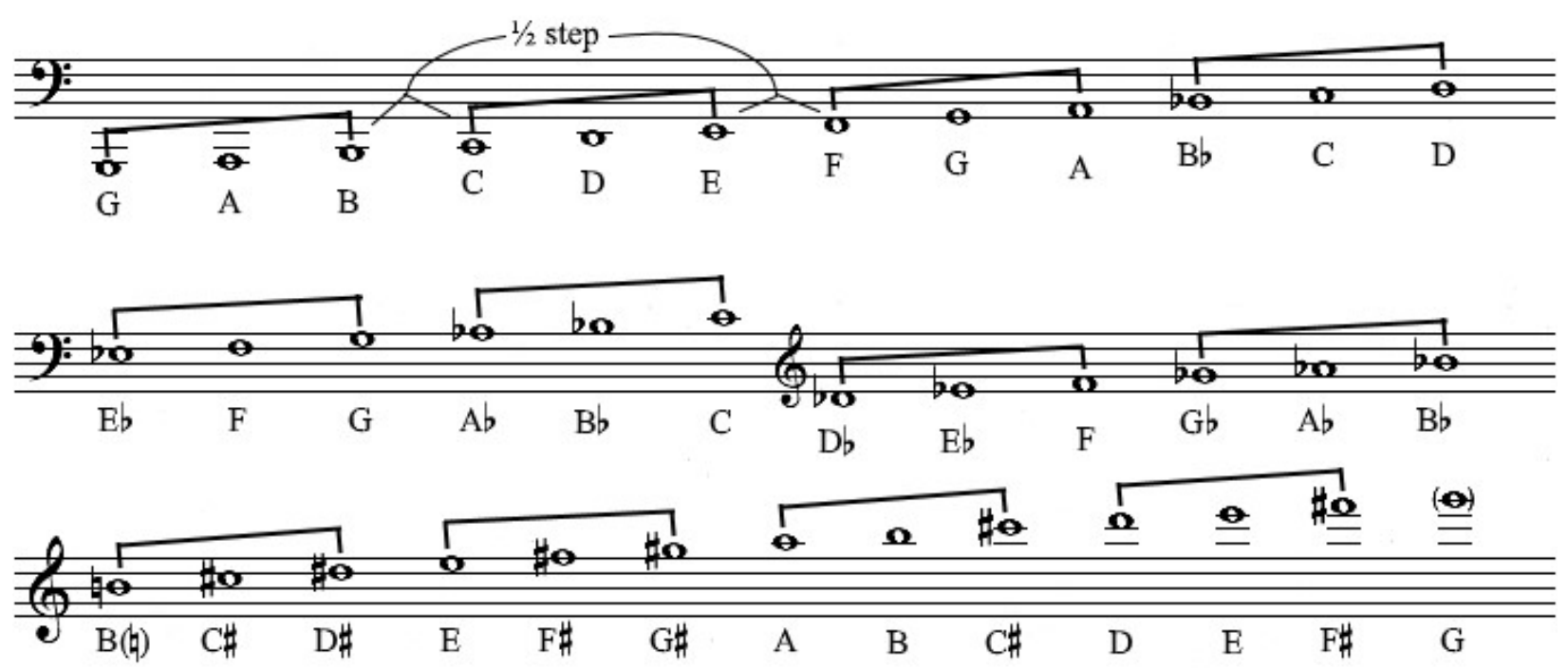

Figure 14. The Obikhod scale, conceptually, in five octaves.

Despite the limitations of the znamenny chant - simple construction of the pitch pattern and the reverence implicit in unduplicated text - each particular chant was made distinctive in its timbre, tempo, and character by their creators. The permutations and free rhythm allowed by the genre fascinated many Romantic-era Russian composers who used it as the base for nationalistic pieces in choral works, providing a force that brought the nation together during a time of renewed "foreign cultural invasion." 34

Some present-day scholars make the argument for preservation of the original ways in which znamenny chant was set. Although partly as a desired defense of church traditions and settings of worship, sentiment is against the deconstruction of the old form by way of the avantgarde approach. While traditionalists do not say that the znamenny chant scale cannot entertain

34. Wall, 24. 
new experimentation, they argue that the spiritual character must be retained. Russian composer and musicologist Alfred J. Swan, made the case during the mid-twentieth century that despite the recent advances in archaeology and discovery of lost civilizations that the corruption of znamenny chant is part of the danger causing "gigantic wars and revolutions, another migration of peoples fleeing from want and oppression, and all this misery has begotten, on the negative side, a diseased, distorted art in which is reflected, as in a mirror, the hideousness of modern mankind," and believing that a return to the simpler style of worship is necessary to cure the world..$^{35}$

This is not just a concern of a past generation. In 2001 musicologist Olga DolskayaAckerly wrote that that the corruption of modern styles of worship from the West are corrupting the number of parishioners in the Russian Orthodox Church, comparing the trend to Lenin's disregard for the Russian people as he pushed to advance the Soviet Union at the expense of its inhabitants. ${ }^{36}$ Choral conductor Jeffery B. Wall, points out that Rimsky-Korsakov honored this tradition by writing his compositions based on Obikhod chant clearly with respect toward the liturgical worship setting, and that composers wishing to use the Obikhod as inspiration would do well to honor its source. ${ }^{37}$

Wall says that conductors also need to be aware of the solemnity of znamenny chant and other music written in its style or from its influence. "Today the Virgin Sacred," by Alexander Kastalsky (1820-1891), is a choral work that, while not appropriate in an Orthodox worship

35. Alfred J. Swan. "Russian Liturgical Music and Its Relation to Twentieth-Century Ideals." Music \& Letters 39, no. 3 (1958), 266. http://www.jstor.org/stable/730541.

36. Dolskaya-Ackerly, "Aesthetics and National Identity," 16.

37. Wall, "Influence of Znamenny Chant," 24-26. 
service, Wall considers the arrangement in the choral parts sincere in its respect for the znamenny chant that is embedded within through highlighting the chant's importance in performance. $^{38}$

Conversely, the hyperscale in the sacred music of the Obikhod has had its share of influence on the secular; some Russian folk music is based exclusively on this pitch set and the livenka, a long-bellowed accordion, contains the Obikhod hyperscale pitch set in one of its natural fingering positions on one keyboard. ${ }^{39}$ Later composers have also used the scale and added extra groups of trichords on either side of the standard foursome to expand into a contemporary vocal range for all voices. Some art music that employs the Obikhod chants include Russian Easter Festival Overture (1888) by Nicholas Rimsky-Korsakov (1844-1908) and Obikhod (2003) by Alexander Raskatov (1953- ). ${ }^{40}$

Sergei Rachmaninoff (1873-1943) is distinguished for making himself very familiar with styles that he would borrow from, including the znamenny. Rachmaninoff was zealous to search for lesser-known practices and borrowed frequently from Russian sacred music, and he found them in a range of subjects, from monastic chants in various regions to church bells rung by local townfolk. ${ }^{41}$ While The All-Night Vigil: Vespers, a "choral symphony," employs chants from

38. Wall, "Influence of Znamenny Chant," 30-31.

39. Eugene Belianski. Russian Folk Traditions in Contemporary Musical Literature for Winds: Analysis and Composition in the Musical Languages of Russian Vocal Folk Polyphony (As Described by Aleksandr Kastalskiy), Russian Village Accordion Repertoire and Soviet Tourist/Traveller Bard Songs. PhD diss., York University, 2015. Toronto: York University, 2015: 21-22.

40. Donald N. Ferguson. "Nicolas Andreivitch Rimsky-Korsakoff (1844-1908)." In Masterworks of the Orchestral Repertoire: A Guide for Listeners, 463-64. University of Minnesota Press, 1954. http://www.jstor.org/stable/10.5749/j.cttts92j.43; Alexander Ivashkin. “Amsterdam: Alexander Raskatov's 'A Dog's Heart'.” Tempo 65, no. 256 (2011): 54. http://www.jstor.org/stable/23020691.

41. Joseph Yasser. "The Opening Theme of Rachmaninoff's Third Piano Concerto and Its Liturgical Prototype.” The Musical Quarterly 55, no. 3 (1969), 326-27. http://www.jstor.org/stable/741003. 
Greece and Kiev of which the composer succeeded to "strip completely of their eighteenthcentury sweetness," Rachmaninoff supplants the underlying tone with that of the stately znamenny chants. $^{42}$

\section{$\underline{\text { Algerian Scale }}$}

French composer Jacques Ibert (1890-1962) studied under Gabriel Fauré and won the 1919 Prix de Rome in the first such contest resumed after the Great War. For most of his career, Ibert's works lean on impressionism and other tonal categories of style written for a wide range of performing forces, including orchestra, chamber music, solos, ballet, and opera). ${ }^{43}$ Escales (Ports of Call) was written for chamber orchestra in 1924 in three movements, the second of which, "Tunis-Nefta," features an oboe solo on the Algerian hyperscale that the composer discovered on a Mediterranean trip at sea while passing through Tunisia.

Historical critical opinion of Ibert as a composer and Escales as a piece of music is mixed. An example of the composer's ability to write light-hearted, witty music in a tonal setting, Escales is one of two pieces that elevated Ibert's reputation as a composer but only with limited success in his home country and across the rest of Europe. ${ }^{44}$ The premiere of the work in Italy "did not evoke admiration, the material used in their construction lacking both in invention and development-shortcomings that brilliance in orchestration did not compensate." 45 An

42. Swan. "Russian Liturgical Music," 271.

43.”Jacques Ibert." Columbia Electronic Encyclopedia. 6th ed. 2017. Accessed March 2, 2018. Academic Search Complete [EBSCO].

44. Alexandra Laederich. "Ibert, Jacques." Grove Music Online. 12 Mar. 2018; Pei Chao. The Boston Symphony Orchestra, Serge Koussevitzky and the Cultivation of French Music in America during the First Half of the Twentieth Century. PhD diss., University of North Texas, 1997. Ann Arbor: ProQuest, 32.

45. Charles D'If. "Musical Notes from Abroad.” The Musical Times 70, no. 1038, 1929, 750. http://www.jstor.org/stable/914415. 
English critic found the orchestral accompaniment to be "vague" and "meaningless," and judged that Ibert as a composer "did not have much to show."46

Out of the handful of books available today that concern themselves with scales, only the Algerian scale is found consistently comprised of unique notes outside of the first octave. ${ }^{47}$ Despite the tepid approval by his contemporaries, "Tunis-Nefta" is an archetypal piece for a hyperscale that allows Ibert to demonstrate his skillful compositional abilities using a scale infrequently heard - if not otherwise ever - in Western art music to this point. Although the term hyperscale did not exist one hundred years ago, an analysis of the movement shows that the composer understood the special medium with which he was working.

During my examination of the work I discovered that Ibert demonstrates in "Tunis-Nefta" an effective way to both establish a "new" hyperscale that is foreign to the Western ear and stretch the boundaries of the hyperscale within the same piece. The statement of the theme at section $\mathrm{A}$ in the oboe explores almost precisely the range of the Algerian scale - a nadir of $\mathrm{D}_{4}$ and zenith of $\mathrm{F}_{5}$ - and does not engage the subprimary-octave pitch of middle $\mathrm{C}$ at any point in this movement.

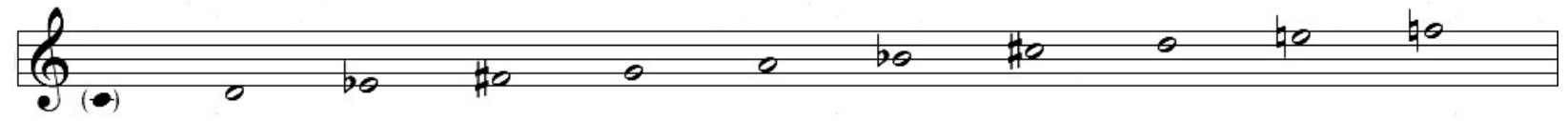

Figure 15. Hyperscale used in oboe part in Ibert, Escales, II. "Tunis-Nefta." $\mathrm{D}_{4}$ is the tonic of this scale, and $\mathrm{C}_{4}$ is the sole subprimary pitch.

46. C. H. "Music in Manchester." The Musical Times 68, no. 1010, 1927, 359. http://www.jstor.org/stable/912811.

47. Emily Freeman Brown. A Dictionary for the Modern Conductor. Lanham, Md.: Rowman \& Littlefield, 2015, 12; Peter Fischer. Rock Guitar Secrets. Brühl, Germany: AMA Verlag, 1995, 160; Ron Middlebrook. Scales \& Modes in the Beginning: Created Especially for Guitarists. Anaheim Hills, CA: Centerstream, $1982,125$. 
Aside from its property as a hyperscale, the Algerian scale contains two prominent features: a pair of augmented seconds - between $E b^{\prime}$ and $F \#^{\prime}$, and between $B b^{\prime}$ and $C \sharp{ }^{\prime \prime}$ - and a change in the last two notes in the second octave - the Eb'-to-F\#' augmented second in the lower octave becomes E"-to-F", a minor second in the upper.

In section B of "Tunis-Nefta," Ibert shows his understanding of the Algerian scale by manipulating the characteristics of the hyperscale. The oboe starts on the highest note of the hyperscale's range, F", and then begins to break some of rules implied by the scale. First, the part extends higher to $\mathrm{A}_{5}$, also in the secondary octave. Although exceeding the hypertonic is not an issue for use of the hyperscale - for the range of an instrument or musical idea is not limited by the scale itself - this is the first time that Ibert has stretched the melody beyond the given scale range in the oboe part.

In measures 25-26, the first two bars of section $\mathrm{B}$, a displaced $\mathrm{F} \#^{\prime}$ in octave five chromatically resolves to $\mathrm{F}^{\prime \prime}$, an event less important as a chromatic passage than it is as the occurrence of a displaced pitch from the primary octave. Later in measure 29, an E $b^{\prime}$ similarly resolves to Eq" in the ensuing ascending passage. From this point the oboe melody continues to ascend gradually toward $\mathrm{E}_{6}$ at measure 31 ; the passage returns to the primary octave, borrowing the displaced $\mathrm{E}^{\prime \prime}$ from the secondary octave. Displaced $\mathrm{Eb}^{\prime}$ still finds its way back into the secondary octave at measures 34 and 35 after $E^{\prime \prime}$, reintroducing tension that is not soothed until the undulating cadenza that continually peaks at $\mathrm{F} \natural^{\prime \prime}$ and $\mathrm{E}^{\prime \prime}$ exclusively. In brief, Ibert takes two pitches out of their position in the primary or secondary octave, uses them chromatically through octave displacement, and then settles them back into place within the boundary of a twelve-measure cadenza. (See Figure 16, below.) 

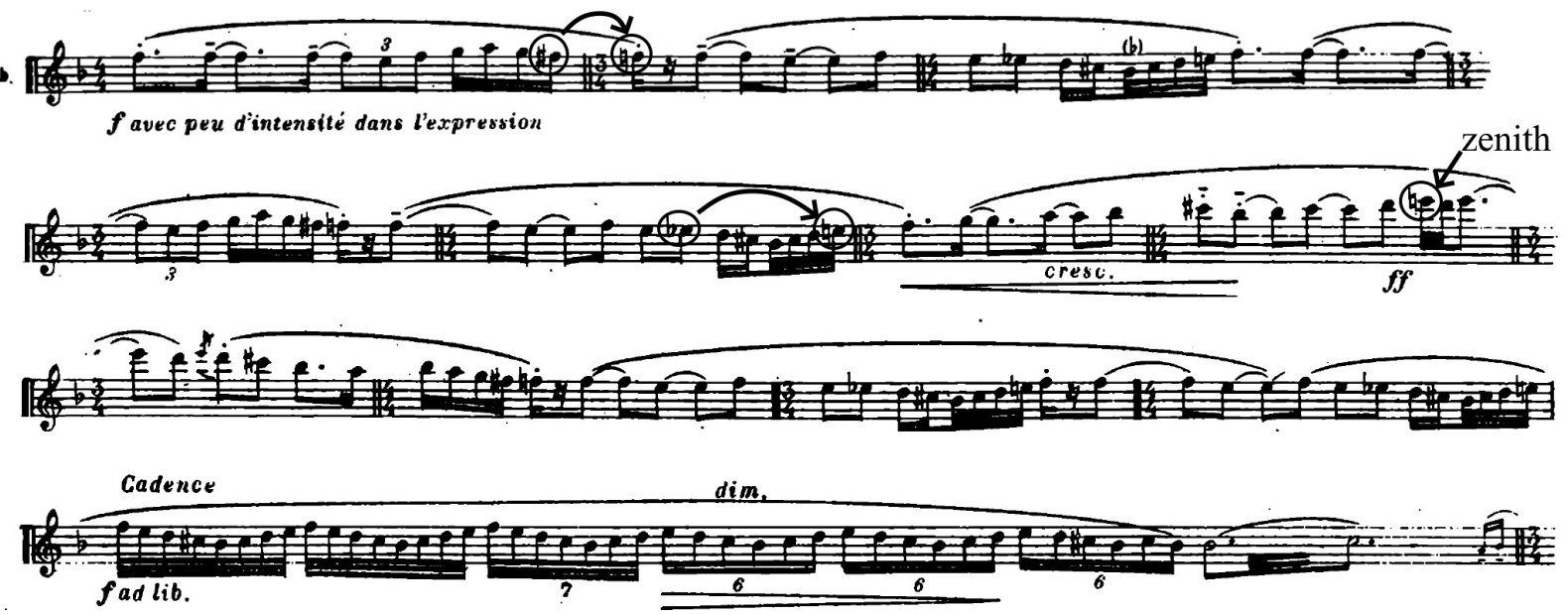

Figure 16. Escales, II. "Tunis-Nefta," oboe, mm. 25-36, illustrated with circles showing the resolutions from displaced pitches to non-displaced pitches in mm. 25-26 and 29, and showing the zenith at the displaced $\mathrm{E}^{\prime}$ residing in the secondary octave in $\mathrm{m} .31 .{ }^{48}$

Though $\mathrm{D}_{4}$ is the tonic of the hyperscale - as indicated by the key signature - the aural tonic pitch of the piece is not the $\mathrm{D}$, but rather the $\mathrm{G}_{4}$, suggesting modality. ${ }^{49}$ Ibert shapes this ambiguity in the introduction of the movement (see Figure 17, below) with quintal harmony - G, $\mathrm{D}$, and $\mathrm{A}$ - in both parts for contrabasses, both for cellos, both for violins, plus the timpani paired with an ostinato rhythm. The viola and portions of the cello A parts have $C \sharp, A b(G \sharp)$, and $E b(D \sharp)$ as a quintal chord in tritone dissonance to the original quintal harmony. Only with the $\mathrm{G}_{1}$ in the lowest string parts does the listener perceive that the tonal center of the piece is also centered on G. Further, Ibert extends the concept of bitonality within the quintal harmony by pairing two sets of perfect fifths with half-step dissonance in the second measure of the piece (see Figure 17, below): $\mathrm{G}$ and $\mathrm{D}$, against $\mathrm{A} b$ and $\mathrm{Eb}$.

48. Jacques Ibert. Escales (Ports of Call). Paris: Leduc, 1925.

49. The term modality is used in the Western sense here. This chapter previously explained a common use for the word mode and its various grammatical forms in some Eastern music theory that differs from standard use in the West. 
Introduction /Sections A \& A'

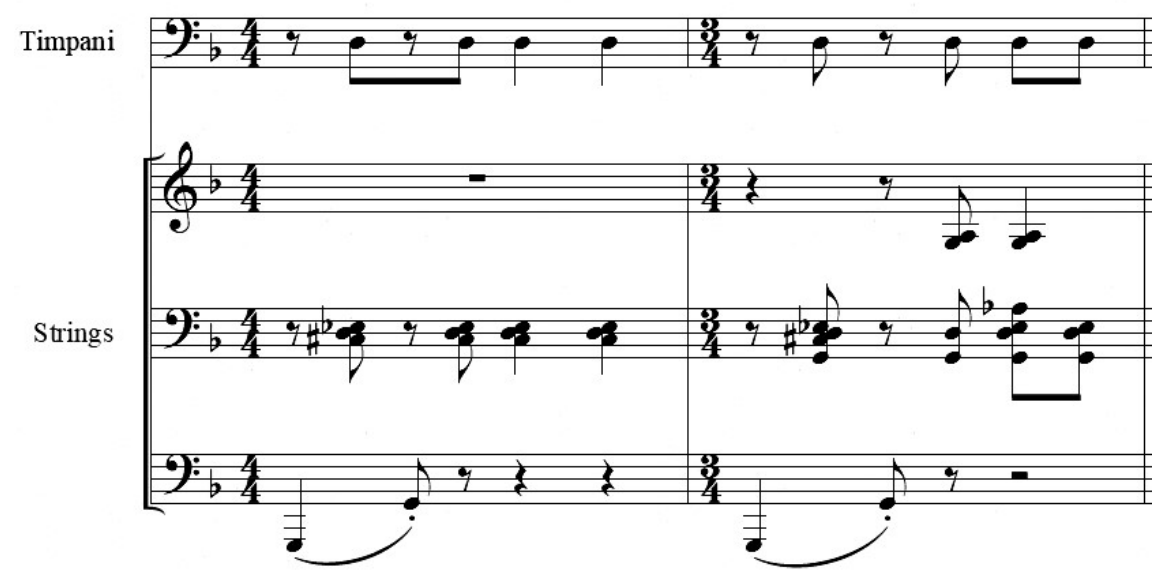

Figure 17. Escales, II. "Tunis-Nefta," two-measure accompaniment reduction of the introduction, section $\mathrm{A}$, and section $\mathrm{A}^{\prime}$.

In the transition section (see Figure 18, below) - which occurs twice in the movement identically - Ibert adds another dimension to the quintal harmony. Two quartal pairs found in the violas and three violin parts - Eb up to $A b$ and $G$ up to $C$, quintal pairs inverted - resolve to the prevailing D/G/A pedal pitches, also quartal (in quintal inversion), while the highest violins hold a quartal pair of $\mathrm{C}$ and $\mathrm{F}$.

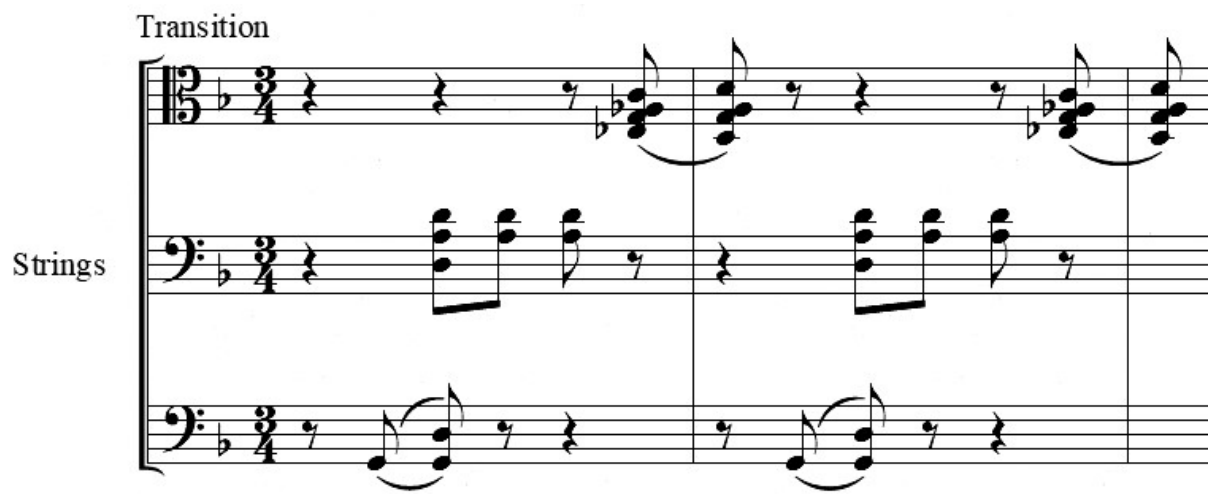

Figure 18. Escales, II. "Tunis-Nefta," two-measure accompaniment reduction of the transition. 
The pitches of G, D, and A are still present in Section B (see Figure 19, below), and the return of two pairs of two-note clusters in minor seconds, $\mathrm{C} \# / \mathrm{D}$ and $\mathrm{E} / \mathrm{F}$, mark a shift from the first main section in the movement by emphasizing the held $\mathrm{F}$ - and less so, the $\mathrm{E}$ - in the oboe. These long notes in the cadenza (see Figure 16, above), which functions also as the retransition back to section A, continue to reinforce the bitonality of the piece.

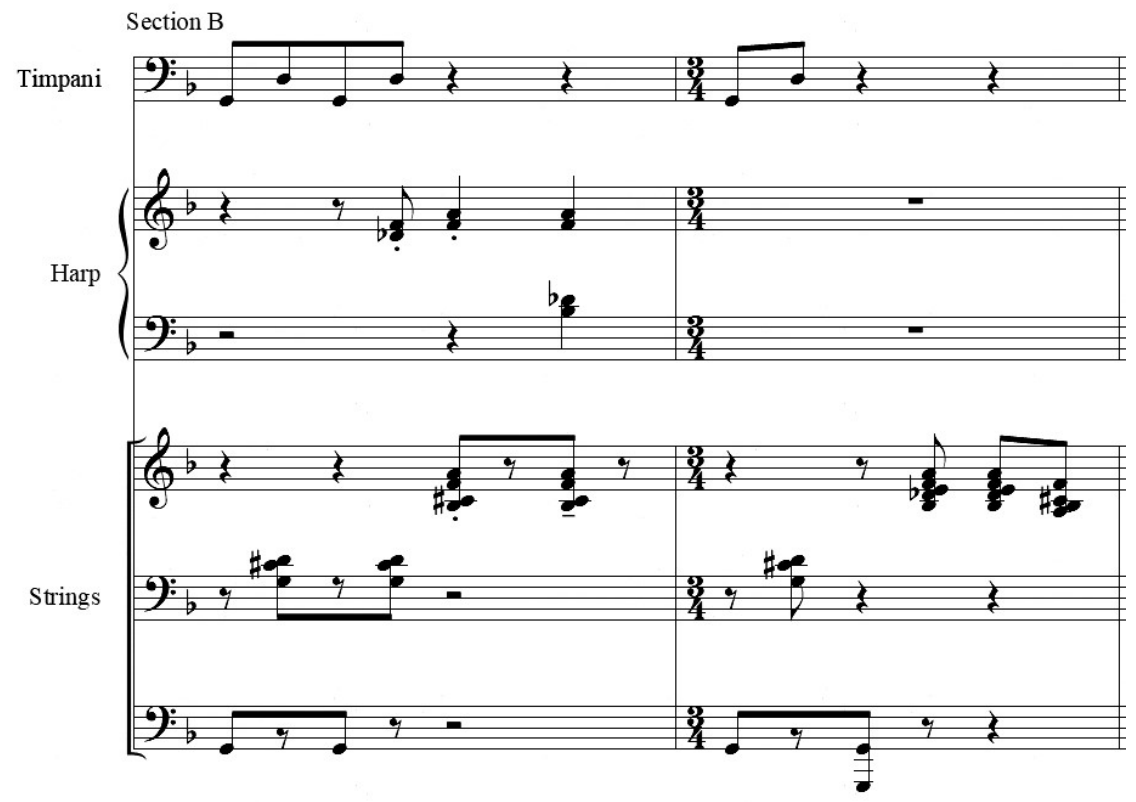

Figure 19. Escales, II. "Tunis-Nefta," two-measure accompaniment reduction of section B.

The pairs of pitches noted above are also important to the analysis of the Algerian scale because there is a discrepancy between Ibert's scale and that reported by three sources that also mention the Algerian scale. While the oboe does indeed follow the scale as shown in Figure 20, below, the scale catalogued by Brown, Fischer, and Middlebrook (see Figure 21, below) place 
the second augmented second at $\mathrm{A} b$ and $\mathrm{B} \sharp$ rather than Ibert's Algerian scale, which places the interval at $\mathrm{B} b$ and $\mathrm{C} \#$.

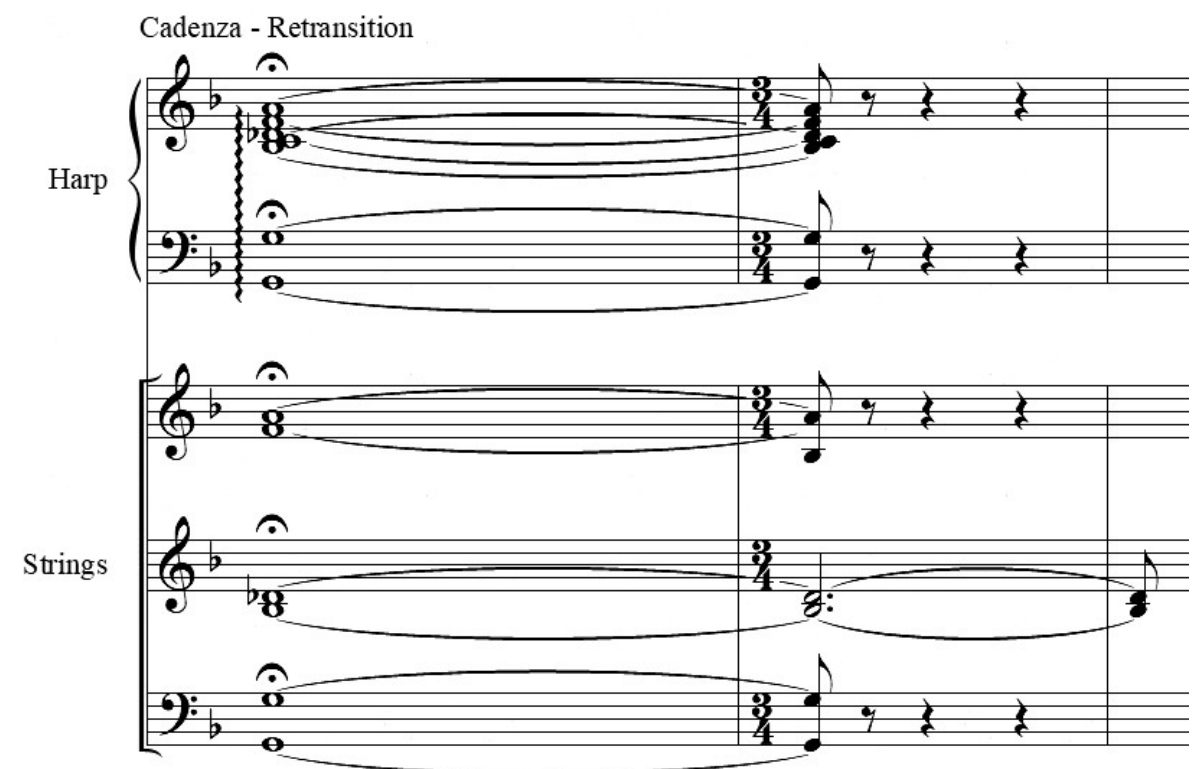

Figure 20. Escales, II. "Tunis-Nefta," accompaniment reduction of the cadenza-retransition.
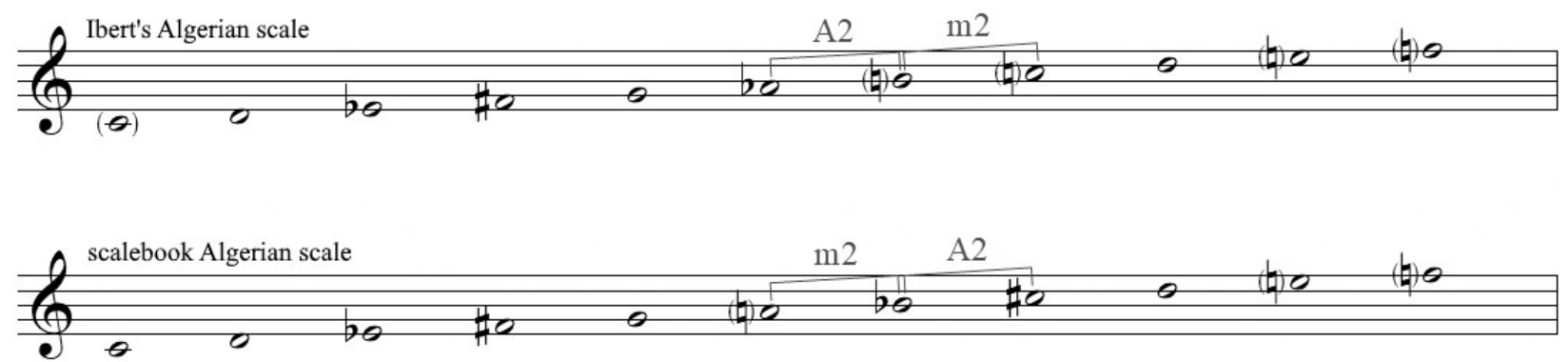

Figure 21. The Algerian scale, as used by Ibert and proposed by three scale book authors. ${ }^{50}$

The oboe in "Tunis-Nefta," aside from the controlled exceptions in section B, stays faithful to the $\mathrm{Bb} / \mathrm{C} \#$ iteration of the scale. However, while the orchestral accompaniment most frequently adheres to the same scale, it also occasionally employs $\mathrm{A} b$, but never $\mathrm{B}$. . Because its use is

50. Brown, Dictionary for Modern Conductor, 12. Fischer, Rock Guitar Secrets, 160; Middlebrook, Scales \& Modes, 125. 
limited, the Ab suggests that Ibert may be acknowledging the difference in what the scale is actually comprised of versus what the composer employs in the oboe. In the introduction and A sections, the $\mathrm{Ab}$ is played against $\mathrm{A}$ घ only once late during the two-measure vamp, and in the very short coda as the root of the held $\mathrm{Ab}$ major triad in the woodwinds (see Figure 22, below). All other A's, employed frequently, are natural. Chapter Five (see "Unreliable Sources" on p. 86) contains more thoughts about this inconsistency.

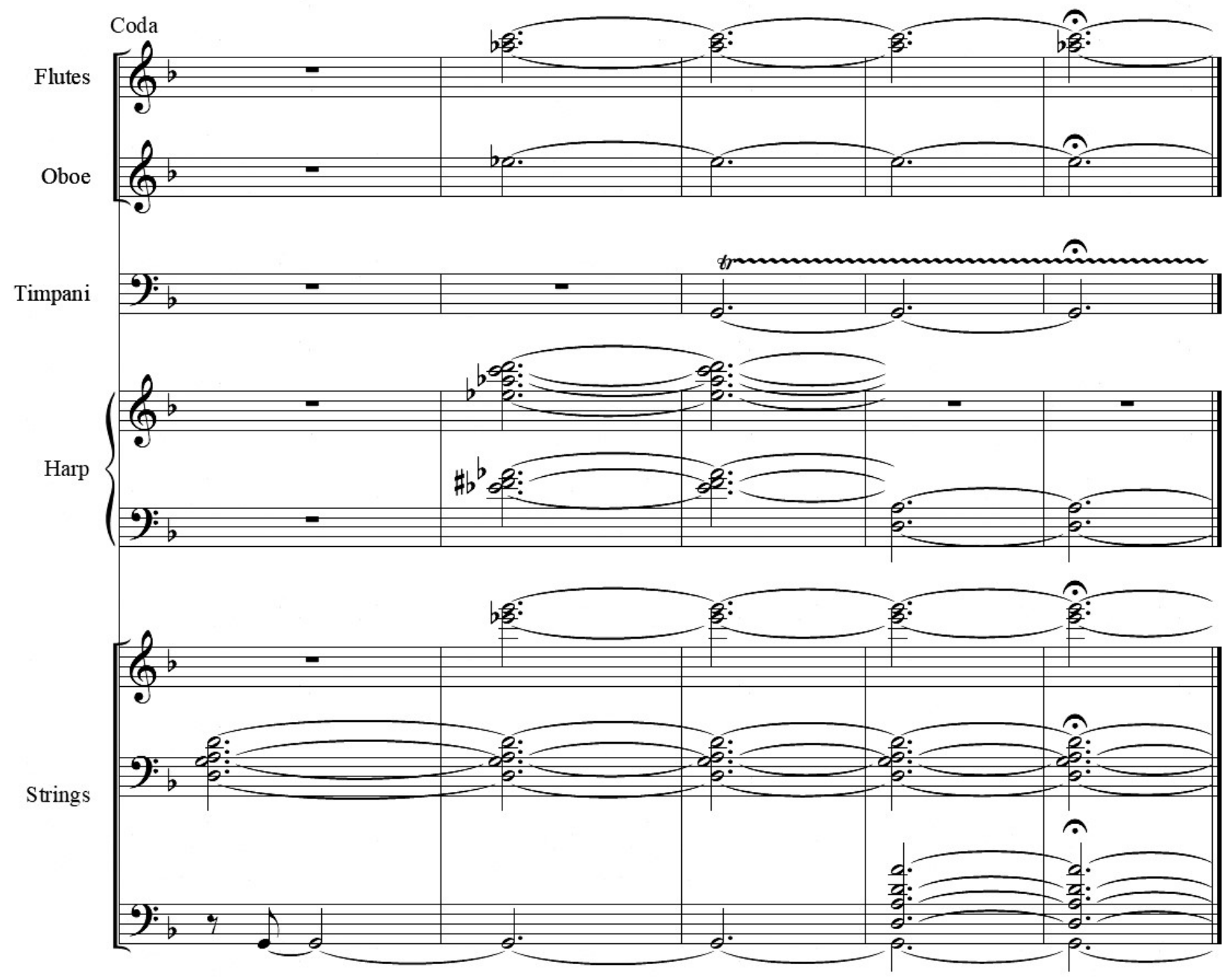

Figure 22. Escales, II. "Tunis-Nefta," reduction of the coda in accompanying instruments. 
Regardless of what the true Algerian scale may be, Ibert is unconcerned with respecting octave placement in the orchestral accompaniment and its harmony implies a different tonal center $(\mathrm{G})$ from the scale's original tonic (D). Meanwhile the oboe is tasked with the work of defining the Algerian hyperscale by staying strictly within the confines of the scale until released to break the barriers of the scale in the cadenza.

\section{Contemporary Hyperscales: Joel Hoffman}

Joel Hoffman (1953-), now faculty emeritus at University of Cincinnati - Cincinnati Conservatory of Music, learned the idea for scales that do not fit inside the span of one perfect octave from Chinese composition colleague, Gao Weijie, at Beijing Music Conservatory where Hoffman has a guest faculty position. While the technique used for the invention of the artificial scales used by Gao and Hoffman produce scales with various ranges, those that exceed one octave generally qualify for inclusion as hyperscales. Hoffman has written at least two significant works using scales with a span of a major ninth. ${ }^{51}$ In 2008, Hoffman wrote his first piano concerto using this technique, employing a heptatonic scale with a major ninth from tonic to tonic. However, for this analysis I chose a chamber piece by Hoffman entitled 6-8-2-4-5-8 over Piano Concerto No. 1 because the composer has allowed chromatic pitches (that is, from outside the scale) to enter the piece for comparison to the techniques used in Streetwise. Differences in the way Hoffman and I employ the hyperscale in these two works contain numerable points of examples for analysis of possible composition applications.

51. "Biography." Joel Hoffman. Accessed March 8, 2019. http://www.joelhoffman.net/biography; Joel Hoffman. "6-8-2-4-5-8." E-mail message to author. February 21, 2019. 
A. Analysis Introduction, 6-8-2-4-5-8

6-8-2-4-5-8, ${ }^{52}$ a piece written in 2006 for the Pierrot ensemble Eighth Blackbird - flute (piccolo), clarinet, violin, cello, piano, plus percussionist - uses a heptatonic scale, just as in his first piano concerto, with a total interval of a major ninth. The pitch collection is different, however, from the previous work with intervals based mostly on minor seconds and major thirds. The piece is classified as a rondo (see Table 5, below) due to the alternating styles of articulation and motivic presence; after the opening section develops into the pitch motive F-D-C\#-D-C\#-A at mm. $48 \mathrm{ff}$. , with each pitch in close proximity to each other, each subsequent A section is dominated by this motive (see Figure 23, below). Except for the retransition into the last, each section is demarcated exclusively by rests of one measure or greater. Apparent when it arrives in $\mathrm{A}^{5}$, the six-note motive is drawn out as a coda through minimalist-style compositional technique.

Section $\mathrm{A}^{1} /$ Introduction, mm. 1-110

Section B, legato, mm. 111-161

Section $\mathrm{A}^{2}$, mm. 162-181

Section C, dolce e espressivo, 3/4 meter, mm. 182-245

Section $\mathrm{A}^{3}$, mm. 246-264

Section D, staccato, mm. 265-337

Section $\mathrm{A}^{4}$, mm. 338-371

Section E, pesante, mm. 372-444

Retransition at m. 423 ff. in $2 / 2$ meter

Section $A^{5} /$ Coda, mm. 445-533

52. The title of 6-8-2-4-5-8 comes from the pattern of the meter used throughout most of the work. Measures in 6/8 are typically followed by those in $2 / 4$, and then by those in 5/8. Joel Hoffman. 6-8-2-4-5-8. Cincinnati: Onibatan Music, 2006. PDF. Used with permission. 
Table 5. Formal outline of $6-8-2-4-5-8$.

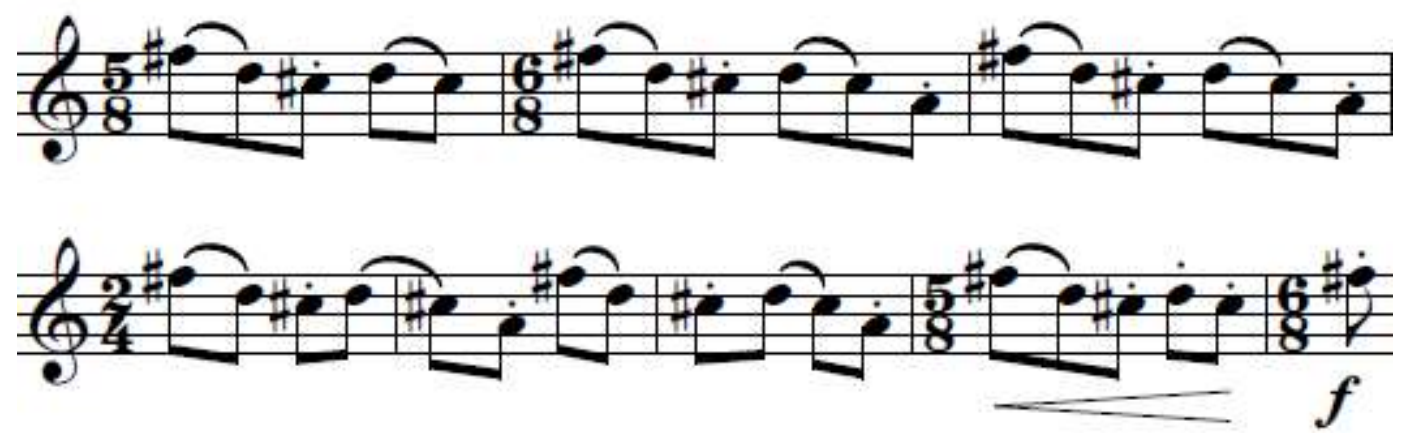

Figure 23. The F\#-D-C\#-D-C\#-A motive in violin at mm. 48-55.

The 6-8-2-4-5-8 hyperscale has a pattern of seven intervals with a total distance of a major ninth, an instance that is then repeated so that the hypertonic of the first instance is also the tonic of the next. This configuration is repeated for a total of six instances of the hyperscale that begin on $B b_{0}, C_{2}, D_{3}, E_{4}, F_{5}$ and $G_{\#}$, with $A \#_{7}$ as the highest hypertonic, with an extension of total range to $\mathrm{B}_{7}$ at the terminus. Notably, this scale consists an opening half step that is followed by a major third, a whole step, a series of three consecutive half steps, and a final major third. (See Figure 24, below.)

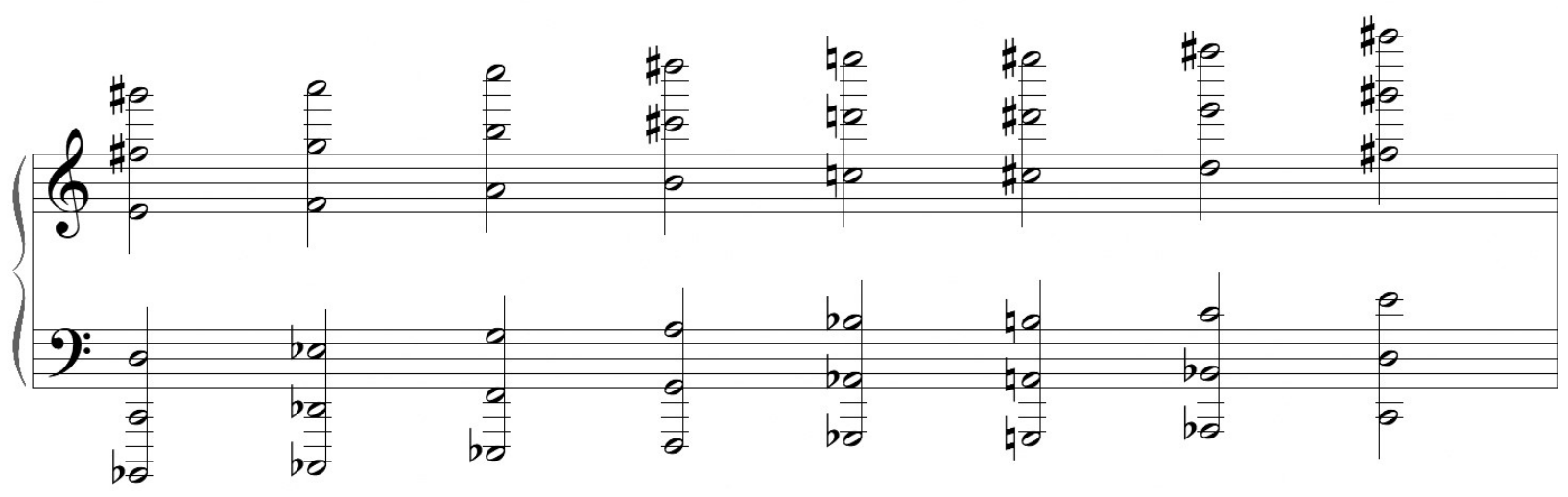

Figure 24. The hyperscale of 6-8-2-4-5-8, in six consecutive instances, from $\mathrm{B} b_{0}$ to $\mathrm{A} \#$. 
Hoffman chose to ease the listener gradually into the new hyperscale pattern. In using the natural placement of pitches in the hyperscale to create tertian patterns across different registers, $\mathrm{Ab}$ and $\mathrm{G}$ in the cello and piano allude to the key of $\mathrm{Eb}$ Major in its initial development except for a pesky A and B in the marimba part that leave evidence of the nontraditional scale that the piece will eventually invoke. While the emerging pattern of sonority is unfamiliar, triads common to tonality are still present. The melody in measures 3-5 outline a broken $\mathrm{G}$ minor triad, followed by the outline of an Eb major triad in 5-6. The placement of this small moment is critical - and likely intentional - as evidenced by the presence of the $\mathrm{E} b_{4}$ that will prove later in the piece to fall outside Hoffman's hyperscale.

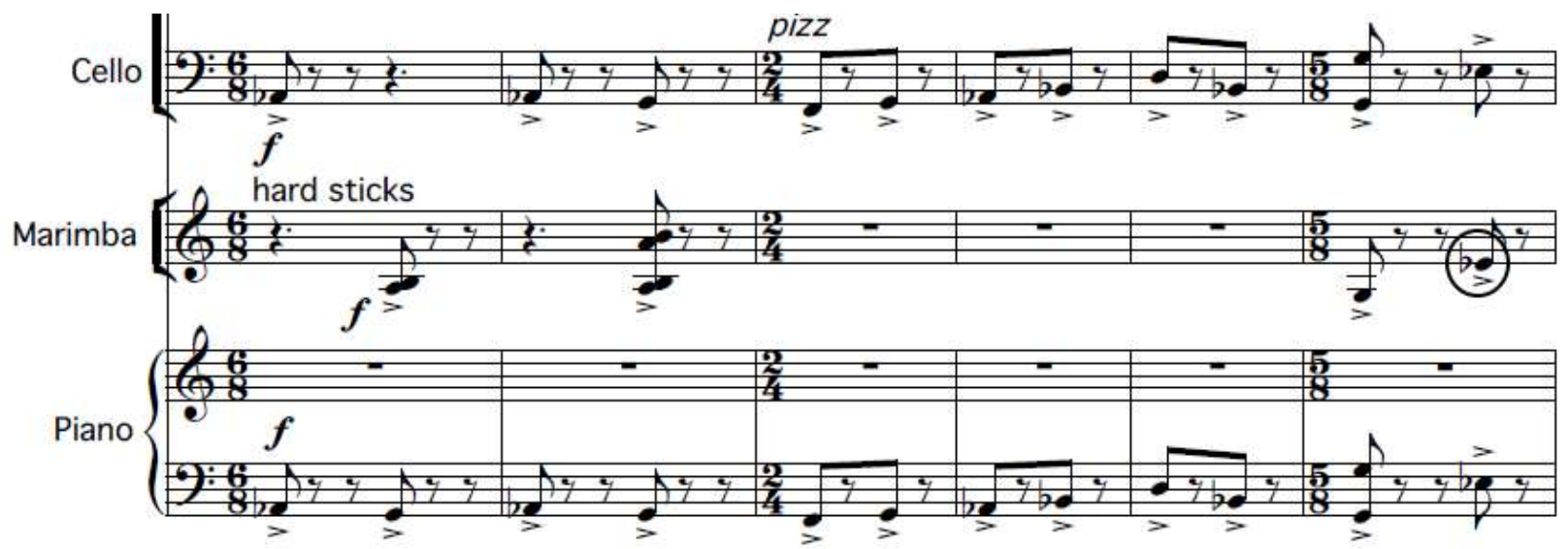

Figure 25. The first six measures of 6-8-2-4-5-8, with circled $E b_{4}$ which is chromatic to the hyperscale in this work. Note that the simultaneous $E b_{3}$ in the cello and piano parts are diatonic to this hyperscale.

The composer continues to reveal the scale slowly by tarrying to bring in the possible pitches in the ensemble's tessitura, letting the pitches unfold carefully and introducing only a part of the full spectrum in each section as if to make sure the listener is properly introduced to every part of the hyperscale in all registers. Not until measure 61 is the $A_{2}$ found; all other pitches 
from $\mathrm{C}_{2}$ through $\mathrm{D} \mathbb{\#}_{6}$ have been previously introduced by this point, and on the upper side the pitches $E_{6}$ and $\mathrm{G}^{\sharp} 6$ round out the fourth instance of the hyperscale in $\mathrm{mm}$. 78. This trend continues until measure 331 , where $\mathrm{B}_{0}$ (in the scale, $\mathrm{C}_{0}$ ) and $\mathrm{B}_{7}$ make their debut in the piccolo and piano, respectively, at the apex of the piece.

Hoffman is also careful to introduce the four pitches that form three consecutive half-step intervals in his hyperscale. The interval of the whole step in the first half of the piece bridges the natural three-half-step run before the scale fully shows its teeth. The half steps inside the third instance of the hyperscale (A-Bb-B-C) display the best example, even though these pitches are displaced into other instances where the pitches are still in the scale. $\mathrm{A}_{3}$-to- $\mathrm{B}_{3}$ is followed by $\mathrm{B}_{3}$-to- $\mathrm{C}_{4}$ in violoncello at measures 45-46, then after the start of section $\mathrm{B}$ in mm. 96-97 an ascent of the half steps at the ninth lower are interrupted by an eighth rest where the $\mathrm{B} b_{2}$ begins a new phrase separately from the pitches in the previous phrase, and in mm. 128-129 further tension is introduced with the run of $\mathrm{A}-\mathrm{B} b-\mathrm{C}$ in the left hand of the pianist overlapping the $\mathrm{B}$ in the right hand. At measures 164-166 the notes are found consecutively and consistently for the first time as the hyperscale descends almost in its entirety in the cello, marimba, and piano. By the end of section $\mathrm{A}^{2}$ at mm. 241-242, Hoffman removes from limit his use of the pitches that comprise the minor seconds. An excellent example of free use of the pitches of the minor seconds interval is found in the clarinet, violin, and cello parts of mm. 414-416. The previous abrupt introduction at the beginning of the work with the A-B cluster countering the $\mathrm{A} b, \mathrm{G}$, and chromatic $\mathrm{E} b$ that suggest the key of $\mathrm{E} b$ Major now becomes apparent as foreshadow. (See Figure 26, below) 

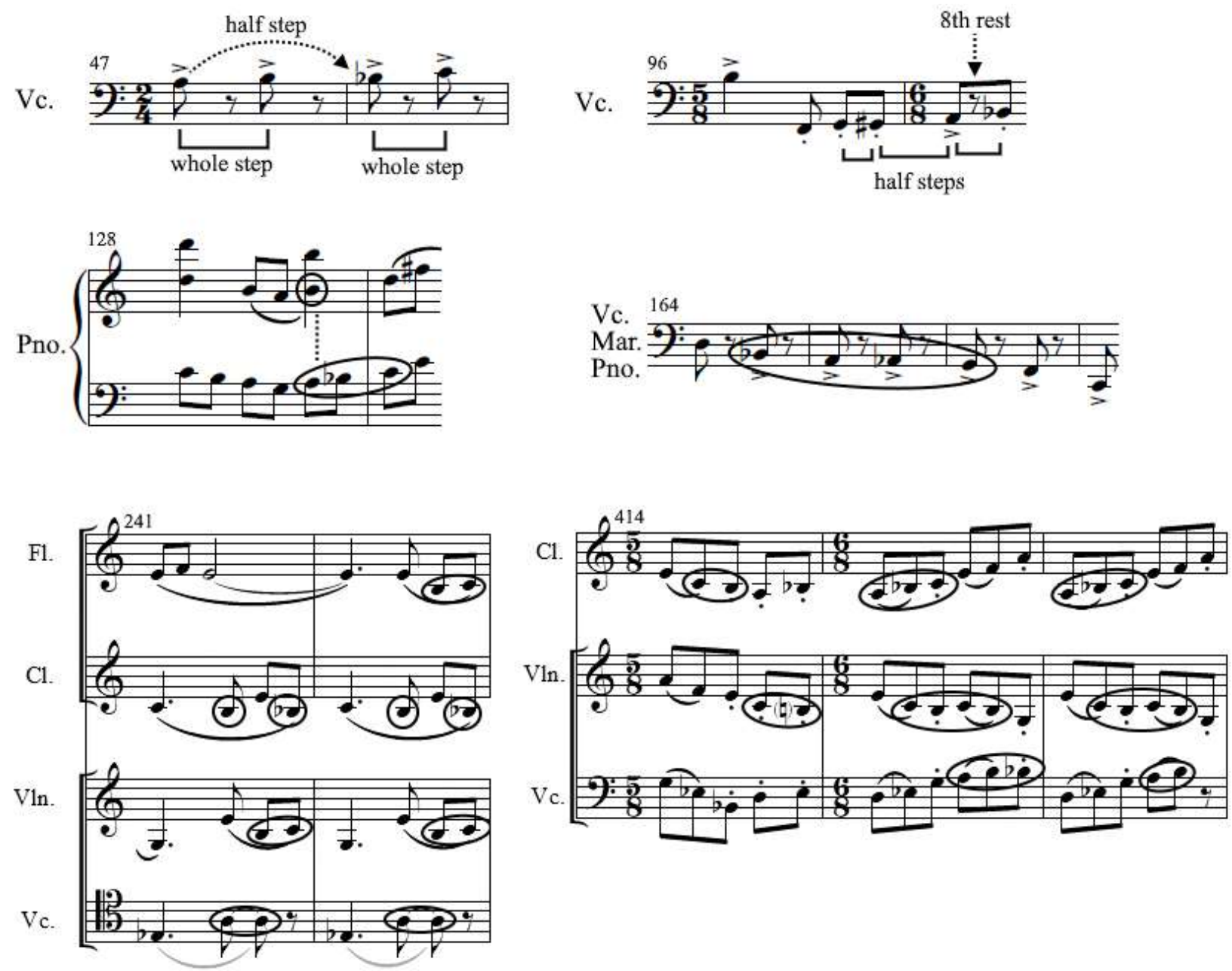

Figure 26. Gradual introduction of the half-step sequence of the 6-8-2-4-5-8 hyperscale. The clarinet part is shown in $\mathrm{C}$ for illustrative purposes.

\section{B. The Perfect Fifth}

The most interesting feature of $6-8-2-4-5-8$ is how Hoffman treats the intervals that comprises half of the major-ninth range of the hyperscale: the perfect fifth. As the midpoint of the major ninth scale, the perfect fifth is, essentially, the intervallic equivalent of the tritone in the middle of the perfect octave; however, unlike the tritone, the fifth is more agreeably harmonic as suggested by the natural interval between the first and second partials in the harmonic series. Hoffman takes advantage of this sonority by basing the important intervals in 
the piece on multiples of the perfect fifth: the major ninth, major thirteenth, and major seventeenth (doubled major ninth), plus the perfect twelfth. ${ }^{53}$ Being equal to the range of the hyperscale, the major ninth is given the most attention by Hoffman.

$6-8-2-4-5-8$ is replete with examples of the major ninth in both harmonic and melodic figures. Though not the very first instance of a major ninth - the $\mathrm{A}_{3}-\mathrm{B}_{4}$ combination in measure 2 has that distinction - the first time the interval is obvious is in measures $30-31$ where $\mathrm{D}_{3}, \mathrm{E}_{4}$, and $\mathrm{F}_{5}$ form a chord that precedes a prominent descending four-measure outline of ninths that happens in each A section. A good example of obscure-then-discernable ninths, the clarinet and violin together at mm. $385 \mathrm{ff}$. with violoncello and piano have independent eighth-note lines with counterpoint that occasionally coincides at the major ninth then at $\mathrm{mm} .393 \mathrm{ff}$. form complete lines of major-ninth intervals.

Stacks of pitches in short chords toward the end of the work always contain interwoven major ninths with other important intervals often within. Every pitch in the first downbeat of measure 432 has a major-ninth pair, except for $A_{3}, G_{3}$, and doubled $C_{6}$, yet in the beat-two stack of measure 433 , movement of one $\mathrm{C}_{6}{ }_{6}$ to a major-ninth pair of $\mathrm{G}_{5} / \mathrm{A}_{6}$ imply that the composer is aware of the "incompleteness" of the chord, addressing the issue even if he does not completely resolve the discrepancy. (See Figure 27, below.)

53. These intervals are constructed as a perfect fifth times two, times three, times four, and as a perfect octave plus perfect fifth, respectively. In this paper, the major seventeenth is most commonly referred to as the doubled major ninth, both reflecting the significance of its function and simplifying a larger number that approaches esoterica in mainstream musical usage. 


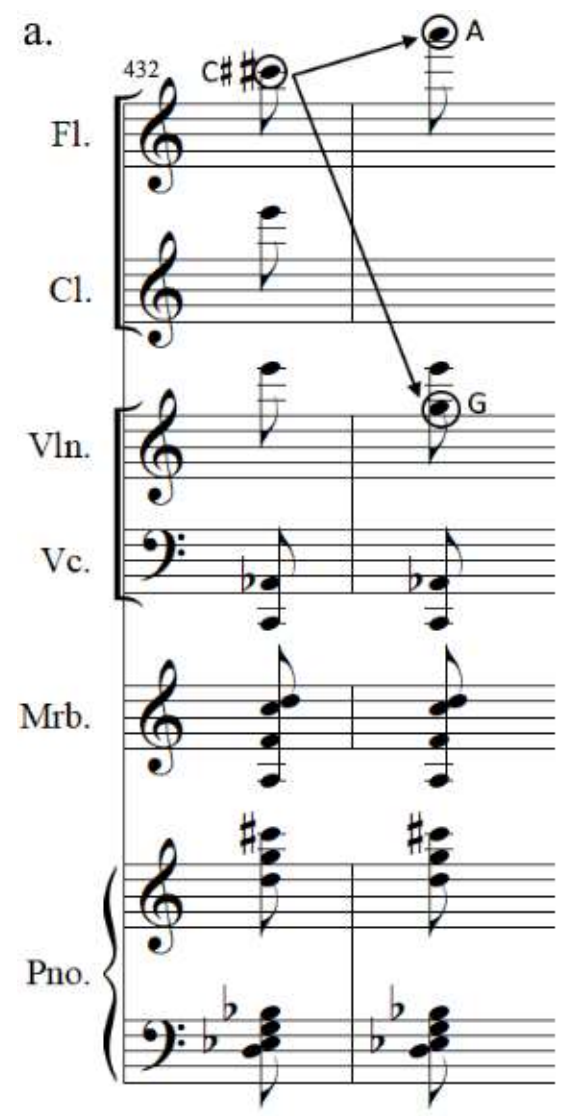

b.
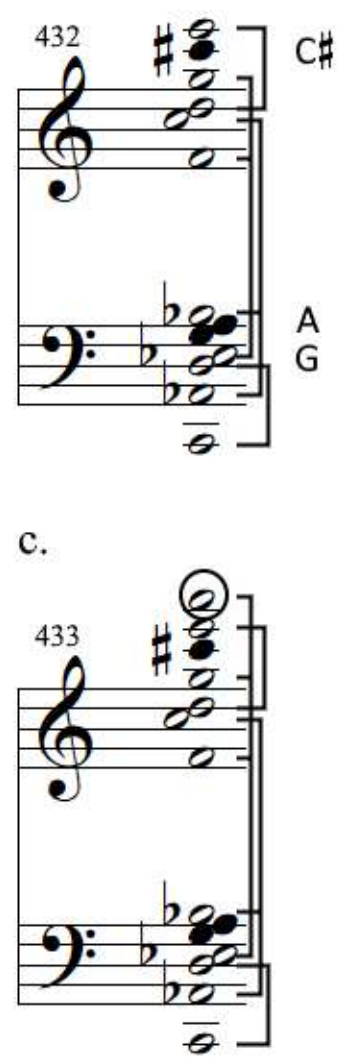

Figure 27. a) Significant chords of mm. 432-433 of 6-8-2-4-5-8 in concert pitch; circled notes are unique to each chord. b) Condensed chord of $\mathrm{m} .432$, and c) condensed chord of $\mathrm{m}$. 433, with circled $\mathrm{A}_{6}$ new to the chord in $\mathrm{m}$. 432. Open noteheads and their respective brackets represent intervals of the major ninth; closed noteheads have no paired major ninth.

$\mathrm{B}_{5}, \mathrm{C}_{7}$, and $\mathrm{F}_{7}$ - the latter two notes a major ninth and perfect twelfth above the first - appears in every iteration of the A section beginning at mm. 33-36 and develops periodically in the introduction. At the end of the first section in $\mathrm{mm}$. 174-180 where the $\mathrm{B}_{5}, \mathrm{CH}_{7}, \mathrm{~F}_{7} 7$ section again appears, Hoffman fills in the chord further with the insertion of $\mathrm{G}_{6} 6$ and $\mathrm{D}_{6} 6$ in $\mathrm{m} .179$ to fill in the first-inversion minor triad built on the $\mathrm{G}^{\sharp} 6$. Instead of a thirteenth chord, the functional harmony here is a minor triad set within a quintal triad. Another example of interwoven chords includes two major ninths stacked around an $\mathrm{f}^{7}$ at measures 194, 199, and 207. (See Figure 28, below.) 

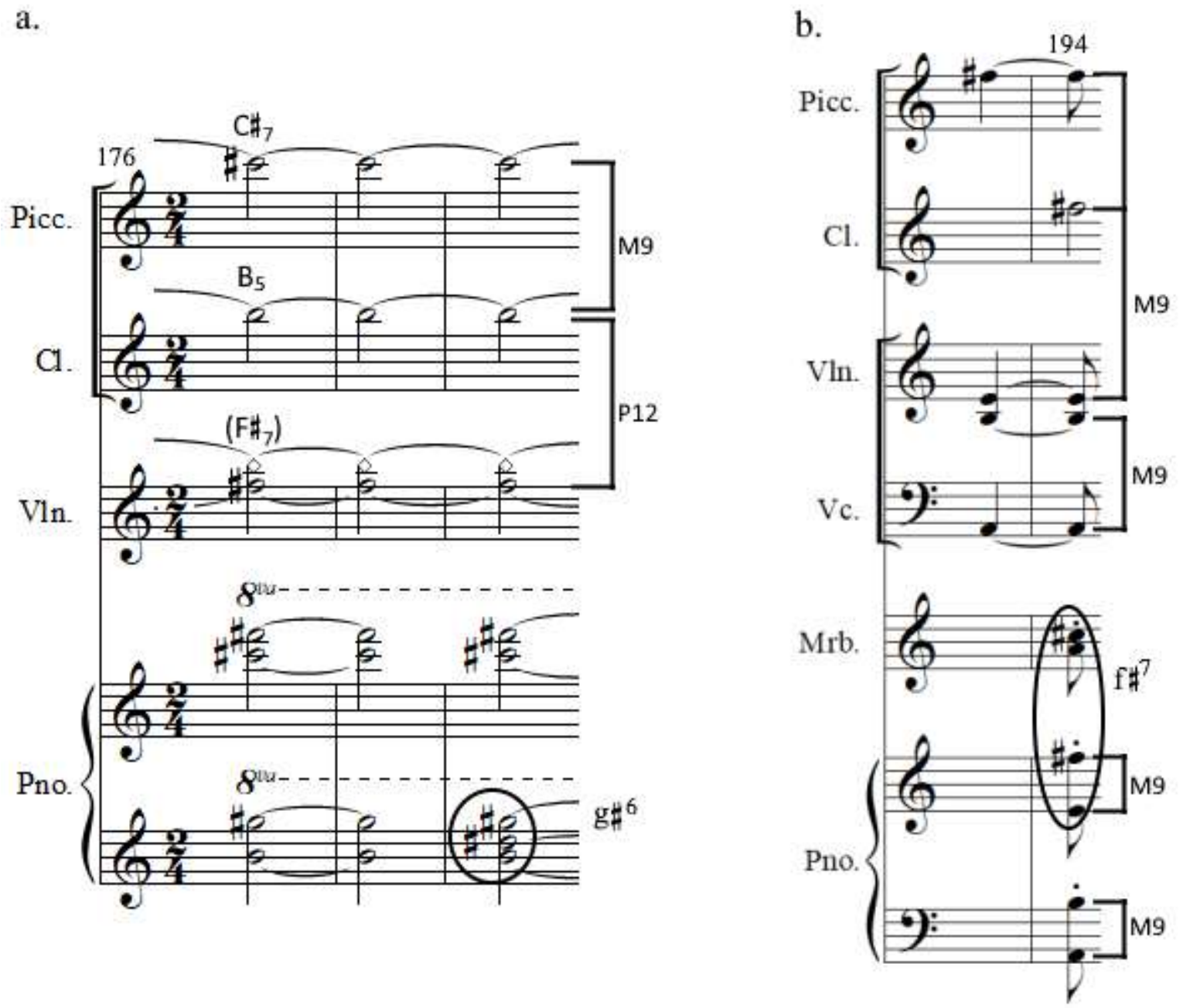

Figure 28. Two examples of interwoven chords in 6-8-2-4-5-8 at mm. 176-178 and 193-194, with analysis. The clarinet part here is displayed in $\mathrm{C}$.

Perfect twelfths and major thirteenths make a regular appearance in this work. Note that the pairs of major ninths in the second example in the above figure are also set off by a twelfth. A four-bar, eighth-note theme of major ninths in the cello, marimba, and piano that strike the first beat of each measure first found at mm. 33-36. This pattern combines in mm. 170-173 with the drone of $\mathrm{B}_{5}, \mathrm{C}_{7}$, and $\mathrm{F} \#_{7}$ along with a new group of chromatic pitches. (See Figure 29, below; and the next section, "The Chromaticism Puzzle.”) Though it receives less attention in the piece than the other intervals mentioned here, the major thirteenth is often expressed as three 


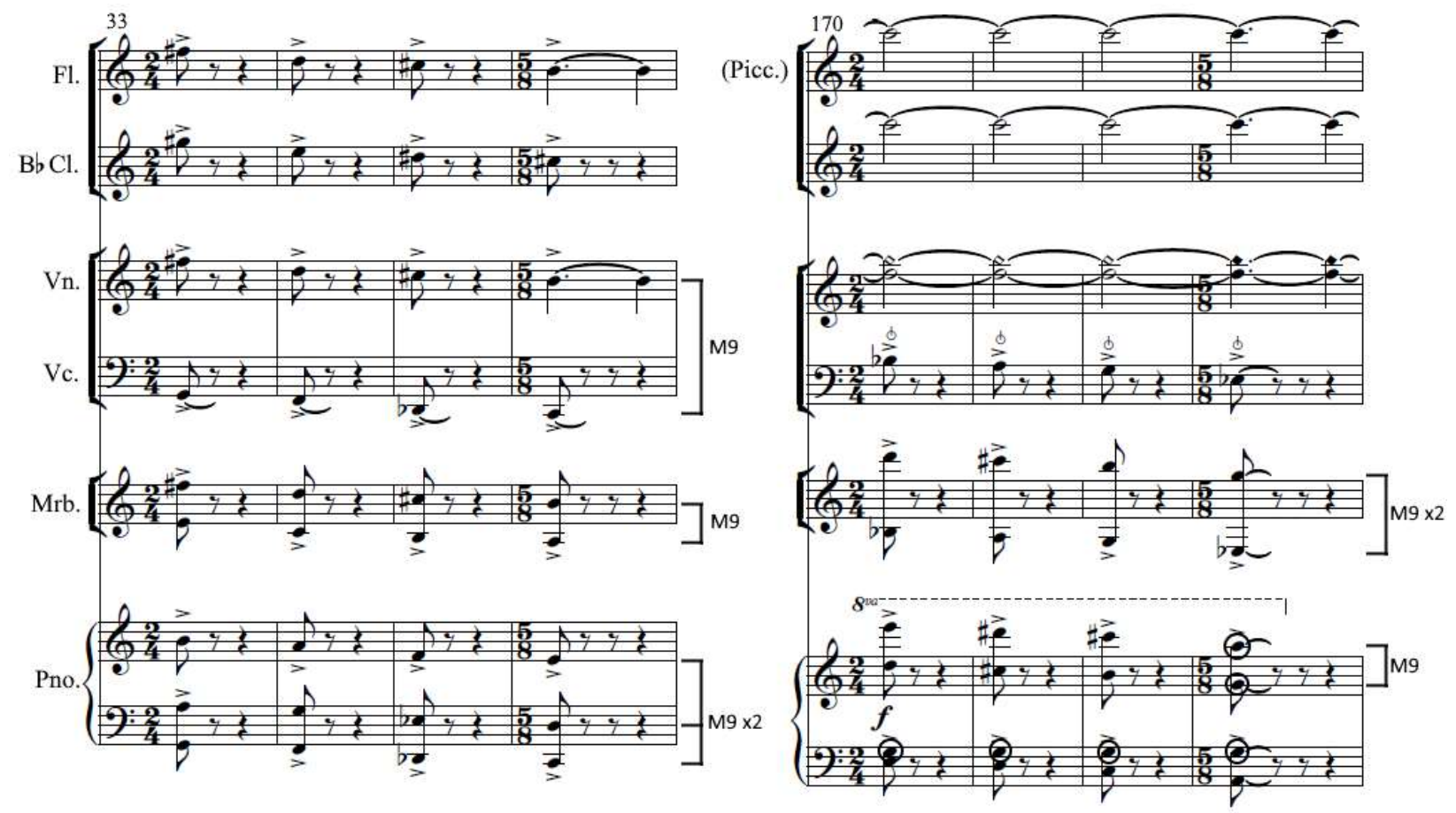

Figure 29. Measures 33-36 and mm. 170-173 of 6-8-2-4-5-8, with analysis. Circled pitches are extrascalar. See the next section, "The Chromaticism Puzzle."

stacked perfect fifths, such as the four-mallet marimba chord of $\mathrm{Bb}_{3}, \mathrm{~F}_{4}, \mathrm{C}_{5}$, and $\mathrm{G}_{5}$ in measure 155. (See Figure 30, below.)

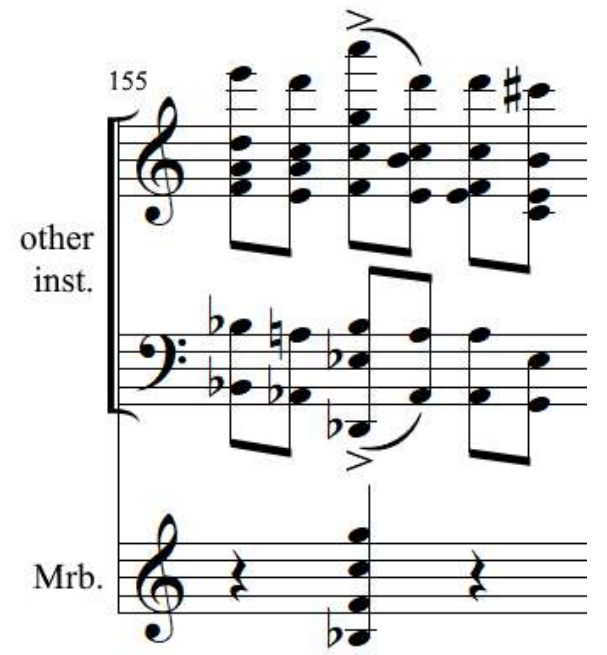

Figure 30. Measure 155 of 6-8-2-4-5-8. The four pitches in the marimba part are three intervals of a perfect fifth, a major thirteenth in total. 


\section{The Chromaticism Puzzle}

Aside from regularly engineering ways to use the major-ninth interval of the hyperscale and its cousins, Hoffman judiciously includes chromatic pitches across the work. Aurally, these pitches are indiscernible as falling outside the scale, except perhaps to one with perfect pitch who has foreknowledge of the theory behind the work:

In section $\mathrm{D}, \mathrm{D}_{4}$ is found in one note of the clarinet melody in $\mathrm{m} .214$ that foreshadows the $\mathrm{D}_{7}$ repeated in the piccolo four times in $\mathrm{mm} .274,285,286$, and 295 . By placing a rare run of the scale in measure 320 containing a chromatic $D_{7}$, the displaced pitch appears to be deliberate even though the scale is so rapid that the off-pitch in the scale is imperceptible.

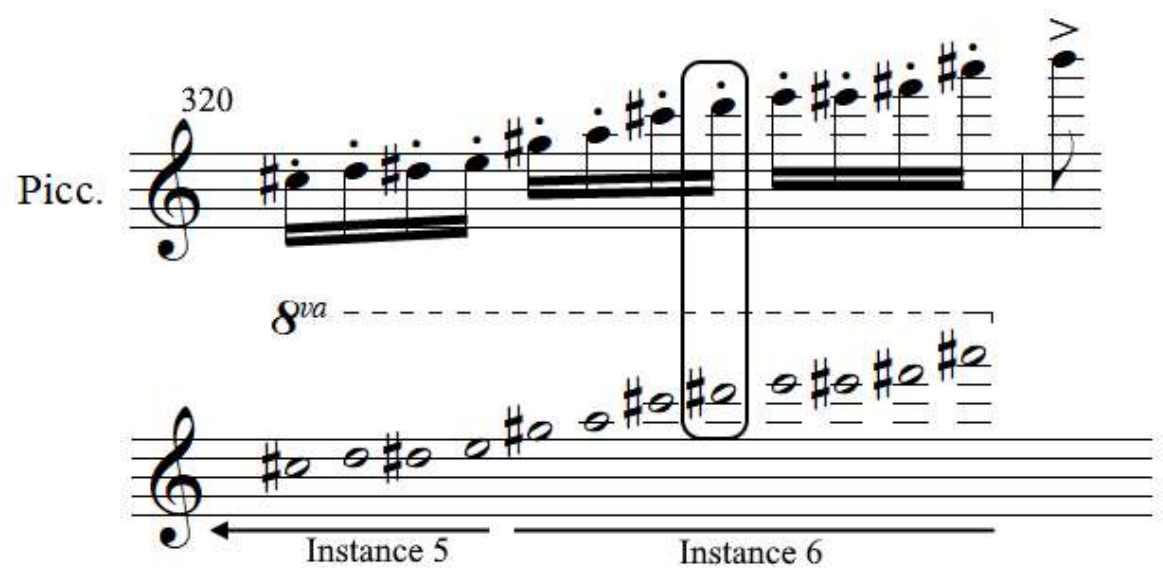

Figure 31. Measures 320-321a in the piccolo (an instrument that plays one octave higher than written) of 6-8-2-4-5-8 compared with the corresponding hyperscale instances in the piece. Note that $\mathrm{D}_{7}$ is a chromatic pitch to Hoffman's hyperscale.

The $\mathrm{E}_{5}$ repeated in the left hand of the piano in $\mathrm{mm} .170-173$ also does not belong in the scale and, combined with the phrase-ending $\mathrm{G}_{4}$ and $\mathrm{A}_{5}$, also out of the scale, and a doubled major ninth. Repeated in mm. 348-351, this chromatic feature verifies that Hoffman may have planned their appearance, occurring several times before and after in the piece with diatonic pitches 
instead, beginning with the first appearance in mm. 51-54. (See the second illustration in Figure 29, above, on p. 51.) $\mathrm{C}_{6}$ is sustained in the flute and clarinet in $\mathrm{mm} .137-139$ and then continued by the clarinet into m. 145 (see Figure 32, below). Including the $\mathrm{E} b_{4}$ in measure 6 (See Figure 25 , discussion on p. 45 , above), this is the complete set of chromatic pitches in $6-8-2-4-5-8$. Given both their small number of appearances and deliberate use, Hoffman evidently uses extrascalar pitches with care in order to establish the unfamiliar new scale.

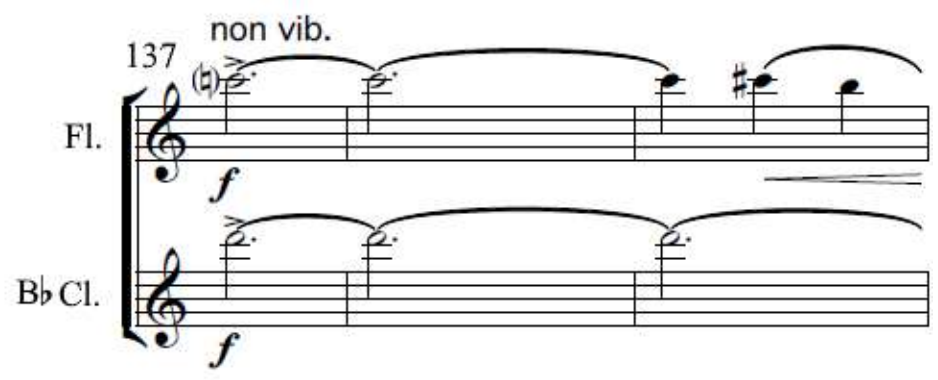

Figure 32. Chromatic $\mathrm{C}_{6}$ in mm. 137 ff. of 6-8-2-4-5-8.

D. Solving the Puzzle and Confirming the Intervals

As mentioned in the previous section, the $E b_{4}$ in the fourth measure played by the marimba introduces a riddle, similar to a mystery presented in Streetwise (see pp. 61, 64, 75-76), that is solved at the end of the composition. This chromatic pitch at the front of the concerto does not appear elsewhere in the piece but is alluded to in the final note. The $\mathrm{E} b_{3}$ is the resolution to the chromatic $\mathrm{E} b_{4}$ so that $\mathrm{Eb}$ is now in its correct octave, as if to say that the stray pitch at the beginning found its rightful place. First approached by major ninth in cello and piano, every other pitch in the last note is paired: major ninth (perfect fifth plus perfect fifth), major thirteenth (three times perfect fifth), doubled major ninth (four times perfect fifth), and perfect twelfth 
(perfect octave plus perfect fifth), and the perfect octave at the bottom is prominent, but the $\mathrm{Eb}$ is the outlier in the chord. (See Figure 33, below.)

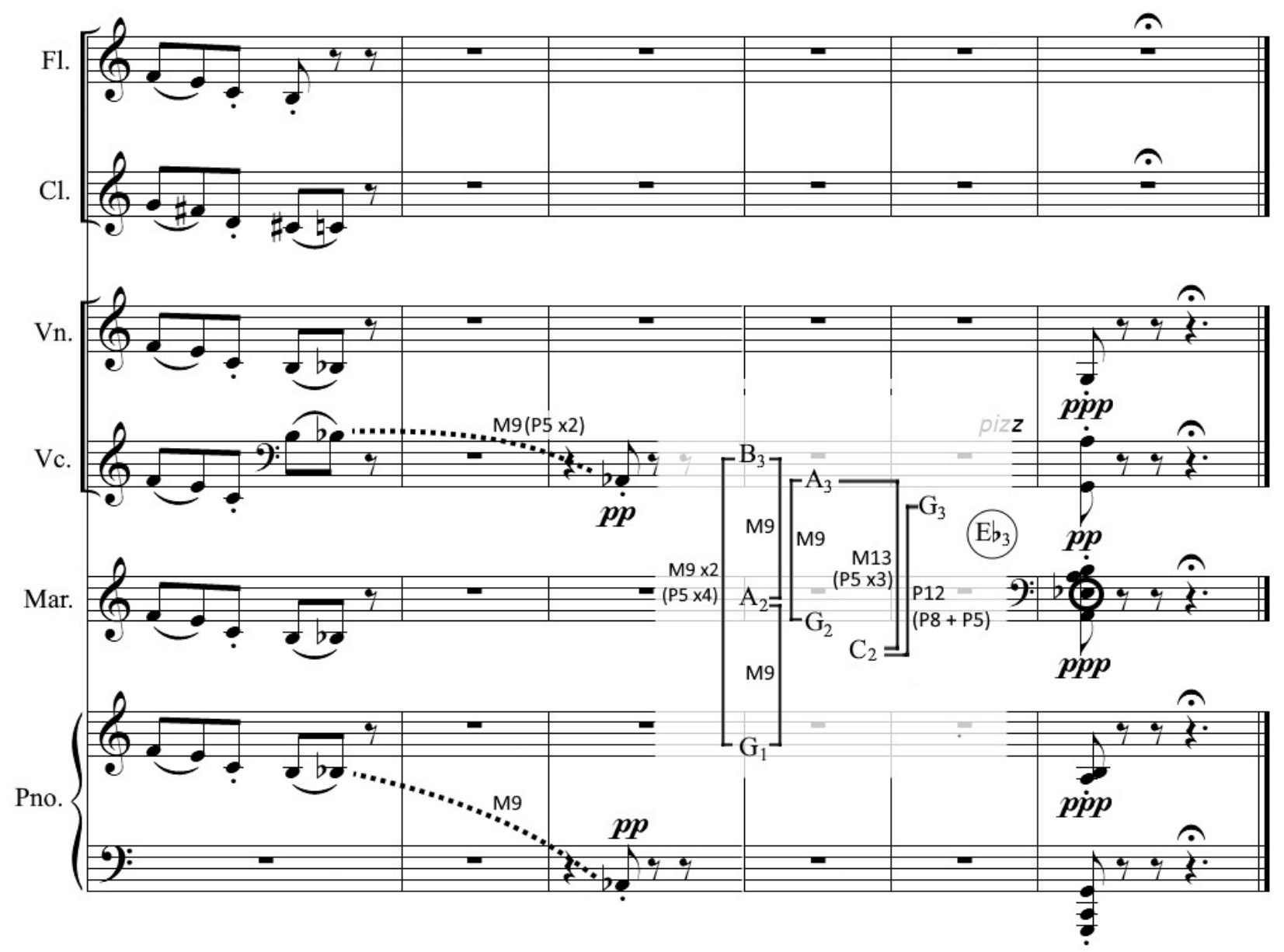

Figure 33. The final system of 6-8-2-4-5-8, with analysis of the final chord. The clarinet part is transposed in $\mathrm{B} b$.

\section{Unpublished Composers}

It would come as no surprise to discover that there are now composers - unpublished, emerging, and students - that use, and even embrace, the hyperscale in their own works thanks to composers like Gao and Hoffman who pass their styles on through university teaching. 
Obviously, it is difficult to quantify the number who use existing hyperscales or create their own, and thus I do not attempt to guess at the number who do.

\section{Other Schemes of Pitch Organization}

I ran across other examples during my pursuit to find other examples of compositions that use hyperscales that, while not appearing to qualify as using hyperscales, merit citation and light scrutiny here.

\section{A. Process Composition}

The composition style of Karlheinz Stockhausen (1928-2007) changed dramatically, though not immediately on a permanent basis, using the innovation of the "formula technique" with a piece for two pianos named Mantra (1970). ${ }^{54}$ Microphones are attached to the piano which send the played sounds through a device called a ring modulator - so called for the roundabout path of the four diodes in the electronic circuitry - which measures the sine wave of two frequencies and outputs both the sum and the difference. ${ }^{55}$ Although Stockhausen temporarily abandoned the electronic technique, he eventually came back to it and spent most of the rest of his writing career exploiting formula technique. Later, Stockhausen's work on Licht, a seven-part operatic cycle, gave him distinction outside the world of avant-garde music where he gained his initial praise.

54. Richard Toop, “Stockhausen, Karlheinz.” Grove Music Online. January 20, 2001.

55. In the example at this source, a $1,000 \mathrm{~Hz}$ wave and a $400 \mathrm{~Hz}$ wave are combined by the ring modulator to create the sum, $1,400 \mathrm{~Hz}$, and the difference, $600 \mathrm{~Hz}$, of the two numbers. The modulator then modifies the two inputs based on these calculations and broadcasts the results via amplifier. In reality there are a myriad of pitches simultaneously sounded by both pianos, and the modulator performs millions of calculations to produce new pitches. Richard Orton. "Ring Modulator." Grove Music Online. January 20, 2001. 
Before this fame came Spiral (1968), an aleatoric piece that incorporates a short-wave radio to be manipulated by the performer that is scored with a range of over three octaves. "Process composition" contains pictographic directions for transforming the sounds with plus, minus, and equal signs giving general directions to the performer on how to change the elements of pitch, dynamics, and other features of the instruments involved that may be modulated. The first twenty events of Spiral are shown in Figure 34, below. Though premiered on guitar, the work is not written for a specific instrument and may be performed on any instrument with a great range. ${ }^{56}$

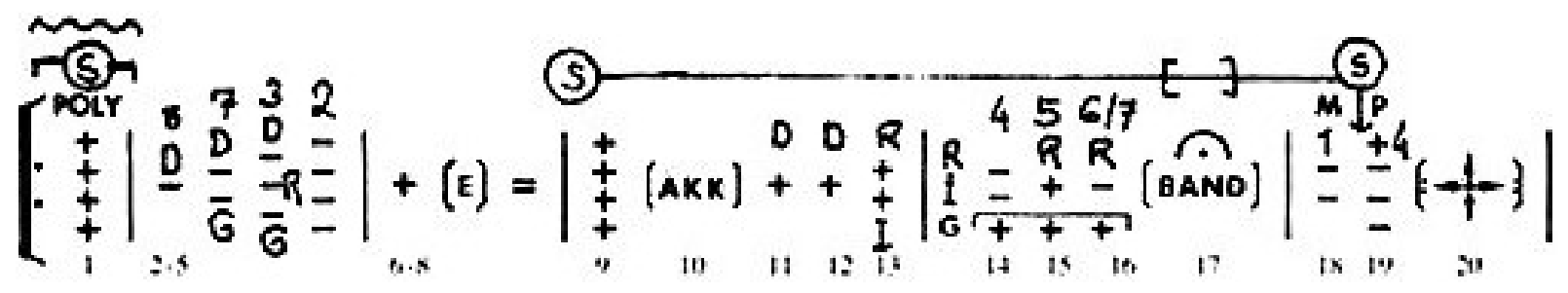

Figure 34. Opening line of score in Spiral, with annotations by the performer of the premiere. ${ }^{57}$

The range in Spiral does not fit the parameters of a hyperscale as defined in this paper for two reasons. The pitches derived from this process in the range, first, have the property of having no defined set in any sort of order and, second, use non-discrete pitches that are relatively higher or lower than one another but not at specific intervals. Although not enough to qualify process composition as a hyperscale, this example is here, however, because it contains pitches in a range greater than one octave.

56. Toop. "Stockhausen, Karlheinz."

57. Toop. 


\section{B. Hyper-diatonicity}

In an analysis of a Stefan Wolpe work entitled Second Piece for Violin Alone, Matthew Greenbaum, who studied under the composer, uses the term "hyper-diatonic" in reference to a section of the piece that the author calls an "F diatonic collection plus $\mathrm{E} b$ and $\mathrm{B}$," possibly implying that a nine-pitch hyperscale of sorts is employed. ${ }^{58}$ While the use of the special term coined by Greenbaum denotates that these two extra pitches are used outside the scale, they are integrated into the work in the same register as the other pitches, and therefore do not fit the scheme of being hyperscalar. This does not take away from the additive feature of the pitch set (or the use of the term hyper-diatonic) as described by Greenbaum, but only to point out that Greenbaum's terminology is not related to hyperscale as defined in this paper because the pitch organization of Second Piece is still contained within the bounds of a one-octave scale; nothing is contextually separated into a secondary octave.

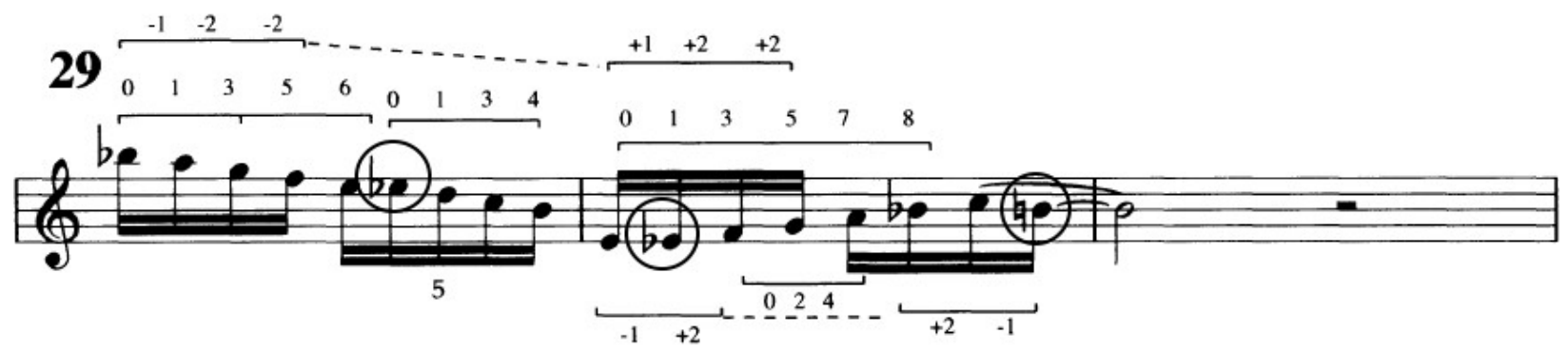

Figure 35. Moment 29 of Second Piece for Violin Alone, annotated with Greenbaum's analysis (circled $\mathrm{B} \sharp$ and $\mathrm{E} b$ added for emphasis). ${ }^{59}$

58. Matthew Greenbaum. "Stefan Wolpe's Dialectical Logic: A Look at the 'Second Piece for Violin Alone'.” Perspectives of New Music 40, no. 2 (Summer 2002): 95.

59. Greenbaum, “Stefan Wolpe's Dialectical Logic,” 107. http://www.jstor.org/stable/25164488. 
C. Pitch Fields

A pitch field is a section of music that "contains an unordered collection of pitches... kept in circulation to the exclusion of other pitches," similar to a scale, except that a pitch field allows for leaping intervals of three half steps or greater. By definition, pitch fields are not restricted to the intervallic size of its upper and lower boundaries, and most every example spans greater than one octave. Those fields less than one octave come across clearly as a chord, a pitch set in the sense of Modernism, or a subset of an entire one-octave scale. ${ }^{60}$

A given pitch field is also a scale - and, by observation, for most fields used by contemporary composers, a hyperscale - when the interval series of the pitch collection repeats itself higher or lower than the outer boundaries of the collection. However, pitch fields appear to exist, in the greater number of cases, without repetition of the set of intervals.

Composer and music theorist Paul Nauert (1967-2019) purports a thesis of the "truncated" hyperoctave pitch field - that is, not repeated beyond its upper and lower bounds as being inherently infinite. I disagree with this argument, especially since his own definition of the "pitch field" places it outside the structure of the scale. All pitch sets, no matter how structured, are naturally truncated by the instruments' range limitations, and therefore, pitch fields could be considered a property of the hyperscale or a "subset" of one should the parameters for repetition of the intervallic set exist. ${ }^{61}$

60. Paul Nauert. "Field Notes: A Study of Fixed-Pitch Formations." Perspectives of New Music 41, no. 1 (2003): 181-183. http://www.jstor.org/stable/25164511.

61. Nauert, "Field Notes," 191. 
Further, a pitch collection that has a significant enough number of intervals greater than a whole step begins to imply something more closely akin to a chord, a premise to which Nauert agrees. ${ }^{62}$ Having two intervals which are a minor third apart within a scale already implies a diminished triad and begins to tear at the definition of a scale. In Sequenza VII, composed by Luciano Berio (1925-2003), the oboe is used for every note in its practical range - except for five pitches, from $\mathrm{B}_{3}$ to $\mathrm{G}_{6}-$ which in this example implies something closer to the half-step chromatic scale with a few missing pitches. ${ }^{63}$

The idea of the pitch field being distinct from the hyperscale is further supported by Sequenza VI for viola, also by Berio, which has moments scattered regularly through the piece that have the hyperscalar attribute of unique pitch collection spanning more than one octave containing unique pitches in each octave. However, the span of time inside the piece that each set is used in is so short and different from one another that an established harmony is difficult to perceive. Instead of establishing a scale, Berio seems more interested in exploiting the intervals (see Figure 36, below). ${ }^{64}$

Berio appears to use the pitch field historically in temporal moments by (e.g., Epifanie A, Sequenza VII, Sequenza VI), only to change to another pitch field or form of pitch organization quickly, although one notable exception is a group of arias in Un re in ascolto that use the same pitch field exclusively in each song (see Figure 37, below). ${ }^{65}$ Jacques Ibert, Joel Hoffman, and I use the hyperscale to establish an idiom for an entire piece or movement, even if that idiom is

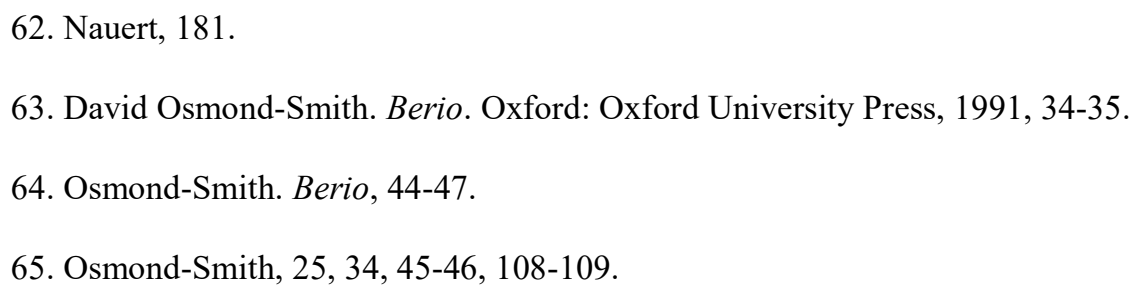



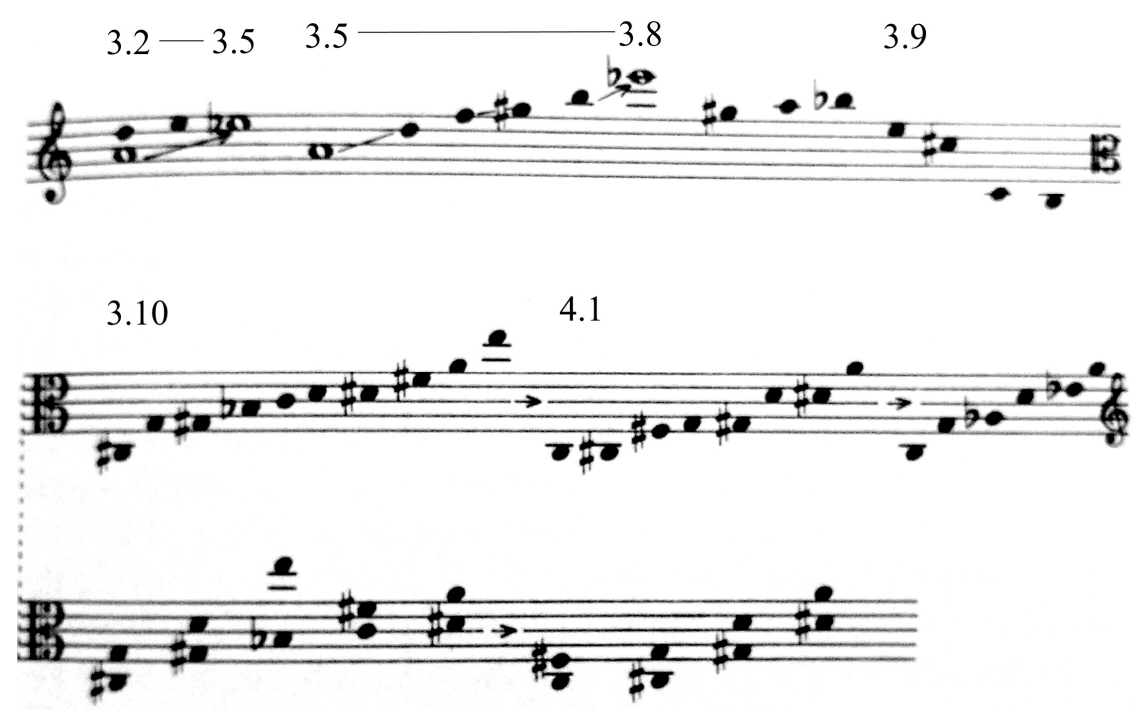

Figure 36. Excerpt from analysis by David Osmond-Smith of Sequenza VI by Luciano Berio. This section contains multiple pitch fields in rapid order so that establishment of a scalar idiom is not possible. ${ }^{66}$

altered for a period. (See pp. 33 ff., pp. 42 ff., and below on pp. 60 ff., respectively, for analyses of these works). A scale is more closely associated with the techniques of the Common Practice Period compared to the pitch field, which lies closer to the disruptive nature of Modernism.

Ultimately, a given pitch collection may be used as both a pitch field and a hyperscale simultaneously. These properties are mutually exclusive; a pitch collection may be either a pitch field or a hyperscale (or neither), or a pitch collection may be both simultaneously.

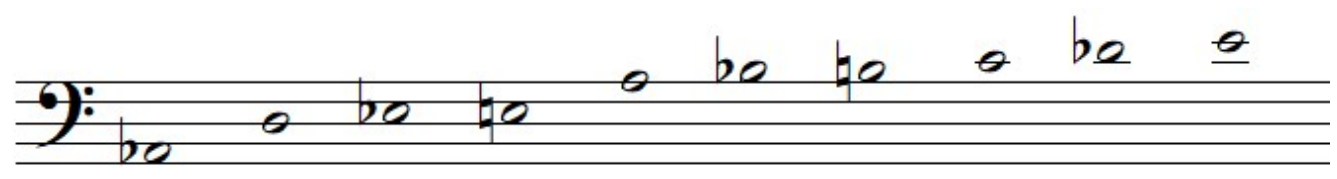

Figure 37. Pitch field of all five arias for the character Prospero in Berio's Un re in ascolto. ${ }^{67}$

66. Osmond-Smith, 45.

67. Osmond-Smith, 108. 


\section{Chapter 4. Creation of a Practical Piece for Performance, Streetwise}

Centered around the key of F, Streetwise is a three-movement work for tuba and piano that I wrote, using various techniques to display characteristics that are distinctive to the major and minor hyperscales. This chapter focuses on the similarities and differences between hyperscale and one-octave scales and compares Streetwise to Hoffman's 6-8-2-4-5-8 to illustrate the choices I made for the organization of pitches in the major and minor hyperscales.

The harmonies produced by triads in these hyperscales are not just different, but also numerous by comparison. Because these harmonies both omit possibilities found in standard tertian harmony and add chords that do not otherwise occur in major and minor scales, Streetwise showcases the potential for new harmonic idioms of structured consonance as a complement to the Common Practice Period. During the composition process, I felt that rigidly sticking to the diatonic triads formed by a hyperscale is not necessary for either the casual listener or the seasoned - in the same spirit that composers in the Baroque, Classical, and Romantic eras sought ways to expand on contemporary ideas already established in tertian harmony. In this analysis I reveal some consequences that I discovered that are inherent with staying to a set of new rules that do not necessarily apply to tertian harmony. Refer to Table 6, following, for the naturally occurring triads in the major and minor hyperscales.

Each of the three movements explore different areas of experimentation within the two hyperscales. The first establishes the harmony of the major hyperscale in the mind of the listener with points of modulation that have a tempered emphasis on harmonic transition between scale types, and returning to a more familiar, though uncommon, minor-major scale in alternate 


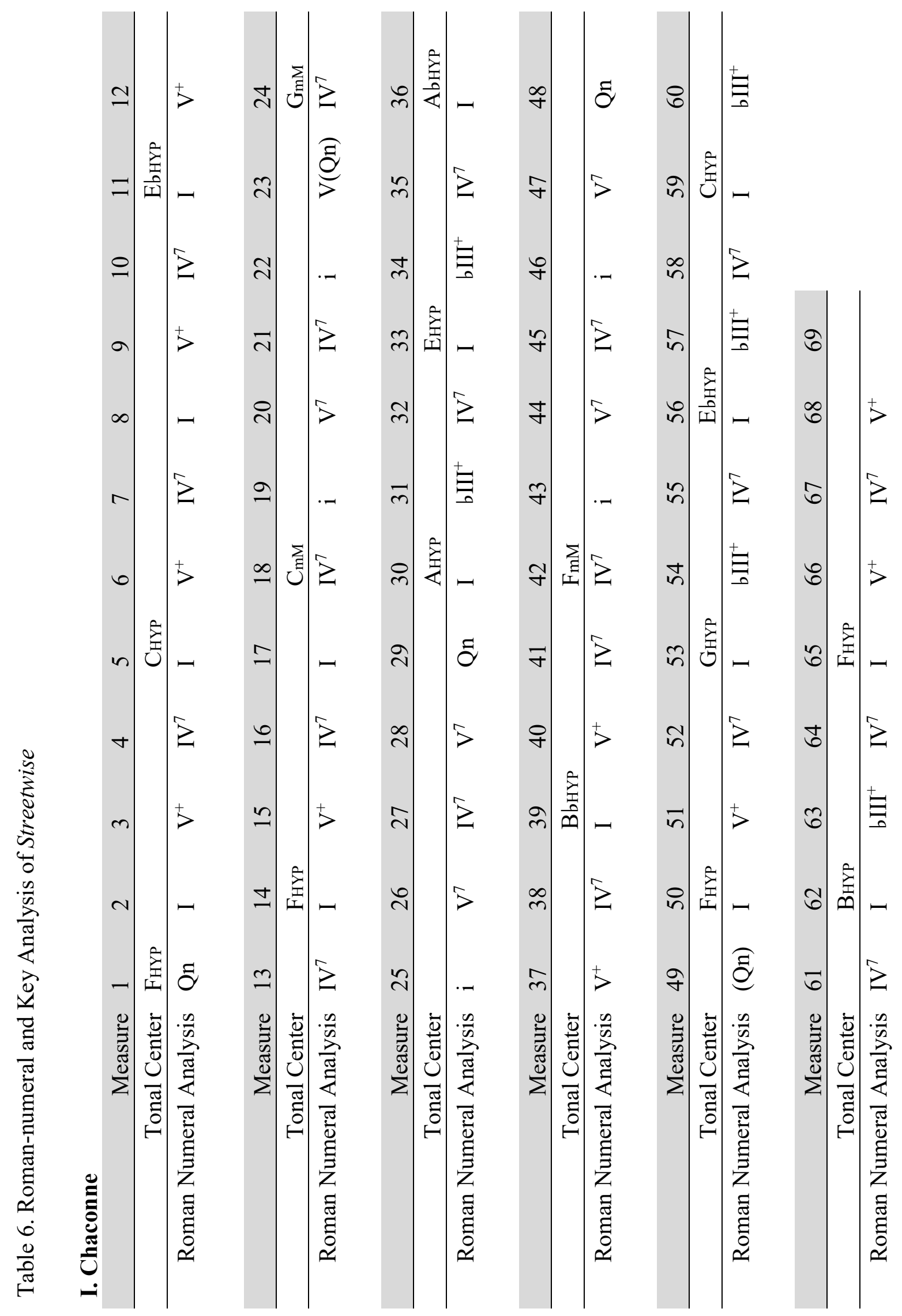




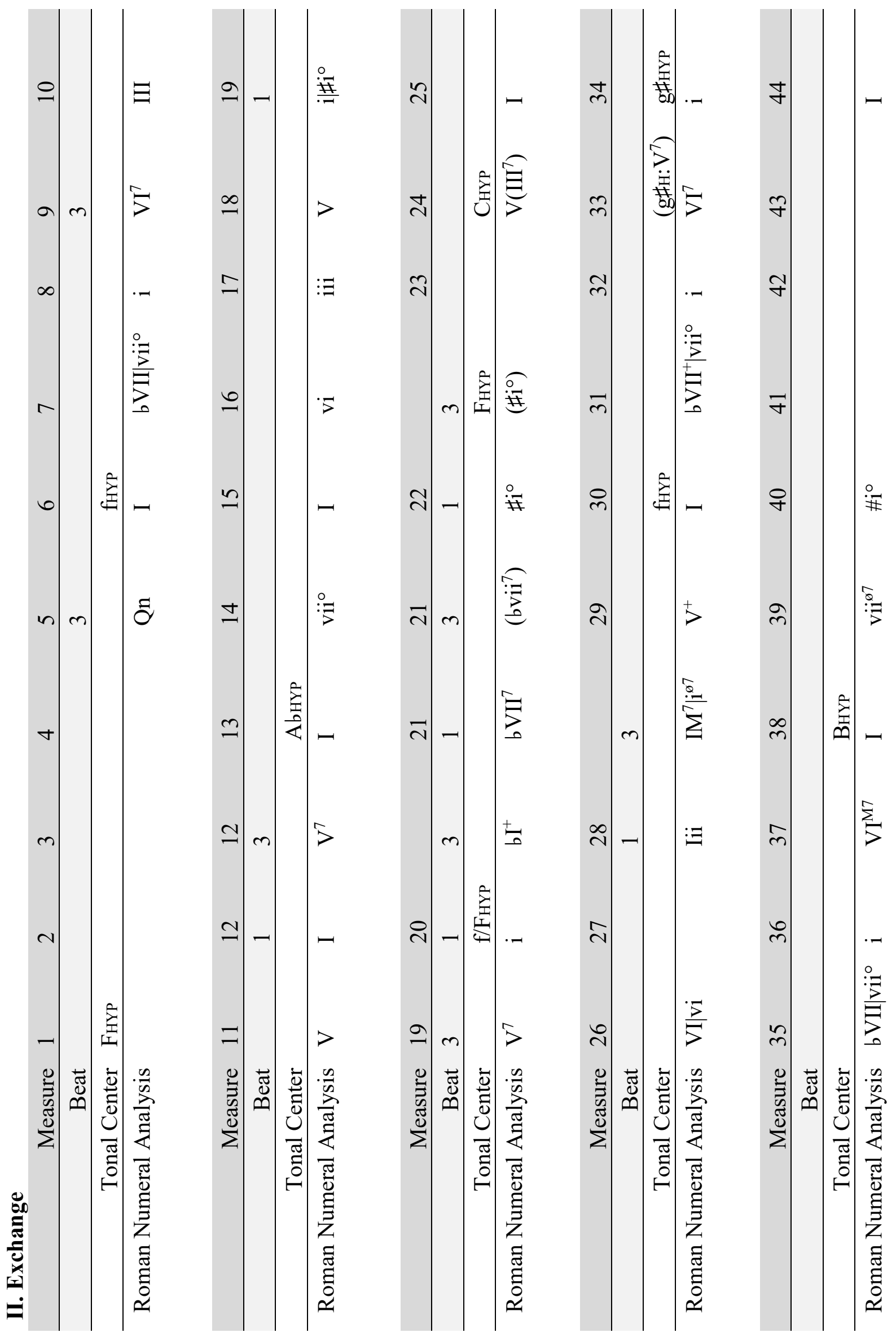




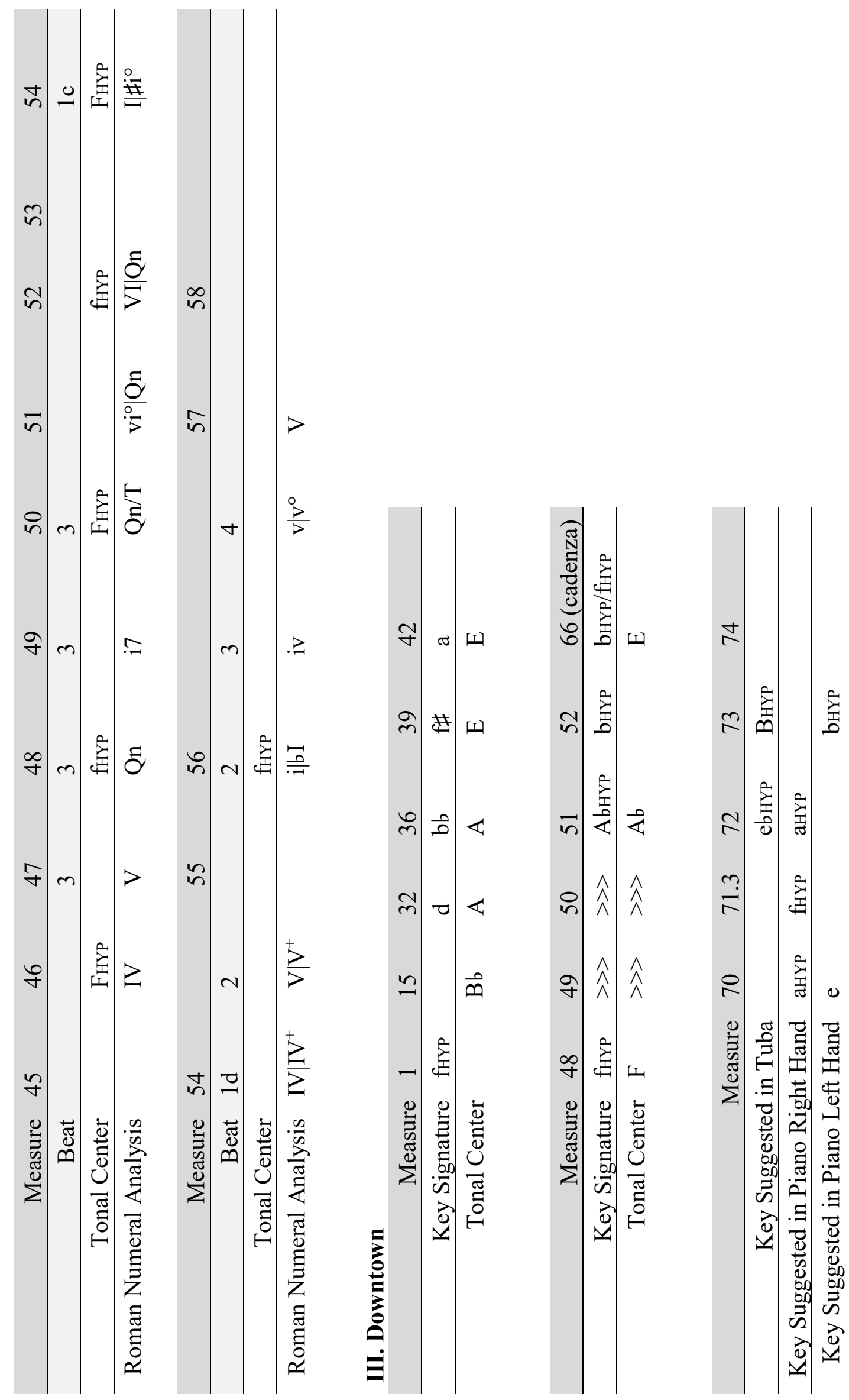


sections. ${ }^{68}$ In the second movement I focused on "modal" transition and subtle harmonic variation through alternation of the major and minor hyperscales, and in the third I experimented with modulation in the hyperscale, mostly in its minor form. ${ }^{69}$

\section{Chaconne}

The opening piece, "Chaconne," begins with two figures in the pickup and first measure that foreshadow a harmonic mystery present in both the first and second movements. The first chord, $\mathrm{F}-\mathrm{B} b-\mathrm{C}$, is a quintal triad representing the roots of the basic cycle of functions typical of tertian harmony. ${ }^{70}$ As in the major and minor one-octave scales, these three pitches are the core in both the major hyperscale and the minor hyperscale, thus appearing together regularly throughout the work. The $A b_{3}$ functions as a G\# within the key of FHYP and appears in this enharmonic form for two reasons: first, foreshadowing the use of minor hyperscale later in the work and, second, facilitating a slightly easier pitch to read for the pianist who needs to reconcile

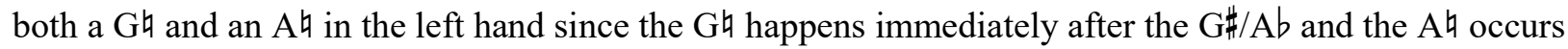
a half step later, allowing for a little more mental adjustment time for the pianist. In the short introduction, scale degrees 8, 9, and $10(F \sharp ", G \sharp "$, and $A \# ")$ are otherwise avoided and saved for later introduction of the new scale.

68. A minor-major scale, also known as jazz harmonic minor, has degree three at a minor interval above tonic and the sixth and seventh degrees at major intervals above tonic. In C, this scale is C-D-Eb-F-G-A-B-C. Middlebrook. Scales \& Modes, 88.

69. Movement from major to minor keys, and vice versa, are often modal in traditional music. The characteristics of the construction of the major and minor hyperscale prevent such true modality.

70. Use of the term quintal in this paper implies the use of quartal harmony when such a figure is inverted in a way that a chord appears to be dominated by perfect fourths. 
Written in a rondo-like form - sections are labeled here as $\mathrm{A}^{1}, \mathrm{~B}^{1}, \mathrm{~A}^{2}, \mathrm{~B}^{2}$, and $\mathrm{A}^{3}-$ "Chaconne" is so named for the stable harmony used in the A sections that firmly establish the atmospheric ambience of the hyperscale, with frequent modulation occurring after every one or two iterations of the chord progression. Attempting to mimic the typical I-IV-V pattern from the major scale rather yields $\mathrm{I}-\mathrm{IV}^{+}-\mathrm{V}^{+}$in the major hyperscale, so I chose to reconfigure the chord progression to better match the aural mechanics of the hyperscale by juxtaposing the last two chords, resulting in $\mathrm{I}^{+} \mathrm{V}^{+}-\mathrm{IV}^{7}$. While $\mathrm{IV}^{7}$ sounds rather unusual, the $\mathrm{V}^{+}$, which sounds identical to bIII ${ }^{+}$in first inversion, is more familiar in tertian harmony, so I placed $\mathrm{V}^{+}$in the typical "predominant" position to make the augmented triad more agreeable with the consonant sounds of tertian harmony. At times I changed the spelling of $\mathrm{V}^{+}$to $\mathrm{bIII}^{+}$for the purposes of ease of performance. I added a seventh to the IV chord by adding the third scale degree in the primary octave to create a major-minor seventh chord to help the new $\mathrm{IV}^{7}$, nearly equivalent to $\# \mathrm{ii}^{\circ 6}$ in the hyperscale, fit into the "dominant" position of the progression. Omitting the fifth of the chord (the tonic degree) - a favorite technique of Slonimsky, ${ }^{71}$ as mentioned earlier and used coincidentally in this movement - facilitates use of the chord irrespective of the octave in which the pitch may appear. The resulting three-measure chord progression sounds like the dominant is cut off, running in reverse order to standard tertian harmony when multiple series of progressions are strung together. See Figure 38, below.

71. Nicolas Slonimsky. Thesaurus of Scales and Melodic Patterns. New York: Coleman-Ross, 1947. Accessed July 14, 2017, v. http://hdl.handle.net/2027/uc1.32106007393371. 


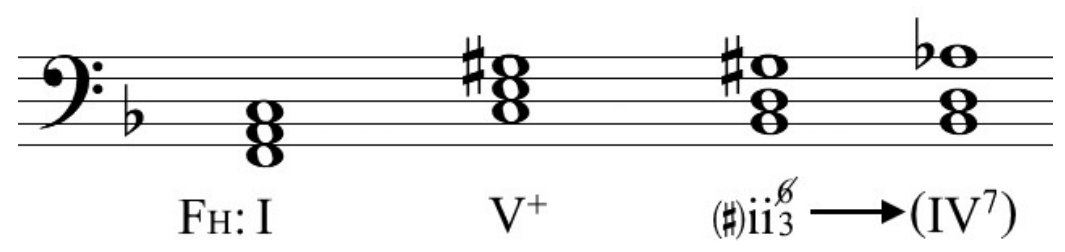

Figure 38. Harmonic progression used in "Chaconne" featuring a triad that sounds as a seventh chord.

In section $\mathrm{A}^{1}$, the key modulates from F Major Hyperscale to CHYP, then EbHYP, and back to FHYP. The I-V-I movement between the tonal centers - F, C, and F again - functions normally within the harmonic context. EbHYP, is inserted into the middle of the cycle at m. 11, demonstrating modulation to bVII using raised scale degrees.

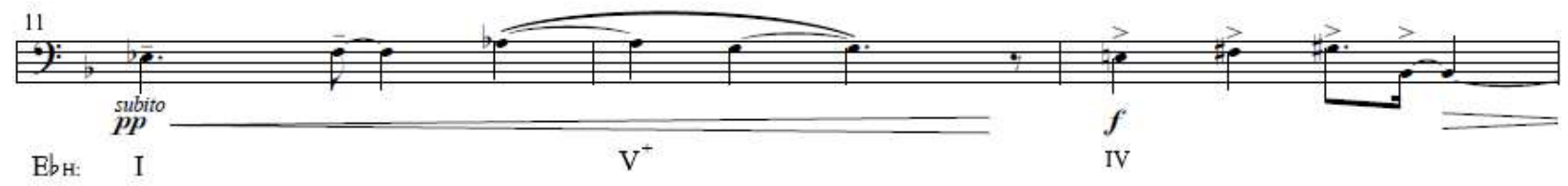

Figure 39. I. "Chaconne," m.11-13, tuba.

Sequence by half step is possible in major (and minor) hyperscale without the use of chromaticism. In measure 11 (see Figure 39, above), the tuba plays pitches $\mathrm{Eb}^{\prime}, \mathrm{F}^{\prime}$, and $\mathrm{A} b^{\prime}$ before settling back down on $\mathrm{G}^{\prime}$; then plays a figure with a pitch collection sequenced up by a half-step, this time of displaced scale degrees eight, nine, and ten - which are one half-step higher ( $\left.E^{\prime \prime}-\mathrm{F} \# "-G \sharp "\right)$ - then jumping back down to the secondary octave in which they belong by moving up a whole step to $\mathrm{B} b^{\prime}$. The first three pitches of the following FHYP key center are sequenced one half-step higher than this still $\left(F^{\prime}-G^{\prime}-A^{\prime}\right)$, as exhibited in the sixteenth-note run of the right hand of the piano while the tuba continues the run from $B b^{\prime}\left(A \#\right.$ ") up through $C^{\prime \prime}, D^{\prime \prime}, E^{\prime \prime}$ and $\mathrm{F}^{\prime}$ in measure 14 (see Figure 40, below). 


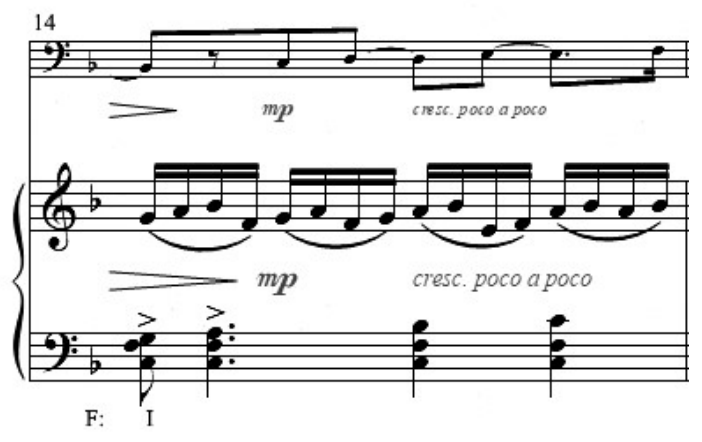

Figure 40. I. “Chaconne," m.14.

Both B sections contain three-measure, three-chord progressions that cycle through various keys in similar manner to each A section, but now within the minor-major scale (in analysis, abbreviated as $\mathrm{mM})$ :

\begin{tabular}{|c|c|c|c|c|c|c|c|}
\hline $9:$ & 0 & bo & 0 & $\mathbf{\theta}$ & (a) 0 & $\$ 0$ & 0 \\
\hline $\mathrm{G}_{\mathrm{mM}}: \hat{1}$ & 2 & 3 & $\hat{4}$ & $\hat{5}$ & $\hat{\sigma}$ & $\hat{7}$ & $\hat{1}$ \\
\hline
\end{tabular}

Figure 41. G Minor-Major scale.

The chord progression present in section $\mathrm{A}^{1}$ is phased by one measure in the $\mathrm{B}$ sections: $\mathrm{IV}^{7}-\mathrm{i}-$ $\mathrm{V}^{7}$. I believe that using more customary pitch set in contrasting sections while employing an unorthodox scale and reversed cycle of functions helps bridge the harmony between the alien hyperscale world and the tertian harmony with which most listeners find familiar.

The key center of section $\mathrm{B}^{1}$ beginning at measure 18 starts in the key of $\mathrm{CmM}-$ which is the dominant of the beginning key of FHYP - on a IV ${ }^{7}$ chord that has $\mathrm{F}$ as its root, fulfilling both typical dominant key center movement (based on the $\mathrm{I}^{-} \mathrm{V}^{+}-\mathrm{IV}^{7}$ cycle of functions in this piece) to a second section and reiteration of the tonic center of $\mathrm{F}$ in the first section. The second half of 
this section moves to $\mathrm{GmM}$, the secondary dominant key center to F that suggests F-C-G quintal harmony; the last measure of $\mathrm{B}^{1}, \mathrm{~m} .29$, is the second overt occurrence of the mysterious quintal harmony in "Chaconne," emphasizing the pitch C.

Both hyperscales ease diatonic resolution possible through half-step movement in two directions at the first retransition to $\mathrm{A}$. The transition to the first key center of section $\mathrm{A}^{2}$ at measure 30, Анур, is the resolution of the sixteenth-note piano run and sustained note in tuba both ending on $\mathrm{C} h$ in the previous measure, resolving downward by half step to a displaced B" in the piano and upward to $C \sharp '$ in the tuba, the latter of which is the third scale degree of the new key, and the former, acting in suspension as the third of the old key, GHYP, which is not possible diatonically in the standard one-octave scale.

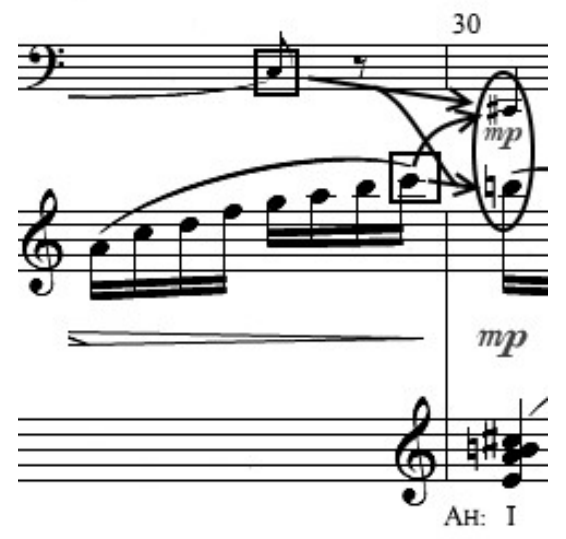

Figure 42. I. “Chaconne,” mm. 29-30, Double resolution from $\mathrm{C}$ ต to C\# and B

Tonic proceeds up by fifth to EHYP in measure 33, which contains one of the new instances of a bIII ${ }^{+}$triad rather than the enharmonic $\mathrm{V}^{+}$, but the diatonic half step does not occur until the following measure. In the next transition - up to AbHYP - at measure 36 , an $\mathrm{A}^{7}$ chord 
with a missing fifth acts as an upper leading tone chord, substituting what would normally be a half-diminished seventh chord leading to $\mathrm{A} b$. The $\mathrm{E}_{6}$ in beat three of the piano precedes the complete $\mathrm{A} b$ major triad in measure 37 with emphasis on another $\mathrm{E} b$ from the tuba.

Section $\mathrm{B}^{2}$ is entirely in the $\mathrm{F}$ Minor-Major scale, following the same $\mathrm{IV}^{7}-\mathrm{i}-\mathrm{V}^{7}$ pattern as before but with a two-measure-ending retransition on a quintal chord. $\mathrm{D} b$ in the left hand of the piano at measure 44 suggests modal borrowing from the natural minor as a continuation of the same figure one step lower than found in the earlier B section in measure 26. The tuba is tacit during this section to give the player a chance to rest, and - save for the mysterious quintal chord in measures 48-49 - the music theory in the piano part is otherwise unremarkable.

The movement in the concluding $\mathrm{A}^{3}$ section finishes by shifting through familiar keys. As is the case for many forms, this "Chaconne" begins the final section where it began the first, in FHYP. In contrast to the middle A section, this section is dedicated to using ascending or descending three-note patterns at each change of keys. Harmonically, three measures of FHYP are succeeded by Gнyр and Ebнyp, which sit a whole step on either side of the principal key. Next, CHYP, the dominant of F returns, but instead of resolving directly to FHYP as before, spends a three-measure cycle in BHYP, a tritone away from the final modulation to F.

Measure 64 illustrates the two types of octave displacement possible in a hyperscale. First, $\mathrm{C}^{\mathbf{x}}$ is respelled as $\mathrm{D}$ in the tuba and placed in the primary octave in order to facilitate the B Minor-Major scale that has been effectively borrowed from the B section. Second, this D also hints at the scalar displacement that follows; the run in the tuba drops one octave between $\mathrm{F} \#$ and $G \#$ so that scale degrees six and seven flow into scale degree one to stay in the primary octave through means of displacement. The minor-major scale ascends one more step to $\mathrm{C}$ দ in direct modulation as the fifth scale degree of F. The ninth degree of the BHYP scale is also 
written for the piano as $\mathrm{D}$, respelled from $\mathrm{C}^{\mathrm{x}}$ " to accommodate the $\mathrm{IV}^{7}$ spelled as $\mathrm{G} \#-\mathrm{D}-\mathrm{E}$

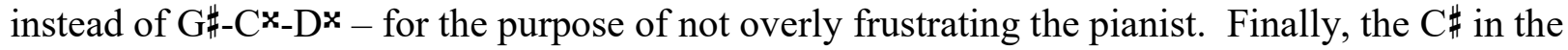
bass of the piano is one whole step higher than the tuba's B - in the same octave - both resolving to the ominously present pitch $\mathrm{C}$ at the fifth instead of the more solidly rooted $\mathrm{F}$.

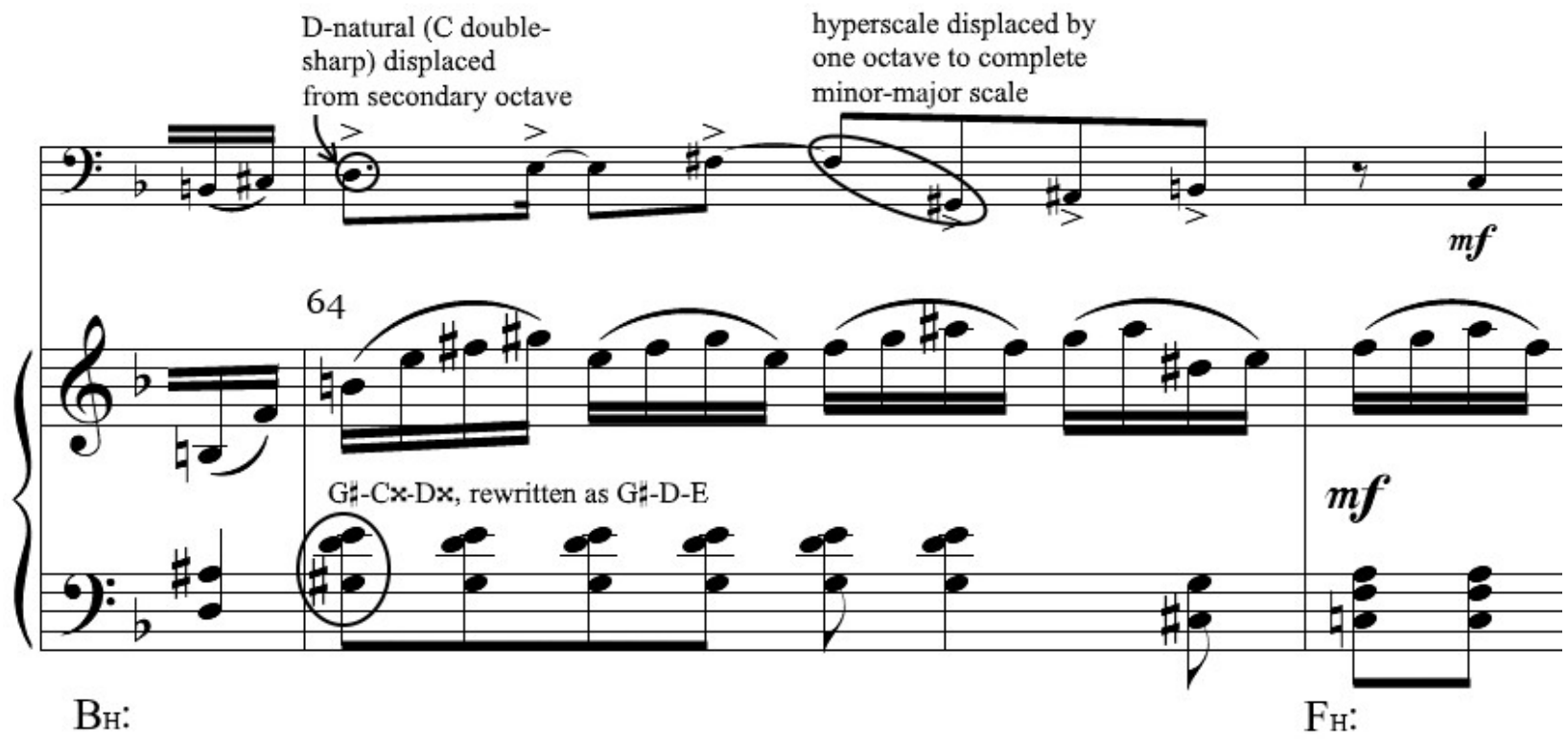

Figure 43. I. Chaconne, mm. 63b-65a.

The last chord in "Chaconne" is different depending on if the first movement is performed by itself or with the second. If alone, the first ending instructs the pianist to play a simple tonic chord in FHYP for closure. If played through to the second movement as prescribed, the last chord remains an augmented dominant on $\mathrm{C}-$ a prominent moment of tension - before making the segue into the next movement.

\section{$\underline{\text { II. Exchange }}$}

The title "Exchange" refers to two different aspects of the movement: the middle piece joins the first movement, primarily in major hyperscale mode, with the ending movement that 
chiefly uses the minor hyperscale; and both forms of the hyperscale are used in roughly equal measure here. The first six pitches in the tuba part were selected by a random roll of dice - the resulting pitch collection rotated to begin with " 0 " so that the tonic pitch in fHYP coincidentally begins the movement. The rest of the melody in the work is developed from this pair of threenote motives in the first two measures.

Within the body of "Exchange," key changes mark each new section, which repeats similar harmonic patterns. I did not create a chaconne in the sense of the first movement where the functional chord progression is essentially the same every certain number of measures; instead, I made the chord quality and length of the progression chain vary with each pass to compare how various chord progressions may sound in each scale:

\begin{tabular}{|c|c|c|c|c|c|c|c|c|c|c|c|}
\hline $\begin{array}{l}\text { Measure } \\
\text { Numbers }\end{array}$ & $\begin{array}{l}\text { Time } \\
\text { Signature }\end{array}$ & $\begin{array}{l}\text { Total } \\
\text { Beats } \\
\end{array}$ & Key & Chord & Progression & & & & & & \\
\hline $6-12$ & $4 / 4$ & 28 & fHYP & $\mathrm{i}$ & bVII|vii ${ }^{\circ}$ & $\mathrm{i}$ & $\mathrm{VI}^{7}$ & III & $\mathrm{V}$ & I & $\mathrm{V}^{7}$ \\
\hline $13-19$ & $4 / 4$ & 28 & AbHYP & I & $\mathrm{vii}^{\circ}$ & I & vi & iii & $\mathrm{V}$ & $\mathrm{I} \mid \mathbb{\#} \mathrm{i}^{\circ}$ & $\mathrm{V}^{7}$ \\
\hline $20-22 a$ & $5 / 4$ & 13 & fHYP & $\mathrm{i}(b \mathrm{I}+)$ & $\begin{array}{l}b \mathrm{VII}^{7} \\
\left(b \mathrm{vii}^{7}\right)\end{array}$ & $\# i^{\circ}$ & & & & & \\
\hline $22 b-23$ & $5 / 4$ & 7 & FHYP & & & & & & & $\mathrm{I} \mid \# \mathrm{H}^{\circ}$ & {$[\mathrm{CH}:$} \\
\hline $24-29$ & $5 / 4$ & 30 & СНYP & & $\left.\mathrm{V}^{7}\left(\mathrm{iii}^{7}\right)\right]$ & I & VI|vi & iii & & $\mathrm{I}^{\mathrm{M} 7} \mid \mathbf{i}^{\circledR 7}$ & $\mathrm{~V}^{+}$ \\
\hline $30-33$ & $6 / 4$ & 24 & fHYP & $\mathrm{i}$ & $\mathrm{VII}^{+} \mid \# \mathrm{vii}^{\circ}$ & $\mathrm{i}$ & $\mathrm{VI}^{7}$ & & & & \\
\hline $34-37$ & $6 / 4$ & 24 & g\#HYP & $\mathrm{i}$ & VII $\left.\right|^{\#}$ Vii $^{\circ}$ & $\mathrm{i}$ & $\mathrm{VI}^{\mathrm{M} 7}$ & & & & \\
\hline $38-45$ & $7 / 4$ & 56 & ВнYе & I & vii $^{\circ 7}$ & $\# i^{\circ}$ & & & & I & \\
\hline
\end{tabular}

Table 7. Chord progressions in the main body of II. "Exchange."

Chords in the above table and in the following analysis that are separated by a vertical line ( | ) contain elements that may be distinguished by the listener as one chord, the other, or both at the 
same time. For instance, the piano in measure 31 strikes the pitches $\mathrm{E} k / \mathrm{Fb}, \mathrm{E} b, \mathrm{G}$, and $\mathrm{B} b$, which represent the pitches of $\mathrm{VII}^{+}$and $\# \mathrm{vii}^{\circ}$ in fHYP. Streetwise exhibits several different qualities of chords available diatonically in the major and minor hyperscales.

An open-fifth chord introduces the body of the movement in a modulation from FHYP to fHYP, making unclear until the third measure of the chain (m. 8 of the movement) what the intended quality of the chord - and, therefore, the scale - should be. The F $b^{\prime \prime}$ in the second measure creates the first duality - listed as bVII|vii ${ }^{\circ}$ in the table, foreshadowing the minor hyperscale mode. The lowered eighth scale degree, $\mathrm{Fb}$, pairs with the seventh degree, $\mathrm{E} b$, to form two roots again for the triad in first inversion; both pitches are diatonic to the minor hyperscale, sounding two possible qualities for chords in tertian harmony without going outside the scale.

Modulation techniques available to the normal scales are generally available to hyperscales also. In an example demonstrating a common characteristic with regular scales, from fHyp to AbHyp, the modulation in measures 12-13 uses a melody walking stepwise down the scale, $\mathrm{G} b-\mathrm{F} b-\mathrm{E} b$, and arriving at the fifth scale degree of AbHYP through a modal pivot chord that underscores an authentic harmonic cadence (see Figure 44, below). The $\mathrm{C}_{2}$ acts as a suspension or pedal tone and is not considered in the analysis of the chord on the third beat of measure 12, which is dissonant enough to take attention away from this previously-struck pitch.

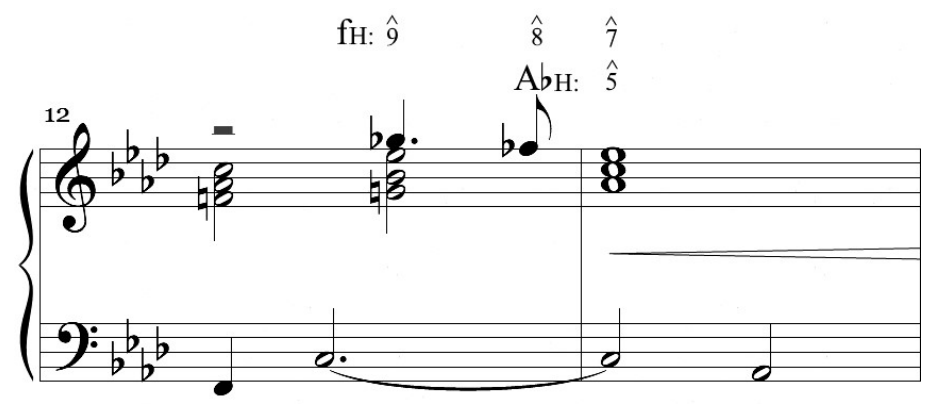

fH:VII|vii

$\mathrm{A} b_{\mathrm{H}}: \mathrm{V} \mid \mathrm{V}$ I

Figure 44. Pivot chord and melodic analysis in Streetwise, II. "Exchange," mm. 12-13. 
Diatonic arrival at two possible chords identified by the same base Roman numeral is achievable by the naturally augmented octave (or diminished octave) created in the secondary octave of the major and minor hyperscale, as seen in measure 19 . With simultaneous I and $\# \mathrm{i}^{\circ}$ triads, the I is more likely to be identified by the listener because $\mathrm{A} \downarrow$ is obscured by the strong $\mathrm{Ab}$ major triad in the first beat and the $\mathrm{Ab}$ in the bass of the second beat, with the $\mathrm{A}{ }^{\natural}$ providing, ironically, diatonic color.

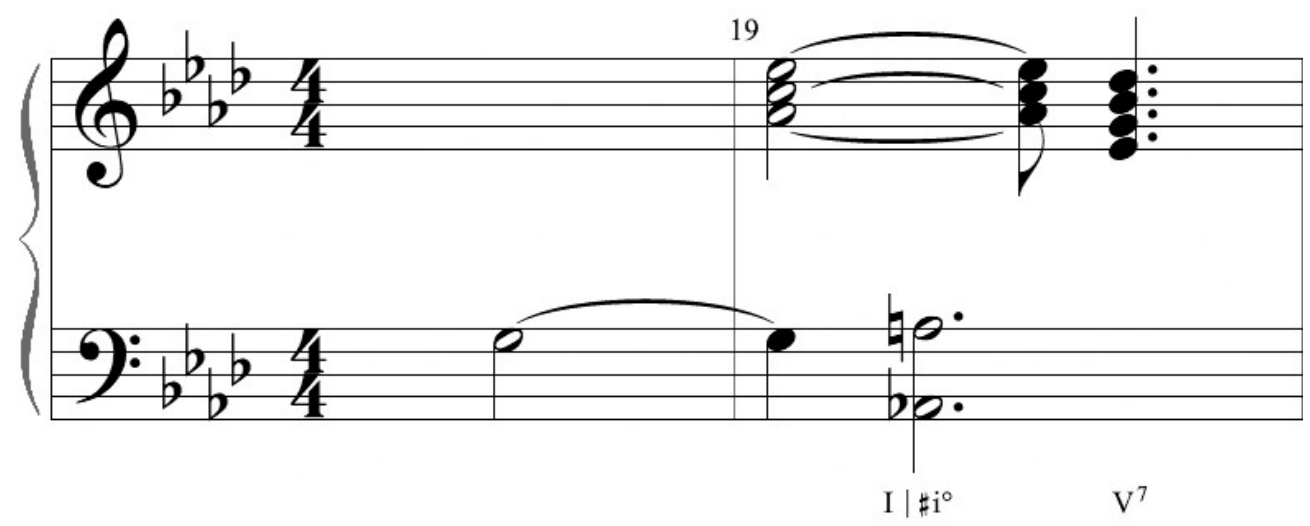

Figure 45. II. Exchange, mm. 18b-19.

The quintal chord appears in the second movement at measure 5, beat 3, centered around the pitch $\mathrm{C}(\mathrm{G}-\mathrm{C}-\mathrm{F})$ as the last chord of the introduction, and shows up another time in the third beat of the third measure (m. 48) of the coda. Though not possible in F Major or F Minor scales, the pitches here, $\mathrm{G} b-\mathrm{D} b-\mathrm{Ab}$, are viable diatonically in the F Minor Hyperscale due to the lowered ninth scale degree $(\mathrm{Gb})$, a property of the scale important to the end of the movement. The appearance of this tritone interval of the quintal chord foreshadows the imminent breakdown of "Exchange." At its next appearance in measure 50, the quintal chord is corrupted by a G\# that creates a tritone rather than a perfect fourth, and in measures 51 and 52, respectively, a quintal chord is stacked with a VI ${ }^{+}$in FHYP and a VI inside fHYP. 
As the coda begins in measure 46, the key alternates every two measures between FHYP and fHYP, and programmatically the tuba is seemingly lost when the piano begins to respond with quintal chords in various iterations. The melody is expanded in the coda from its original sequence in the introduction as the piano finally calls attention to the matter in measure 54 with a quick, emphatic progression through the complete cycle of functions, $\mathrm{I}\left|\# \mathrm{i}^{\circ}-\mathrm{IV}\right| \mathrm{IV}^{+}-\mathrm{V} \mid \mathrm{V}^{+}-\mathrm{a}$ two-octave major hyperscale series of triads in close position that can only attempt to sound like tertian harmony - followed by a calming parallel progression in the minor hyperscale: i $\mid$ bI- iv-v.

Immediately following in measure 57 is the final chord - a "triad" of $\mathrm{C}, \mathrm{Fb}$, and $\mathrm{G}$ - that offers a startling theoretical conclusion within a calm aural repose: the tonic, subdominant, and dominant triads in the cycle of functions behave strangely in a duo of hyperscales that are resolved by a major dominant triad, using a trio of inverted quintal tones altered diatonically by the lowered eighth scale degree to function as the third of the chord. The puzzle presented by the quintal chord centered on $\mathrm{C}$ at the beginning of the first movement - and appearing intermittently since - is now finally solved, and the tuba confirms this with a low $\mathrm{C}$ of its own,

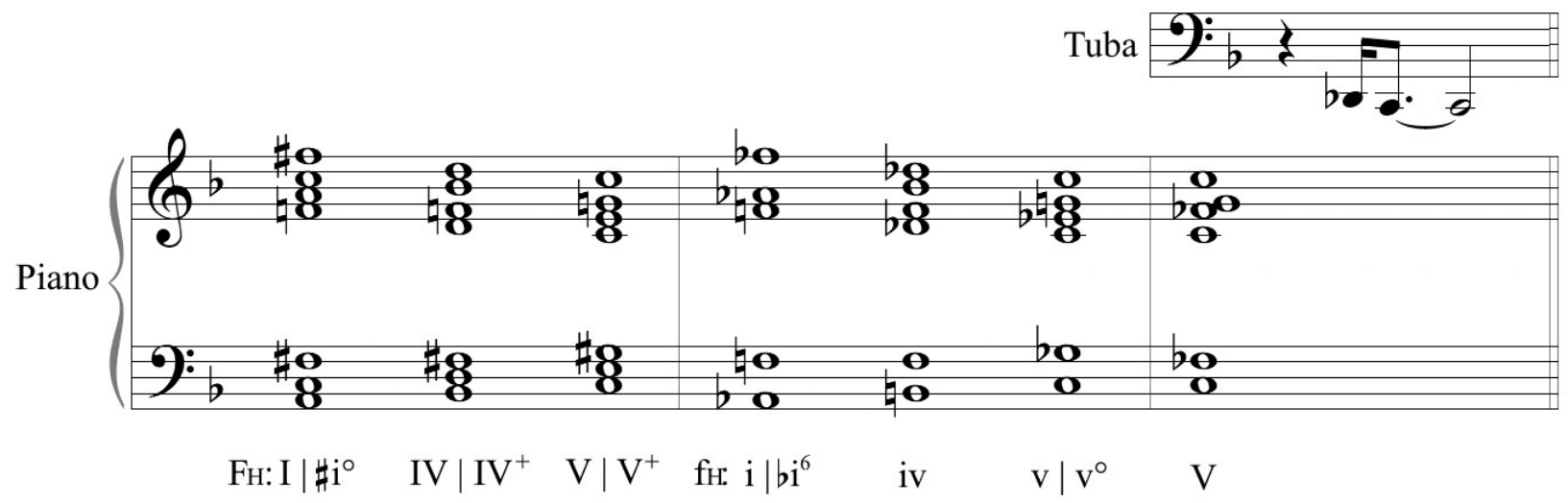

Figure 46. Analysis of the final chords of "Exchange." 
but not before preceding it with a short $\mathrm{D} b-\mathrm{a}$ restrained reminder that the prevailing key is in minor hyperscale so that not all is as it seems.

\section{Downtown}

The last movement of Streetwise, "Downtown," is an energetic piece where I developed three various exploits. First, modalization tonicizes the minor hyperscale in different ways; that is, any given key signature that represents the corresponding minor hyperscale may not necessarily represent the actual tonal center, just as use of a historical church mode in contemporary music may belie what may first appear as a major or minor mode. The movement, with a key signature suggesting F Minor (or F Minor Hyperscale), begins ambiguously with a rhythmic $\mathrm{B} b_{2}$ in the right hand of the piano, which is answered by a lower pattern centered on $\mathrm{E} b$ in the left hand; this interval of a fifth gives the piece a sense of an $\mathrm{Eb}$ tonal center that is shortlived. Measure 5 starts, but does not quite fulfill, a $\mathrm{B} b$ major chord that turns out to be closer to a half-diminished seventh chord, which is closer to dominant with its lowered fifth, $\mathrm{Fb}$. Eb tries to work its way back in at measure 7 , but in the ensuing fight the $\mathrm{B} b$ comes out tentatively victorious in measure 15 as the root-position bass of another dominant seventh, this time leaving out the eighth scale degree of fHYP. While the key signature and corresponding pitch set of the opening thirty-one measures indicate the key of fHYP, by measure 20 the tonal center is unmistakably $\mathrm{B} b$ as the pitch punches its ticket by starting a strong ascending bass line that reasserts itself relentlessly until the next key arrives. Figure 47, below, reveals why the stage is set for the fight to occur in the first place. 


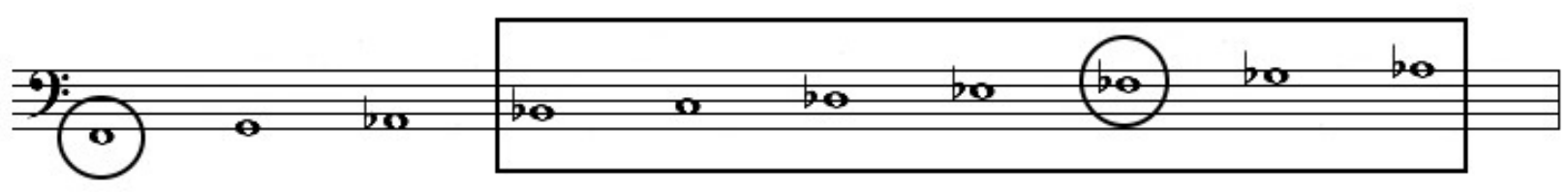

Figure 47. F Minor Hyperscale, with analysis of its relationship to $\mathrm{B} b$ Minor and $\mathrm{E} b$ Minor.

Scale degrees four through ten of the pitch collection of F Minor Hyperscale (indicated by the boxed area in the figure) are a series of notes that share much in common with both $\mathrm{B} b$ Minor and $\mathrm{E} b$ Minor, which in turn both share more in common with F Minor Hyperscale than the vanilla F Minor itself does. While Eb Minor needs six flats, the untouched note, $\mathrm{C}$, is unable to fulfill this possibility; $\mathrm{Cb}$ is missing, which gives $\mathrm{B} b$ Minor the door it needs to claim supremacy: although the $\mathrm{Fb}$ (circled) is also incorrect for $\mathrm{B} b \mathrm{Minor}$, the $\mathrm{C} h$ is in its proper place for $\mathrm{B} b$ Minor, and the $\mathrm{F} h$ (also circled) at the bottom of the scale provides the complete scale by displacement. During the B section, starting at measure 32, the tonal center drops by thirds into minor keys, but instead of settling on the tonic indicated by the key signature, each key centers into a different mode just as the A section does. The key signature of one flat is actually A Phrygian, five flats is A Mixolydian, three sharps is E Mixolydian, and no sharps or flats is E Phrygian. As "Downtown" makes the retransition back into the $\mathrm{A}^{\prime}$ section at measure 48, the return to four flats as the line in the piano winds its way from $\mathrm{F}$ to $\mathrm{A} b$ does not make easily clear whether this is a return to the original F Minor Hyperscale or the presence of a key center of $\mathrm{Ab}$.

Sometimes I get the impression that composers of today tend to use the tritone modulation just for the sake of using the tritone, so I make a conscious effort to reduce the number of times I use this overexploited cliché. However, the major and minor hyperscales in this work contain extra tritone intervals (see Figure 48, below). In development of the piece I 
considered exploitation to be inevitable, and even necessary. As a result, tritone modulation is the second idea I worked with in "Downtown" with the idea as a disruption to the tonal center. The key area of B appears regularly in this work with F as its home key. The major hyperscale has four natural tritone intervals, one augmented fourth each beginning on scale degrees four through seven; though aurally identical, the 4-7 and 7-10 tritones are theoretically discrete. In addition to the tritone interval between the second and sixth scale degrees, the minor hyperscale also has one between the fifth and eighth degrees, highlighted in the two-sharp section that begins at measure 52 in "Downtown." The key signature plus the eighth, ninth, and tenth scale degrees indicate bHy, and the tonal center is on E. In measures 53-54 two tritones are established in the piano - a diatonic run from $\mathrm{C}_{5}$ to $\mathrm{G}_{5}$ and a harmonic pair of $\mathrm{E}_{5}$ and $\mathrm{B} \mathrm{b}_{5}$ - both of which occur in every other measure.
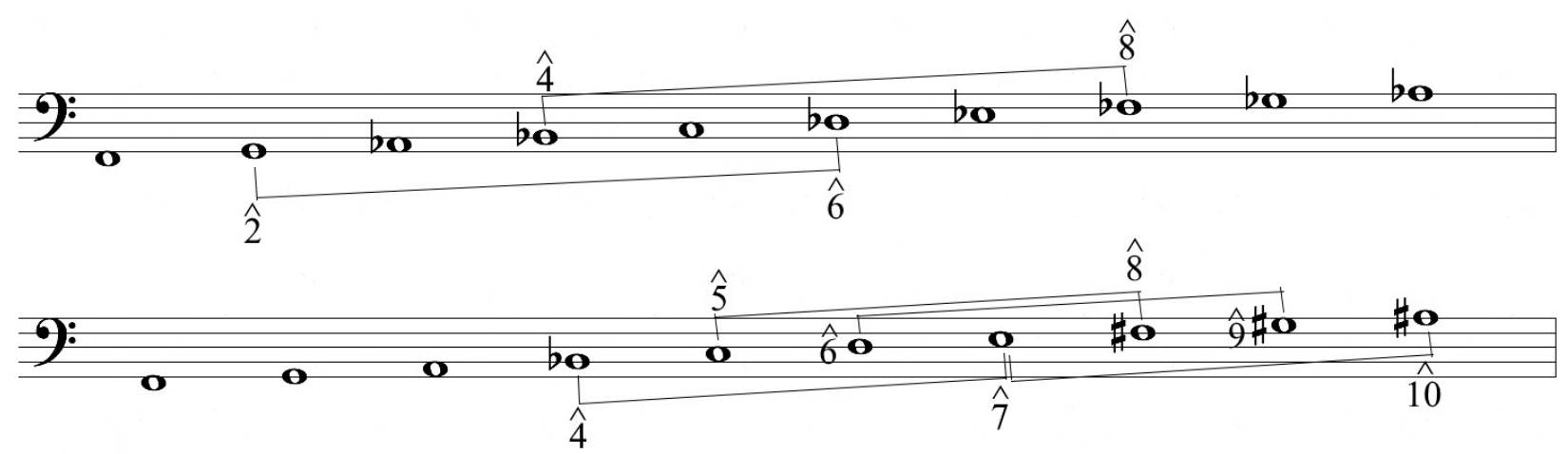

Figure 48. Location of tritones in the minor and major hyperscales, using the key of $\mathrm{F}$ as an example.

At this point, the tuba melody has an argument with itself, drawing attention to this unusual 4-8 tritone in the B Minor Hyperscale. In tandem with the previously noted tritone pair of E-Bb established in measures 54 and following of the piano part, the tuba also recognizes the 
$\mathrm{E}-\mathrm{Bb}$ pair as a tritone interval in the melody at measures 54-55. However, the tuba then returns to a displaced $\mathrm{B} \sharp$ in measure 56 , as if to remind everyone that the key signature actually indicates $\mathrm{B} h$ as the tonal center. The $\mathrm{B} b$ returns in measure 57 with a growling figure only to be returned by a growling $\mathrm{B} \sharp$ in measure 59 . All the while the piano is repeating the same pattern, which contains the $\mathrm{E}-\mathrm{B} b$ tritone stack. The $\mathrm{B} \sharp$ cannot seem to win.

The final area I wanted to explore was to see how much chaos I could produce while keeping the piece intact musically and true to the previously established mood. At the start of the cadenza in measure 66, two hyperscales engage in a battle for supremacy: the reigning B Minor Hyperscale in mode E, and the ever-present F Minor Hyperscale. More of the cadenza is in fHYP than bнYр, but in the end a trilled and fluttered F\# announces the result of the scuffle: no key is actually central anymore as chaos now leads the way through to the end. The right hand of the pianist plays in aHYP while the left plays in енур before switching to bHYP for the last two measures. Two notes in fHYP punctuate two notes in measure 71 before a return to aHYP, followed by the tuba expressing stepwise motion in ebHYP at measure 72 , then matching the piano left hand at measure 73 in the parallel key of BHYP.

In a nod to the quintal figure of the first two movements - and especially the ending of the second movement - octave displacement of the chord in the right hand of the piano at the final measure provides a quartal figure that doesn't quite match, using a $\mathrm{B} b$ to shade the chord with a tritone interval recalling measure 50 of "Exchange." This displaced pitch marches up the scale as if to try to find the right interval but cannot, as the $\mathrm{Cb}$ that should be adjacent is not displaced itself but is the proper $\mathrm{C}$ घ instead. While the piece itself ends with a passage that is the culmination of energy built up throughout the movement, theoretically the result is disorganized. Had the $\mathrm{B} \sharp$ been present in the last measure instead of the displaced $\mathrm{B} b$, et al., an $\mathrm{F} \#-\mathrm{B}-\mathrm{E}-\mathrm{A}$ 
quintal chord would have finished the work. Instead, the prevailing B $b$ punctuates that "Downtown" is antithetical to the order of "Chaconne" and "Exchange."

\section{Comparison with 6-8-2-4-5-8}

The main reason I chose to examine $6-8-2-4-5-8$ for this paper is for the number of contrasting ways that Hoffman developed and exposited his hyperscale in contrast to the way I cultivated mine in Streetwise. A composer who wishes to create a unique hyperscale has several options available for how to approach its implementation and should not be limited to either the properties with comment in this paper or the binary choices that are presented below.

Hoffman chose to let the hypertonic of his scale become the tonic of the next hyperscale above; i.e., the lowest instance of the scale begins on $\mathrm{B} b_{0}$ and ends on $\mathrm{C}_{1}$, and the next instance begins on $\mathrm{C}_{1}$ and ends on $\mathrm{D}_{2}$, and the next begins on $\mathrm{D}_{2}$, etc. In Streetwise, each instance of the scale begins on the same pitch two octaves apart, and I chose to fill this gap with extrascalar pitches from the hyperscale that are one perfect octave away from those that are inside the scale. (See Figure 7 on page 15.)

Hoffman and I also use different approaches toward the harmony in our works. In contrast to Streetwise, 6-8-2-4-5-8 does not modulate nor does it have the need to do so.

Hoffman establishes his hyperscale more by the distinction of the intervallic pattern and lack of extrascalar pitches, also choosing to focus on intervals with a multiple of a perfect fifth, with particular emphasis on the major ninth. Other intervals related to the perfect fifth - an octave plus a fifth, two octaves plus a fifth, major thirteenth (three times the perfect fifth) - also lie in cleverly noticeable points of tension and resolution in the piece. Streetwise, on the other hand, 
has attention given to the harmonic function by emphasizing the unusual cycle of functions in the opening double chaconne and modulating to related keys.

In order to establish both the major and minor hyperscales in Streetwise, I chose to avoid chromatic pitches. ${ }^{72}$ Hoffman took a few more liberties by inserting occasional pitches from outside of his scale using various textures. The $E b_{4}$ begins the puzzle in measure 6 . At first, this pitch does not sound incorrect since the hyperscale has not been established aurally yet at this point in the piece. I chose to introduce the diatonic $A b / \mathrm{G}_{3}$ at the beginning, but it sounds incorrect; Hoffman's chromatic Eb sounds correct, but eventually is proven not to be. He reconciles it at the end with the $\mathrm{E} b_{3}$, which is in the scale, sitting out of place amongst various intervals related to the perfect fifth.

Hoffman expands the usual heptatonic scale to a major ninth by bookending two intervals of a major third around the string of half steps. I do not use intervals greater than a major second, appending extra pitches to the major and minor scales to form nonatonic scales with ranges of an augmented tenth and minor tenth. The $\mathrm{F}_{5} 5$ in the Hoffman example of Figure 49, below, is not considered in the count because it starts the next series of the scale. The $\mathrm{G}$ and $\mathrm{G}^{\mathbf{x}}$ of the Minor and Major Hyperscale examples below also are not a part of the count because each pitch is repeated one perfect octave lower.

72. While I meant for every pitch in Streetwise to be represented by the prevailing scale and tonal center, it is possible that I made a small number of mistakes. Although I tried to keep the score free of error, ultimately, I allowed myself to not be distraught (e.g., perfectionistic) if I later found any pitches that were incorrect to the hyperscale, instead allowing the music to just be the music. Any pitches that unintentionally do not conform to the scales - even through displacement - do not affect the inherent harmonic function of that moment in the piece. 


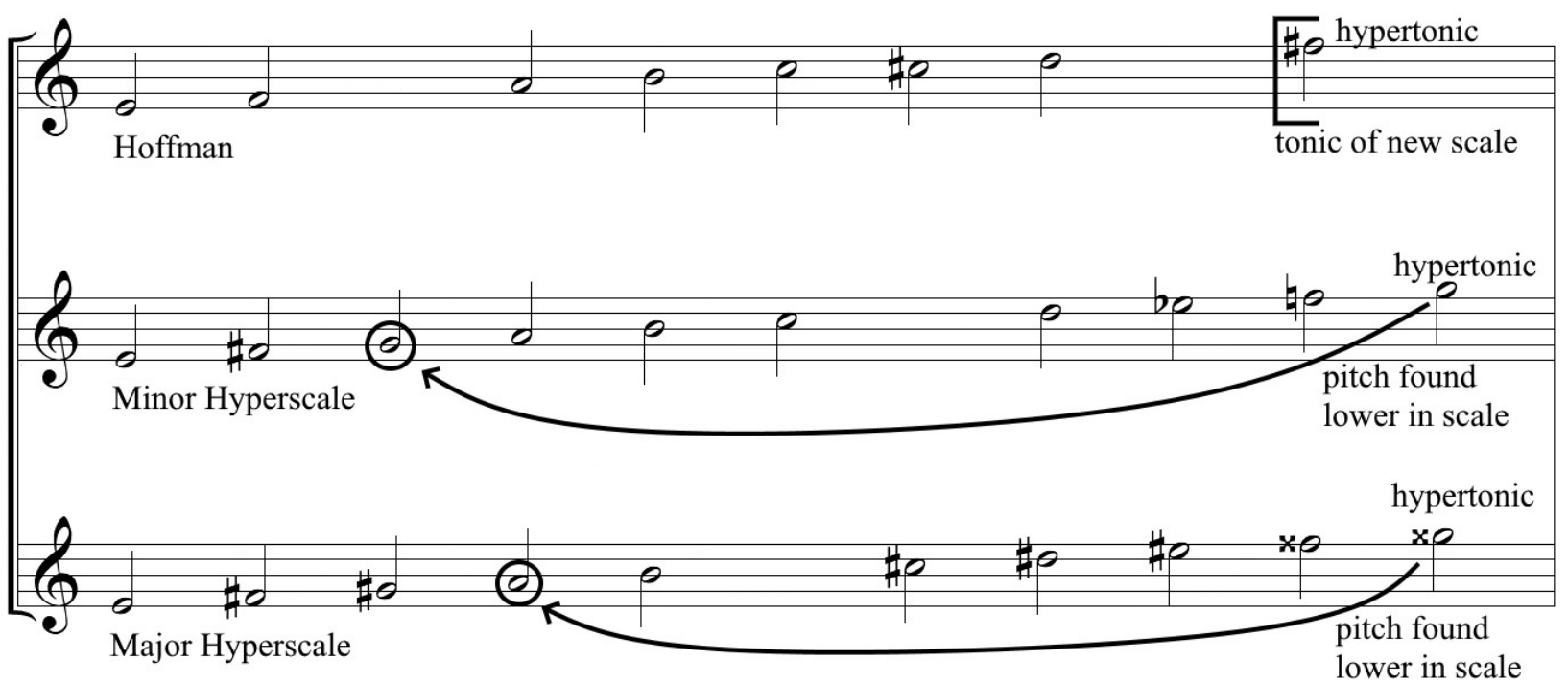

Figure 49. Comparison of pitches in Hoffman Concerto Hyperscale with Major and Minor Hyperscales.

\section{Chapter 5. Final Thoughts: Observations about the Future Development of the Hyperscale}

\section{Challenges of Harmony within the Cycle of Functions}

Although the traditional cycle of functions is largely avoided by many contemporary composers in art music, the tonic-predominant-dominant progression is still arguably the basis of tertian harmony. Both the presence and absence of the cycle are noticeable to the listener on at least a semi-conscious level and, therefore, important to consider within the context of music with tertian harmony that uses a new scale that disrupts the norm.

While a large number of observations about the major and minor hyperscales can be explored, the cycle of functions is such a foundational property of the traditional musical process in composition, performance, and concert listening, that I needed several years of reasoning through how to treat altered diatonicity in a hyperscale until I could mentally fathom how to accomplish the expansion of the scale. The result was that I chose to establish the inherent 
harmony of the two new scales without use of chromaticism as harmonic embellishment in order to establish the diatonicity of the new scales.

After creating tables of all possible triads in all octaves and inversions of the major and minor hyperscales (see Tables 3 and 4, earlier), I found the basis for how I would write the first movement by charting some possible basic progressions formed within the usual cycle of functions (see Tables 8 and 9, following). Also I found that the triads of these hyperscales result in making the ordinary - I-IV-V-I and i-iv-V-i in major and minor, respectively - next to impossible, and the extraordinary, abundant. While composers now hardly limit themselves to a tonic-predominant-dominant-tonic chain of chords, this is still the foundation for tertian harmony provided by the usual major and minor scales. Between new triadic possibilities and deciding how to handle the inherent puzzles that appear, such as how to use octave displacement, the hyperscale opens new possibilities for a remarkable array of pitches.

The analysis of the final measures of "Exchange," solving this puzzle, exposes to the composer the challenge of the cycle of functions used in the hyperscalar context; the common tonic-predominant-dominant-tonic progression in the major and minor hyperscales yields results that may be unintended or not useful, and may often produce chords that are disagreeable with the desired harmony. It is up to the composer to decide whether to accept the result of a given hyperscale as-is or manipulate the harmony as necessary.

\section{$\underline{\text { Unreliable Sources }}$}

Composers wishing to use existing scales should understand the possible challenges associated with sources that may be inaccurate. For instance, while Farhat reports the dastgāh-e 
Table 8. Minor Hyperscale Cycles of Function

\begin{tabular}{|c|c|c|c|c|c|}
\hline Tonic & Pred & ominant & Dor & minant & \\
\hline $\mathrm{i}$ & iv & $\mathrm{ii}^{\circ}$ & $\mathrm{V}$ & Vii & \\
\hline $\mathrm{i}^{7}$ & iv ${ }^{67}$ & $\mathrm{~N}$ & $\mathrm{v}^{\circ}$ & bvii ${ }^{7}$ & \\
\hline & $\mathrm{iv}^{\circ}$ & $\mathrm{ii}^{\varnothing 7}$ & $\mathrm{v}^{7}$ & bVII & \\
\hline & $\mathrm{iv}^{7}$ & $\mathrm{~N}^{7}$ & $\mathrm{v}^{87}$ & $b \mathrm{VII}^{7}$ & \\
\hline i-iv-v & & $\mathrm{i}-\mathrm{ii}^{\circ}-\mathrm{v}$ & & $i^{7}-i v-v$ & $\mathrm{i}^{7}-\mathrm{ii}^{\circ}-\mathrm{v}$ \\
\hline$i-i v-v^{\circ}$ & & $\mathrm{i}-\mathrm{ii}^{\circ}-\mathrm{v}^{\circ}$ & & $i^{7}-i v-v^{\circ}$ & $\mathrm{i}^{7}-\mathrm{ii}^{\circ}-\mathrm{v}^{\circ}$ \\
\hline$i-i v-v^{7}$ & & $\mathrm{i}-\mathrm{ii}^{\circ}-\mathrm{v}^{7}$ & & $i^{7}-i v-v^{7}$ & $i^{7}-i i^{\circ}-v^{7}$ \\
\hline i-iv-vø7 & & $\mathrm{i}-\mathrm{ii}^{\circ}-\mathrm{v}^{ø 7}$ & & $i^{7}-i v-v \varnothing^{7}$ & $i^{7}-i^{\circ}-v^{87}$ \\
\hline i-iv-bvii & & i-ii ${ }^{\circ}-b v i i$ & & $i^{7}-i v-b v i i$ & $\mathrm{i}^{7}-\mathrm{ii}^{\circ}-b v i i$ \\
\hline i-iv-bvii $^{7}$ & & $\mathrm{i}_{-1 i^{\circ}-b v i i^{7}}$ & & $\mathrm{i}^{7}$-iv-bvii ${ }^{7}$ & $\mathrm{i}^{7}-\mathrm{ii}^{\circ}-b v i i^{7}$ \\
\hline i-iv-bVII & & $\mathrm{i}-i^{\circ}{ }^{\circ}-b V I I$ & & $i^{7}-i v-b$ VII & $\mathrm{i}^{7}-\mathrm{ii}^{\circ}-\mathrm{bVII}$ \\
\hline i-iv-bVII 7 & & i-ii ${ }^{\circ}-b \mathrm{VII}^{7}$ & & $i^{7}-i v-b V I I{ }^{7}$ & $\mathrm{i}^{7}-\mathrm{ii}^{\circ}-\mathrm{bVII}{ }^{7}$ \\
\hline$i-i v^{ø 7}-v$ & & $\mathrm{i}-\mathrm{N}-\mathrm{v}$ & & $i^{7}-i v^{67}-v$ & $\mathrm{i}^{7}-\mathrm{N}-\mathrm{V}$ \\
\hline$i-i v^{ø 7}-v^{\circ}$ & & $\mathrm{i}-\mathrm{N}-\mathrm{v}^{\circ}$ & & $i^{7}-i v^{ø 7}-v^{\circ}$ & $\mathrm{i}^{7}-\mathrm{N}-\mathrm{v}^{\circ}$ \\
\hline$i-i v^{ø 7}-v^{7}$ & & $\mathrm{i}-\mathrm{N}-\mathrm{v}^{7}$ & & $i^{7}-i v^{\otimes 7}-v^{7}$ & $\mathrm{i}^{7}-\mathrm{N}-\mathrm{v}^{7}$ \\
\hline$i-i v^{ø 7}-v^{ø 7}$ & & $\mathrm{i}-\mathrm{N}-\mathrm{v}^{67}$ & & $i^{7}-i v^{ø 7}-v^{67}$ & $\mathrm{i}^{7}-\mathrm{N}-\mathrm{v}^{ø 7}$ \\
\hline i-iv $v^{ø 7}-b v i i$ & & i-N-bvii & & $i^{7}-i v^{ø 7}-b v i i$ & $\mathrm{i}^{7}$-N-bvii \\
\hline i-iv ${ }^{87}-b v i i^{7}$ & & i-N-bvii ${ }^{7}$ & & $i^{7}-\mathrm{iv}^{67}-b v \mathrm{iii}^{7}$ & $\mathrm{i}^{7}-\mathrm{N}-b \mathrm{vii}{ }^{7}$ \\
\hline i-iv & & i-N-bVII & & $\mathrm{i}^{7}-\mathrm{iv} \mathbf{0}^{ø 7}-\mathrm{VII}$ & $\mathrm{i}^{7}-\mathrm{N}-\mathrm{b}$ VII \\
\hline i-iv ${ }^{87}-b \mathrm{VII}^{7}$ & & $\mathrm{i}-\mathrm{N}-\mathrm{b} \mathrm{VII}^{7}$ & & $i^{7}-i v^{87}-b \mathrm{VII}^{7}$ & $\mathrm{i}^{7}-\mathrm{N}-b \mathrm{VII}{ }^{7}$ \\
\hline$i-i v^{\circ}-v$ & & $\mathrm{i}-\mathrm{ii}^{87}-\mathrm{v}$ & & $i^{7}-i v^{0}-v$ & $i^{7}-i i^{87}-v$ \\
\hline $\mathrm{i}-\mathrm{iv} \mathrm{v}^{\circ}-\mathrm{v}^{\circ}$ & & $\mathrm{i}-\mathrm{ii}^{\varnothing 7}-\mathrm{v}^{\circ}$ & & $i^{7}-i v^{\circ}-v^{\circ}$ & $\mathrm{i}^{7}-\mathrm{ii}^{\varnothing 7}-\mathrm{v}^{\circ}$ \\
\hline$i-i v^{0}-v^{7}$ & & $i-i i^{87}-v^{7}$ & & $i^{7}-i v^{0}-v^{7}$ & $\mathrm{i}^{7}-\mathrm{ii}^{\varnothing 7}-\mathrm{v}^{7}$ \\
\hline$i-i v^{\circ}-v^{ø 7}$ & & $\mathrm{i}-\mathrm{ii}^{87}-\mathrm{v}^{87}$ & & $i^{7}-i v^{0}-v^{87}$ & $i^{7}-i i^{67}-v^{67}$ \\
\hline $\mathrm{i}-\mathrm{iv} \mathbf{0}^{\circ}-b v i i$ & & $\mathrm{i}-\mathrm{ii}^{87}-\mathrm{bvii}$ & & $\mathrm{i}^{7}-\mathrm{iv} \mathrm{v}^{\circ}-\mathrm{bvii}$ & $\mathrm{i}^{7}-\mathrm{ii}^{87}-\mathrm{bvii}$ \\
\hline i-iv ${ }^{\circ}-b v i i^{7}$ & & $\mathrm{i}^{-\mathrm{ii}^{ø 7}-\mathrm{bvii}}{ }^{7}$ & & $i^{7}-i v^{\circ}-b v i i^{7}$ & $\mathrm{i}^{7}-\mathrm{ii}^{67}-b \mathrm{vii}{ }^{7}$ \\
\hline i-iv $-b V I I$ & & i-iii ${ }^{\varnothing 7}-b V I I$ & & $i^{7}-i v^{\circ}-b$ VII & $i^{7}-i^{ø 7}-b V I I$ \\
\hline i-iv ${ }^{\circ}-b V I I^{7}$ & & $\mathrm{i}-\mathrm{ii}^{87}-\mathrm{bVII}{ }^{7}$ & & $i^{7}-i v^{0}-b V I^{7}$ & $\mathrm{i}^{7}-\mathrm{ii}^{\varnothing 7}-b \mathrm{VII}{ }^{7}$ \\
\hline$i-i v^{7}-v$ & & $i-N^{7}-v$ & & $i^{7}-i v^{7}-v$ & $i^{7}-N^{7}-v$ \\
\hline$i-i v^{7}-v^{\circ}$ & & $i-N^{7}-v^{\circ}$ & & $i^{7}-i v^{7}-v^{\circ}$ & $i^{7}-N^{7}-V^{\circ}$ \\
\hline$i-i v^{7}-v^{7}$ & & $\mathrm{i}-\mathrm{N}^{7}-\mathrm{v}+$ & & $i^{7}-i v^{7}-v^{7}$ & $i^{7}-N^{7}-v^{7}$ \\
\hline$i-i v^{7}-v \varnothing^{7}$ & & $\mathrm{i}-\mathrm{N}^{7}-\mathrm{v}^{ø 7}$ & & $i^{7}-i v^{7}-v^{67}$ & $\mathrm{i}^{7}-\mathrm{N}^{7}-\mathrm{v}^{87}$ \\
\hline i-iv ${ }^{7}-b v i i$ & & $\mathrm{i}-\mathrm{N}^{7}-\mathrm{b}$ vii & & $i^{7}-i v^{7}-b v i i$ & $\mathrm{i}^{7}-\mathrm{N}^{7}-b \mathrm{vii}$ \\
\hline i-iv ${ }^{7}-b v i i^{7}$ & & $\mathrm{i}-\mathrm{N}^{7}-\mathrm{bvii}{ }^{7}$ & & $i^{7}-i v^{7}-b v i i^{7}$ & $\mathrm{i}^{7}-\mathrm{N}^{7}-b \mathrm{vii}{ }^{7}$ \\
\hline i-iv ${ }^{7}-b$ VII & & $\mathrm{i}-\mathrm{N}^{7}-b \mathrm{VII}$ & & $i^{7}-i v^{7}-b$ VII & $i^{7}-N^{7}-b V I I$ \\
\hline i-iv ${ }^{7}-b \mathrm{VII}^{7}$ & & $\mathrm{i}-\mathrm{N}^{7}-\mathrm{bVII}{ }^{7}$ & & $i^{7}-i v^{7}-b V I I^{7}$ & $\mathrm{i}^{7}-\mathrm{N}^{7}-\mathrm{bVII}{ }^{7}$ \\
\hline
\end{tabular}


Table 9. Major Hyperscale Cycles of Function

\begin{tabular}{|c|c|c|}
\hline Tonic & Predominant & Dominant \\
\hline 1 & IV $^{7}$ ii & $\begin{array}{ll}\mathrm{V} & \mathrm{V}^{+}\end{array}$ \\
\hline $\mathrm{I}^{\mathrm{M} 7}$ & $\mathrm{iv}^{07} \quad \# \mathrm{i}^{06}$ & $\mathrm{vii}^{\circ}$ \\
\hline Qn & $\mathrm{IV}^{+} \quad \# \mathrm{i}^{865}$ & $\mathrm{v}^{87} \quad \mathrm{vii}^{07}$ \\
\hline
\end{tabular}

\begin{tabular}{|c|c|c|c|}
\hline $\mathrm{I}-\mathrm{IV}^{7}-\mathrm{V}$ & $\mathrm{I}-\# \mathrm{i}^{06}-\mathrm{V}^{+}$ & $\mathrm{I}^{\mathrm{M} 7}-\mathrm{ii}-\mathrm{V}$ & Qn-ivive $-V^{+}$ \\
\hline I-IV ${ }^{7}-V^{7}$ & $\mathrm{I}-\# i^{\circ 6}-\mathrm{vii}^{\circ}$ & $\mathrm{I}^{\mathrm{M} 7}-\mathrm{ii}-\mathrm{V}^{7}$ & Qn-iv ${ }^{87}$-vii ${ }^{\circ}$ \\
\hline I-IV ${ }^{7}-\mathrm{V}^{ø 7}$ & $\mathrm{I}-\# \mathrm{i}^{\circ 6}-\mathrm{vii}^{\circ 7}$ & $\mathrm{I}^{\mathrm{M} 7}-\mathrm{ii}-\mathrm{V}^{ø 7}$ & Qn-iv ${ }^{87}-$ vii $^{07}$ \\
\hline $\mathrm{I}-\mathrm{IV}^{7}-\mathrm{V}^{+}$ & $\mathrm{I}-\# 1^{1065}-\mathrm{V}$ & $\mathrm{I}^{\mathrm{M} 7}-\mathrm{ii}-\mathrm{V}^{+}$ & Qn-IV ${ }^{+}-\mathrm{V}$ \\
\hline I-IV ${ }^{7}$-vii ${ }^{\circ}$ & $\mathrm{I}-\# \mathrm{i}^{665}-\mathrm{V}^{7}$ & $\mathrm{I}^{\mathrm{M} 7}$-ii-vii ${ }^{\mathrm{O}}$ & Qn-IV $-V^{+}$ \\
\hline I-IV $^{7}-$ vii $^{07}$ & I- $\# i^{965}-\mathrm{v}^{07}$ & $\mathrm{I}^{\mathrm{M} 7}$-ii-viii ${ }^{07}$ & Qn-IV ${ }^{+}-v^{67}$ \\
\hline $\mathrm{I}-\mathrm{i} \mathrm{v}^{87}-\mathrm{V}$ & $\mathrm{I}-\# \mathrm{i}^{665}-\mathrm{V}^{+}$ & $\mathrm{I}^{\mathrm{M} 7}-\# \mathrm{i}^{06}-\mathrm{V}$ & $\mathrm{Qn}-\mathrm{IV}^{+}-\mathrm{V}^{+}$ \\
\hline $\mathrm{I}-\mathrm{i} \mathrm{v}^{07}-\mathrm{V}^{7}$ & $\mathrm{I}-\# \mathrm{i}^{665}-\mathrm{vii}^{\circ}$ & $\mathrm{I}^{\mathrm{M} 7}-\mathrm{Hi}^{\circ 06}-\mathrm{V}^{7}$ & Qn-IV'-vii ${ }^{\circ}$ \\
\hline I-iv $v^{87}-v^{07}$ & I- $-\# i^{065}-$ vii $^{07}$ & $I^{\mathrm{M} 7}-\mathrm{Hi}^{06}-\mathrm{v}^{07}$ & Qn-IV+ - vii $^{+7}$ \\
\hline $\mathrm{I}-\mathrm{i} \mathrm{v}^{ø 7}-\mathrm{V}^{+}$ & $\mathrm{I}^{\mathrm{M} 7}-\mathrm{IV}^{7}-\mathrm{V}$ & $\mathrm{I}^{\mathrm{M} 7}-\# \mathrm{H}^{\circ 6}-\mathrm{V}^{+}$ & Qn-ii-V \\
\hline I-iv ${ }^{ø 7}-$ vii $^{\circ}$ & $\mathrm{I}^{\mathrm{M} 7}-\mathrm{IV}^{7}-\mathrm{V}^{7}$ & $\mathrm{I}^{\mathrm{M} 7}-\#^{\circ}{ }^{6}{ }_{-} \mathrm{vii}^{\circ}$ & Qn-ii-V ${ }^{7}$ \\
\hline $\mathrm{I}-i v^{87}-\mathrm{vii}^{07}$ & $\mathrm{I}^{\mathrm{M} 7}-\mathrm{IV}^{7}-\mathrm{v}^{87}$ & $\mathrm{I}^{\mathrm{M} 7}-\# \mathrm{i}^{06}-\mathrm{vii}^{\mathrm{O} 7}$ & Qn-ii-v ${ }^{87}$ \\
\hline $\mathrm{I}-\mathrm{IV}^{+}-\mathrm{V}$ & $\mathrm{I}^{\mathrm{M} 7}-\mathrm{IV}^{7}-\mathrm{V}^{+}$ & $\mathrm{I}^{\mathrm{M} 7}-\# \mathrm{i}^{ø 65}-\mathrm{V}$ & Qn-ii-V ${ }^{+}$ \\
\hline $\mathrm{I}-\mathrm{IV}^{+}-\mathrm{V}^{7}$ & $\mathrm{I}^{\mathrm{M} 7}-\mathrm{IV}^{7}-\mathrm{vii}^{\circ}$ & $\mathrm{I}^{\mathrm{M} 7}-\# \mathrm{H}^{1065}-\mathrm{V}^{7}$ & Qn-ii-vii ${ }^{\circ}$ \\
\hline $\mathrm{I}-\mathrm{IV}^{+}-\mathrm{V}^{67}$ & $\mathrm{I}^{\mathrm{M} 7}-\mathrm{IV}^{7}-$ vii $^{07}$ & $\mathrm{I}^{\mathrm{M} 7}-\# \mathrm{i}^{865}-\mathrm{v}^{07}$ & Qn-ii-vii ${ }^{\circ 7}$ \\
\hline $\mathrm{I}-\mathrm{IV}^{+}-\mathrm{V}^{+}$ & $\mathrm{I}^{\mathrm{M} 7}-\mathrm{iv}^{87}-\mathrm{V}$ & $\mathrm{I}^{\mathrm{M} 7}-\mathrm{Hi}^{\mathrm{i} 65}-\mathrm{V}^{+}$ & Qn- $\# i^{\circ 6}-V$ \\
\hline $\mathrm{I}-\mathrm{IV}^{+}-\mathrm{vii}{ }^{\circ}$ & $\mathrm{I}^{\mathrm{M} 7}-\mathrm{iv}^{87}-\mathrm{V}^{7}$ & $\mathrm{I}^{\mathrm{M} 7}-\mathrm{Hi}^{{ }^{665}}$-vii ${ }^{\circ}$ & $\mathrm{Qn}-\# \mathrm{i}^{\circ}{ }^{6}-\mathrm{V}^{7}$ \\
\hline $\mathrm{I}^{-\mathrm{IV}^{+}}$-vii ${ }^{\circ 7}$ & $\mathrm{I}^{\mathrm{M} 7}-\mathrm{iv}^{\otimes 7}-\mathrm{v}^{87}$ & $\mathrm{I}^{\mathrm{M} 7}-\#^{1865}-\mathrm{vii}^{\circ{ }^{\circ}}$ & Qn- $\# i^{06}-v^{87}$ \\
\hline I-ii-V & $\mathrm{I}^{\mathrm{M} 7}-\mathrm{iv}^{87}-\mathrm{V}^{+}$ & Qn-IV $-\mathrm{V}$ & Qn- $\# \mathrm{i}^{\circ 6}-\mathrm{V}^{+}$ \\
\hline I-ii- $-V^{7}$ & $\mathrm{I}^{\mathrm{M} 7}$-iv ${ }^{87}$-vii ${ }^{\circ}$ & Qn-IV ${ }^{7}-V^{7}$ & Qn-\#i ${ }^{\circ 6}-$ vii $^{\circ}$ \\
\hline I-ii-v $\mathrm{v}^{\infty 7}$ & $\mathrm{I}^{\mathrm{M} 7}-\mathrm{iv}^{87}-\mathrm{vii}^{87}$ & Qn-IV ${ }^{7}-\mathrm{v}^{87}$ & Qn-\#i ${ }^{06}-$ vii $^{07}$ \\
\hline I-ii- $\mathrm{V}^{+}$ & $\mathrm{I}^{\mathrm{M} 7}-\mathrm{IV}^{+}-\mathrm{V}$ & Qn-IV ${ }^{7}-\mathrm{V}^{+}$ & Qn- $\# i^{\varnothing 65}-\mathrm{V}$ \\
\hline I-ii-vii' ${ }^{\circ}$ & $\mathrm{I}^{\mathrm{M} 7}-\mathrm{IV}^{+}-\mathrm{V}^{7}$ & Qn-IV ${ }^{7}$-vii ${ }^{\circ}$ & Qn- $\# i^{ø 65}-V^{7}$ \\
\hline I-ii-vii ${ }^{\circ}$ & $\mathrm{I}^{\mathrm{M} 7}-\mathrm{IV}^{+}-\mathrm{v}^{\otimes 7}$ & Qn-IV - vii $^{77}$ & Qn- $\# i^{865}-\mathrm{v}^{87}$ \\
\hline $\mathrm{I}-\# \mathrm{i}^{06}-\mathrm{V}$ & $\mathrm{I}^{\mathrm{M} 7}-\mathrm{IV}^{+}-\mathrm{V}^{+}$ & Qn-iv ${ }^{87}-\mathrm{V}$ & Qn-\#i ${ }^{065}-\mathrm{V}^{+}$ \\
\hline $\mathrm{I}-\mathrm{Hi} \mathrm{i}^{06}-\mathrm{V}^{7}$ & $\mathrm{I}^{\mathrm{M} 7}-\mathrm{IV}^{+}-\mathrm{vii}^{\circ}$ & Qn-ivivi $-V^{7}$ & Qn-\#i ${ }^{665}$-vii ${ }^{\circ}$ \\
\hline I- $\# \mathrm{i}^{06}-\mathrm{V}^{07}$ & $\mathrm{I}^{\mathrm{M} 7}-\mathrm{IV}^{+}-\mathrm{vii}^{07}$ & Qn-ivive $-v^{87}$ & Qn- $-\# i^{865}-v_{i i}{ }^{\circ 7}$ \\
\hline
\end{tabular}


Māhur scale of Persia to have pitches $\mathrm{G}_{3}-\mathrm{A}-\mathrm{B}-\mathrm{C}_{4}-\mathrm{D}-\mathrm{E}-\mathrm{F}-\mathrm{G}-\mathrm{A}-\mathrm{B} \mathrm{b}_{4},{ }^{73}$ another source without a cited reference lists them as $\mathrm{C}^{\prime}-\mathrm{D}-\mathrm{E}-\mathrm{F}-\mathrm{G}-\mathrm{B} b^{\prime}-\mathrm{D}^{\prime \prime} .{ }^{74}$ Though the latter is a subset of the former, the contradiction does little to establish either one as legitimate - especially since neither book expounds on from where the information came.

However, one of the greatest mysteries lies in the work from Ibert. Although the scale books from Middlebrook and Fischer agree that the Algerian scale contains Ab and B, Ibert substitutes this augmented second with $\mathrm{B} b$ and $\mathrm{C} \#$, moving this large interval from scale degrees five and six to six and seven. Few sources in the English language are dedicated to this scale and to a small handful of theoretical analyses and musicological studies of Escales, casting doubt on what may be the correct Algerian scale. These scale books do not cite sources directly for this scale either, instead appearing to pass them down through performance tradition, legend, or hearsay. This is not intended to be an indictment of scale books written for guitarists - which I find to be quite useful - however, the field of ethnomusicology would benefit from deeper research into less oft-used scales that finds its way both into academia and into updated and new scale books for the lay musician.

Ibert's form of the Algerian scale in Escales raises questions such as why Ab appears in the piece if it is not a part of his scale. B $\mathrm{h}$ is not in "Tunis-Nefta," let alone used in conjunction with $\mathrm{Ab}$ - which he uses - so perhaps this is Ibert's way of acknowledging that a scale containing the upper augmented second $(\mathrm{Bb} / \mathrm{C} \sharp)$ is different from the standard that is reported by others, or perhaps he remembered the scale incorrectly after his visit to Tunisia. Other possibilities include

\footnotetext{
73. Farhat, “Dastgāh-e Māhur,” 89.

74. Brown, A Dictionary for the Modern Conductor, 12.
} 
the prospect that there may be two or more versions of the scale, that Ibert could have used some artistic liberty, or that the authors of the scale books are passing the scale down from earlier generations of studio musicians who have been taught a historically incorrect scale unwittingly.

In order to find the truth, further study is necessary to understand if the Western-sourced Algerian scale is accurate to the region from which it comes so that the inconsistency may be reconciled. The answer may possibly lie in plain sight in another language - perhaps Berber, Arabic, or French - and has yet to be translated into English. An itinerant scholar may wish to travel to Tunisia to research the correct scale (or scales, if there is more than one); the indigenous Berber people may already know, records may already be sitting in a Near East archive, or local scholarship may already have the answer to this enigma.

\section{$\underline{\text { Microtones }}$}

Microtones are a case that, when used, can still keep the ordered pitch collection within the scope of being hyperscalar. A limited number of microtones tuned closely (but not necessarily exactly) to the one-third, one-sixth, and one-ninth tones found in dastgāh-e Māhur gives the composer a new tool within the relatively dodecaphonic tonality because the microtones are limited to one or two uses in the scale. The dastgāh-e Māhur allows for the use of intervals smaller than a semitone that are a substitutionary embellishment replacing pitches within the scale without creating a new scale. ${ }^{75}$ However, a new scale does not need microtones to play a substitutionary role in order to maintain status as a hyperscale, so long as the scale meets the main criteria.

75. During, Art of Persian Music, 58-59, 92; Farhat, "Dastgāh-e Māhur,” 92. 


\section{$\underline{\text { Cultural Acceptance }}$}

Composers should carefully study and consider the values that an existing scale may have attached to a regional cultural practice, especially when applying principles of Western art to sources from the East. While Farhat explains of Persian music that "lack of conformity to the expected" may be "further evidence that... nothing can be taken as a hard and fast rule" ${ }^{76}-\mathrm{a}$ maxim that is parallel to Western music-writing practice - a Western composer has extra reason to exercise a measure of caution when "breaking the rules." Some of these scalar figures and modes come from religious rites and worship songs, many in religions that allow for free transfer of sacred musical forms to the secular, such as happens in the West with Roman Catholic and Protestant liturgy. Some members of other faiths, such as Islam, are offended by the association of their sacred chants with the word "music," which carries negative connotations of immorality in Western popular music. Rachmaninoff had the capacity to take liberties with the Obikhod scale because he grew up inside the culture of the Russian Orthodox Church, which he understood intimately. On the other hand, the znamenny chant scholars quoted earlier in this paper express their displeasure with the globalization of music and what is perceived as the subsequent breakdown of worship in the Russian Orthodox Church.

Regions across the globe that are in a period of renewed extreme nationalism, enduring a cultural identity crisis, or under a repressive religious or governmental authority may have factions who view any effort to develop their local music as an endeavor for assimilation into Western culture, risking judgment on the composer in the new use of their traditions as a blatant offense. Those wishing to undertake such a project should, in addition to careful cultural study, 
consider the need to make clear at the time of publication or performance how true their intent of the new music is to the original source. ${ }^{77}$

\section{$\underline{\text { Scale Thesaurus as a Resource }}$}

Thesaurus of Scales and Melodic Patterns (1947) by composer Nicolas Slonimsky (18941995), one of many books that the noted conductor and composer published during his lifetime, contains hundreds of synthetic scales designed for use by composers as an inspiration for creating new music. He favored harmonizing scales in his own compositions with triads and sevenths chords and rotating the inversion of these chords in the upper voices based on the direction of the movement in the bass line, pointing out that past composers used the techniques that he discovered extensively, such as the inversion rotations illustrated below in Figure $50 .{ }^{78}$

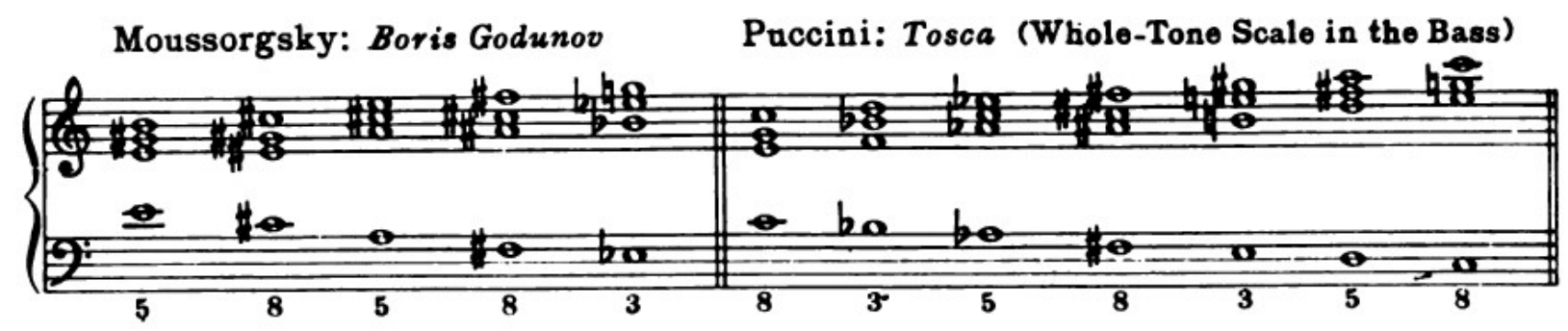

Figure 50. Rotating ascending inversions above descending bass lines.

77. Political discussion for or against "cultural appropriation" of music is beyond the scope of this paper and is not as clear-cut as taking a position "for" or "against". For those interested in delving further into this controversial topic, here are but a few of many places one can begin: Liane Gabora. "Are Accusations of Cultural Appropriation Misguided?" Psychology Today (2017 Apr 29). https://www.psychologytoday.com/us/blog/ mindbloggling/201704/are-accusations-cultural-appropriation-misguided. Accessed November 29, 2019; Susan Scafidi. Who Owns Culture?: Appropriation and Authenticity in American Law. New Brunswick, N.J.: Rutgers University Press (2005); Joanna Stato. "Cultural Appropriation." Off Our Backs 21, no. 9 (1991): 20-21; James O. Young. Cultural Appropriation and the Arts. Malden, MA: Blackwell, 2008.

78. Slonimsky, Thesaurus, v. 
Many of the patterns developed and catalogued by Slonimsky are sequential figures used to create effects of harmonically shifting arpeggiation. While the scales most often demonstrated the use of more than one octave, much of the time those extra octaves are simply the same repeated pitches, just as a student at the piano plays multiple octaves of the same scale. Other scales, however contain notes that are generated based on a formulaic pattern.

Most of the thousand-plus scales catalogued by Slonimsky may be disqualified from categorization as a hyperscale out of the nature of being sequenced by formula without regard for octave designation, since creating a multi-octave scale through placement of specific pitches in specific octaves is somewhat unwieldy, on the same level as using the Circle of Fifths as a hyperscale. The intrepid composer will, however, find the Thesaurus quite useful as a source for new scales, both as source and inspiration for scale creation, hyperscalar or not.

\section{$\underline{\text { Blazing New Scales }}$}

Perhaps nothing is more satisfying to a composer than finding a new way to use an existing concept in music theory. Joel Hoffman took an idea from his time in China and developed a hyperscale with a span of a major ninth for a piano concerto and then continued with the development of a different major-ninth hyperscale two years later in 6-8-2-4-5-8. My work in this field features not only in Streetwise but now in other new works that I have in progress, and these scales are being developed further by altering pitches and introducing limited chromaticism.

If creation of a new scale is not something one desires to do, composers may wish to use one that already exists. Slonimsky created over one thousand scales and published them to great success. In addition to these, other hyperscales are very likely already waiting to be discovered 
(or rediscovered) for the composer to consider using in new works. Slonimsky calculates that there are 479,001,600 possible combinations of dodecaphony available for composers to use. ${ }^{79}$ Whether this figure accounts for hyperscales is less important than the point that the possibilities for the composer to find unique combinations of notes for hyperscales are virtually limitless, while the current oeuvre of scales is a miniscule fraction of that number.

Centuries of Western music are built on the concept that two basic scales exist, major and minor, yet Jacques Ibert is perhaps most well-known as a composer for his piece "Tunis-Nefta," which is based on his development of an existing hyperscale. (See previous analysis on pp. 33 ff.) Although one of the purposes of this paper is to serve up ideas for stretching tonality within the realm of consonance, composers need not be limited by these ideas.

\section{Future Research}

My personal time and effort into researching past hyperscales reveals that very little scholarship exists for any of the historical scales included in this paper, which is not intended to be a full-blown project with a replete source of original research but merely a survey that includes the history of hyperscale use, analyzes the theory behind them, and - hopefully inspires others to dive further into creating new scales and digging into the past. Do not just take my word for it; Musicologist Michael Hewitt also remarks that the hyperscale has been achieved before yet confirms also that little scholarship exists. ${ }^{80}$ Therefore, in addition to creation of new

79. Slonimsky, vi.

80. Michael Hewitt. Musical Scales of the World. N.p.: Note Tree, 2013, 299. 
scales, musicologists and composers who choose to perform deeper research into the history and process of composing for these scales can help to preserve the old styles, technique, and aesthetic of hyperscalar music from the past that generations beyond can enjoy through contemporary application in composition and performance. 


\section{Bibliography}

Abate, Ezra. "Ethiopian Kiñit (scales): Analysis of the Formation and Structure of the Ethiopian Scale System." Edited by Svein Ege, Harald Aspen, Birhanu Teferra, and Shiferaw Bekele. In Proceedings of the 16th International Conference of Ethiopian Studies, 121324. Vol. 4. Trondheim: Norwegian University of Science and Technology, 2009. April 22,2010 .

Ardito, Linda. "Gideon, Miriam.” Grove Music Online, January 20, 2001. Accessed March 19, 2018. http://www.oxfordmusiconline.com/grovemusic/view/10.1093/gmo/9781561592630.001. 0001/omo-9781561592630-e-0000011103.

Babiracki, Carol M., and Bruno Nettl. "Internal Interrelationships in Persian Classical Music: The Dastgah of Shur in Eighteen Radifs." Asian Music 19, no. 1 (1987): 46-98. Accessed February 16, 2018. doi:10.2307/833763.

Bastani-Nezhad, Arya (Ali). "A Critical Study of the Iranian Teaching Textbooks on Iranian Classical Performance." Journal of Historical Research in Music Education 35, no. 2 (2014): 142-54. http://www.jstor.org/stable/43664212.

Belianski, Eugene. Russian Folk Traditions in Contemporary Musical Literature for Winds: Analysis and Composition in the Musical Languages of Russian Vocal Folk Polyphony (As Described by Aleksandr Kastalskiy), Russian Village Accordion Repertoire and Soviet Tourist/Traveller Bard Songs. PhD diss., York University, 2015. Toronto: York University, 2015. http://hdl.handle.net/10315/30111.

Berio, Luciano. Sequenza VI: Per Viola Sola. London: Universal Edition, 1970.

Berio, Luciano. Sequenza VII: Per Oboe Solo. London: Universal Edition, 1971.

Berk, Maynard Hales. The Grand Prix De Rome in Music (1803-1939). PhD diss., New York University, 1944. Ann Arbor: ProQuest. Accessed March 2, 2018. ProQuest Dissertations Publishing.

“Biography.” Joel Hoffman. Accessed March 8, 2019. http://www.joelhoffman.net/biography.

Brown, Emily Freeman. A Dictionary for the Modern Conductor. Lanham, Md.: Rowman \& Littlefield, 2015.

Chao, Pei. The Boston Symphony Orchestra, Serge Koussevitzky and the Cultivation of French Music in America during the First Half of the Twentieth Century. PhD diss., University of North Texas, 1997. Ann Arbor: ProQuest. Accessed March 2, 2018. 
Cohn, Arthur. Twentieth-Century Music in Western Europe: The Compositions and the Recordings. Philadelphia: Lippincott, 1965.

Conomos, Dmitri. "Music (Sacred)." John Anthony McGuckin, ed. The Encyclopedia of Eastern Orthodox Christianity. Chichester: Wiley-Blackwell, 2011: 404-406.

"Dastgāh." Google Translate.

https://translate.google.com/\#view=home\&op=translate\&sl=fa\&tl=en\&text=dastgāh. Accessed February 12, 2019.

D'If, Charles. "Musical Notes from Abroad." The Musical Times 70, no. 1038 (1929): 748-50. http://www.jstor.org/stable/914415.

Dolskaya-Ackerly, Olga. "Aesthetics and National Identity in Russian Sacred Choral Music: A Past in Tradition and Present in Ruins." The Choral Journal 42, no. 5 (2001): 9-24. http://www.jstor.org/stable/23554005.

During, Jean, Zia Mirabdolbaghi, and Dariush Safvat. The Art of Persian Music. Washington, D.C.: Mage Publishers, 1991.

Ewen, David. The World of Twentieth-Century Music. Englewood Cliffs, N.J.: Prentice-Hall, 1968.

Farhat, Hormoz. "Dastgāh-e Māhur." In The Dastgāh Concept in Persian Music, 89-99. Cambridge Studies in Ethnomusicology. Cambridge: Cambridge University Press, 1990. Accessed February 10, 2018.

Ferguson, Donald N. "Nicolas Andreivitch Rimsky-Korsakoff (1844-1908)." In Masterworks of the Orchestral Repertoire: A Guide for Listeners, 461-65. University of Minnesota Press, 1954. http://www.jstor.org/stable/10.5749/j.cttts92j.43.

Fink, Robert, and Robert Ricci. The Language of Twentieth Century Music: A Dictionary of Terms. New York: Schirmer Books, 1975.

Fischer, Peter. Rock Guitar Secrets. Brühl, Germany: AMA Verlag, 1995.

Gann, Kyle. American Music in the Twentieth Century. New York: Schirmer Books, 1997.

The Garland Encyclopedia of World Music. Volume 6, The Middle East: Selected Audio Examples. CD.

Gottlieb, Jack. Funny, It Doesn't Sound Jewish: How Yiddish Songs and Synagogue Melodies Influenced Tin Pan Alley, Broadway, and Hollywood. Albany, NY: State University of 
Greenbaum, Matthew. "Stefan Wolpe's Dialectical Logic: A Look at the 'Second Piece for Violin Alone'." Perspectives of New Music 40, no. 2 (Summer 2002): 91-114. http://www.jstor.org/stable/25164488.

H., C. “Music in Manchester.” The Musical Times 68, no. 1010 (1927): 358-59. http://www.jstor.org/stable/912811.

Halfyard, Janet K. Berio's Sequenzas : Essays on Performance, Composition and Analysis. Aldershot, England: Ashgate, 2007.

Harajian, Mohsen. Ghazal as a Determining Factor of the Structure of the Iranian Dastgāh. $\mathrm{PhD}$ diss., University of Maryland College Park, 1999. Ann Arbor: UMI, 1999. Accessed March 21, 2018. ProQuest.

Harrán, Don. “'Kehi Kinnor’ by Samuel Archivolti (d. 1611): A Wedding Ode with Hidden Messages." AJS Review 35, no. 2 (2011): 253-91. http://www.jstor.org/stable/41310618.

Hewitt, Michael. Musical Scales of the World. N.p.: Note Tree, 2013.

Hoffman, Joel. 6-8-2-4-5-8. Cincinnati: Onibatan Music, 2006. PDF. Used with permission.

Hoffman, Joel. "6-8-2-4-5-8.” E-mail message to author. February 21, 2019. Used with permission.

Hoffman, Joel. Piano Concerto No. 1. Cincinnati: Onibatan Music, 2008. PDF.

Ibert, Jacques. Escales (Ports of Call). Paris: Leduc, 1925.

Ivashkin, Alexander. “Amsterdam: Alexander Raskatov's 'A Dog's Heart'.” Tempo 65, no. 256 (2011): 54-56. http://www.jstor.org/stable/23020691.

“Jacques Ibert." Columbia Electronic Encyclopedia. 6th ed. 2017. Accessed March 2, 2018. Academic Search Complete [EBSCO].

Johnston, Ben, and Bob Gilmore. "Scalar Order as a Compositional Resource: 1962-63." In Maximum Clarity and Other Writings on Music, 10-31. University of Illinois Press, 2006. http://www.jstor.org/stable/10.5406/j.ctt1xcqj6.7.

Kolinski, Mieczyslaw. "Mode." Encyclopcedia Britannica. September 9, 2010. Accessed March 13, 2018. https://www.britannica.com/art/mode-music.

Laederich, Alexandra. "Ibert, Jacques." Grove Music Online. Accessed February 28, 2018. https://doi.org/10.1093/gmo/9781561592630.article.13675.

Larson, Steve. "The Value of Cognitive Models in Evaluating Solfege Systems." Indiana Theory Review 14, no. 2 (1993): 73-116. 
http://www.jstor.org.www.libproxy.wvu.edu/stable/24045329.

Levine, Joseph A. "Toward Defining the Jewish Prayer Modes with Particular Emphasis on the Adonay Malakh Mode." Music Judaica 3, no. 1 (1980): 13-41. http://www.jstor.org/stable/23687478.

London Chorus. “Adonai Malakh (Psalm 93)." Conducted by Ronald Corp. Performed by Patrick Mason. By Miriam Gideon. In Psalms of Joy and Sorrow. 2006, CD. https://wvuwl-naxosmusiclibrarycom.www.libproxy.wvu.edu/catalogue/item.asp?cid=8.559445.

“Mahur, Iran.” Wikipedia. https://en.wikipedia.org/wiki/Mahur,_Iran. Accessed February 12, 2019.

Middlebrook, Ron. Scales \& Modes in the Beginning: Created Especially for Guitarists. Anaheim Hills, CA: Centerstream, 1982.

Minor, Martha Danielson. Hispanic Influences on the Works of French Composers of the Nineteenth and Twentieth Centuries. PhD diss., University of Kansas, 1983. Ann Arbor: ProQuest. Accessed March 3, 2018.

Nauert, Paul. "Field Notes: A Study of Fixed-Pitch Formations." Perspectives of New Music 41, no. 1 (2003): 180-239. http://www.jstor.org/stable/25164511.

Nauert, Paul. "Timespan Hierarchies and Posttonal Pitch Structure: A Composer's Strategies." Perspectives of New Music 43, no. 1 (2005): 34-53. http://www.jstor.org.www.libproxy.wvu.edu/stable/25164572

"Nefta, Tunisia to P3, Tunisia." Map. Google Maps. Accessed March 28, 2018. https://www.google.com/maps/dir/Naftah,+Tunisia/33.7288548,7.5697269/@33.8040846 ,7.6668372,12.54z/data $=! 4 \mathrm{~m} 9 ! 4 \mathrm{~m} 8 ! 1 \mathrm{~m} 5 ! 1 \mathrm{~m} 1 ! 1 \mathrm{~s} 0 \times 12578 \mathrm{c} 998 \mathrm{f} 25 \mathrm{~cd} 5 \mathrm{~b}: 0 x a d 435 \mathrm{f} 019 \mathrm{ff} 4 \mathrm{~b}$ $546 ! 2 \mathrm{~m} 2 ! 1 \mathrm{~d} 7.8803236 ! 2 \mathrm{~d} 33.8761249 ! 1 \mathrm{~m} 0 ! 3 \mathrm{e} 0$.

Netanel, Deborah Kramer. The Kaddish: A Jewish Prayer in Western Art Music. PhD diss., University of Cincinnati, 2003. Ann Arbor: ProQuest.

Orton, Richard. "Ring Modulator." Grove Music Online. January 20, 2001. Accessed March 21, 2018. http://www.oxfordmusiconline.com/grovemusic/view/10.1093/gmo/9781561592630.001. 0001/omo-9781561592630-e-0000023491.

Osmond-Smith, David. Berio. Oxford: Oxford University Press, 1991.

Osmond-Smith, David, and Ben Earle. "Berio, Luciano.” Grove Music Online. 2001; Accessed 6 Sep. 2019. 
https://www.oxfordmusiconline.com/grovemusic/view/10.1093/gmo/9781561592630.001 $.0001 /$ omo-9781561592630-e-0000002815.

Powers, Harold. "The 'maqam World'.” In Yearbook for Traditional Music, 199-218.

Proceedings of First Meeting of the ICTM Study Group on Maqam, Samarkand. Vol. 20. International Council for Traditional Music, 1988. http://www.jstor.org/stable/768174.

Rahn, Jay. 1991. "Coordination and Interval Sizes in Seven-Tone Collections." Journal of Music Theory 35: 33-60.

Reti, Rudolph. Tonality, Atonality, Pantonality : A Study of Some Trends in Twentieth Century Music. Westport, Conn., 1978.

Rimsky-Korsakov, Nikolai. La Grande Pâque Russe: Ouverture (Russian Easter Festival Overture), Op. 36. Leipzig: M. P. Belaïeff, 1890. https:/imslp.org/wiki/Special:ImagefromIndex/32586/hfji.

Roccasalvo, Joan L. “The Znamenny Chant.” The Musical Quarterly 74, no. 2 (1990): 217-41. http://www.jstor.org/stable/742190.

Slonimsky, Nicolas. Thesaurus of Scales and Melodic Patterns. New York: Coleman-Ross, 1947. Accessed July 14, 2017. http://hdl.handle.net/2027/uc1.32106007393371.

Spurgeon, Charles Haddon. "Psalm XCIII." The Treasury of David: Containing an Original Exposition of the Book of Psalms; A Collection of Illustrative Extracts from the Whole Range of Literature; A Series of Homiletical Hints upon Almost Every Verse; and Lists of Writers upon Each Psalm, 2nd ed. New York: Funk \& Wagnalls, 1885, 283-291.

Swan, Alfred J. "Russian Liturgical Music and Its Relation to Twentieth-Century Ideals." Music \& Letters 39, no. 3 (1958): 265-274. http://www.jstor.org/stable/730541.

Swan, Alfred J. "The Znamenny Chant of the Russian Church--Part I." The Musical Quarterly 26, no. 2 (1940): 232-43. http://www.jstor.org/stable/738849.

Swan, Alfred J. "The Znamenny Chant of the Russian Church--Part II." The Musical Quarterly 26, no. 3 (1940): 365-380. http://www.jstor.org/stable/738771.

Swan, Alfred J. "The Znamenny Chant of the Russian Church--Part III." The Musical Quarterly 26, no. 4 (1940): 529-45. http://www.jstor.org/stable/738920.

Tarsi, Boaz. "Lower Extension of the Minor Scale in Ashkenazi Prayer Music." Indiana Theory Review 23 (2002): 153-83. http://www.jstor.org/stable/24046541.

Tarsi, Boaz. "Observations on Practices of 'Nusach' in America." Asian Music 33, no. 2 (2002): 175-219. http://www.jstor.org/stable/834350. 
Taruskin, Richard. "Rimsky-Korsakov, Nikolay Andreyevich." Grove Music Online. Oxford Music Online. Accessed March 19, 2018.

http://www.oxfordmusiconline.com/grovemusic/view/10.1093/gmo/9781561592630.001. 0001/omo-9781561592630-e-5000002126.

Thomas, Philip (2007) "Berio's Sequenza IV: Approaches to performance and interpretation." Contemporary Music Review, 26:2, 189-205, DOI: 10.1080/07494460701295341.

Toop, Richard. "Stockhausen, Karlheinz." Grove Music Online. January 20, 2001. Accessed March 21, 2018.

http://www.oxfordmusiconline.com/grovemusic/view/10.1093/gmo/9781561592630.001. 0001/omo-9781561592630-e-0000026808.

Velimirovic, Milos. "The Present Status of Research in Slavic Chant.” Acta Musicologica 44, no. 2 (July 1972): 235-65. doi: 10.2307/932170.

Wall, Jeffery B. "The Influence of Znamenny Liturgical Chant on the Nineteenth-Century Russian Choral School: A Guide for Performance." The Choral Journal 50, no. 3 (2009): 20-32. http://www.jstor.org/stable/23559804.

Wehner, Walter L. "The Relation between Six Paintings by Paul Klee and Selected Musical Compositions." Journal of Research in Music Education 14, no. 3 (1966): 220-24. http://www.jstor.org/stable/3344055.

Yasser, Joseph. "The Opening Theme of Rachmaninoff's Third Piano Concerto and Its Liturgical Prototype.” The Musical Quarterly 55, no. 3 (1969): 313-28. http://www.jstor.org/stable/741003. 
Works Cited

Bastani-Nezhad, Arya (Ali). "A Critical Study of the Iranian Teaching Textbooks on Iranian Classical Performance.” Journal of Historical Research in Music Education 35, no. 2 (2014): 142-54. http://www.jstor.org/stable/43664212.

Belianski, Eugene. Russian Folk Traditions in Contemporary Musical Literature for Winds: Analysis and Composition in the Musical Languages of Russian Vocal Folk Polyphony (As Described by Aleksandr Kastalskiy), Russian Village Accordion Repertoire and Soviet Tourist/Traveller Bard Songs. PhD diss., York University, 2015. Toronto: York University, 2015. http://hdl.handle.net/10315/30111.

“Biography.” Joel Hoffman. Accessed March 8, 2019. http://www.joelhoffman.net/biography.

Brown, Emily Freeman. A Dictionary for the Modern Conductor. Lanham, Md.: Rowman \& Littlefield, 2015.

Chao, Pei. The Boston Symphony Orchestra, Serge Koussevitzky and the Cultivation of French Music in America during the First Half of the Twentieth Century. PhD diss., University of North Texas, 1997. Ann Arbor: ProQuest. Accessed March 2, 2018.

"Dastgāh." Google Translate. https://translate.google.com/\#view=home\&op=translate\&sl=fa\&tl=en\&text=dastgāh. Accessed February 12, 2019.

D'If, Charles. "Musical Notes from Abroad.” The Musical Times 70, no. 1038 (1929): 748-50. http://www.jstor.org/stable/914415.

Dolskaya-Ackerly, Olga. "Aesthetics and National Identity in Russian Sacred Choral Music: A Past in Tradition and Present in Ruins." The Choral Journal 42, no. 5 (2001): 9-24. http://www.jstor.org/stable/23554005.

During, Jean, Zia Mirabdolbaghi, and Dariush Safvat. The Art of Persian Music. Washington, D.C.: Mage Publishers, 1991.

Farhat, Hormoz. "Dastgāh-e Māhur." In The Dastgāh Concept in Persian Music, 89-99. Cambridge Studies in Ethnomusicology. Cambridge: Cambridge University Press, 1990. Accessed February 10, 2018.

Ferguson, Donald N. "Nicolas Andreivitch Rimsky-Korsakoff (1844-1908)." In Masterworks of the Orchestral Repertoire: A Guide for Listeners, 461-65. University of Minnesota Press, 1954. http://www.jstor.org/stable/10.5749/j.cttts92j.43.

Fischer, Peter. Rock Guitar Secrets. Brühl, Germany: AMA Verlag, 1995. 
Greenbaum, Matthew. "Stefan Wolpe's Dialectical Logic: A Look at the 'Second Piece for Violin Alone'." Perspectives of New Music 40, no. 2 (Summer 2002): 91-114. http://www.jstor.org/stable/25164488.

H., C. "Music in Manchester." The Musical Times 68, no. 1010 (1927): 358-59. http://www.jstor.org/stable/912811.

Harajian, Mohsen. Ghazal as a Determining Factor of the Structure of the Iranian Dastgāh. $\mathrm{PhD}$ diss., University of Maryland College Park, 1999. Ann Arbor: UMI, 1999. Accessed March 21, 2018. ProQuest.

Harrán, Don. “'Kehii Kinnor” by Samuel Archivolti (d. 1611): A Wedding Ode with Hidden Messages.”" AJS Review 35, no. 2 (2011): 253-91. http://www.jstor.org/stable/41310618.

Hewitt, Michael. Musical Scales of the World. N.p.: Note Tree, 2013.

Hoffman, Joel. 6-8-2-4-5-8. Cincinnati: Onibatan Music, 2006. PDF. Used with permission.

Hoffman, Joel. “6-8-2-4-5-8.” E-mail message to author. February 21, 2019. Used with permission.

Hoffman, Joel. Piano Concerto No. 1. Cincinnati: Onibatan Music, 2008. PDF.

Ibert, Jacques. Escales (Ports of Call). Paris: Leduc, 1925.

Ivashkin, Alexander. “Amsterdam: Alexander Raskatov's 'A Dog's Heart'.” Tempo 65, no. 256 (2011): 54-56. http://www.jstor.org/stable/23020691.

"Jacques Ibert." Columbia Electronic Encyclopedia. 6th ed. 2017. Accessed March 2, 2018. Academic Search Complete [EBSCO].

Johnston, Ben, and Bob Gilmore. "Scalar Order as a Compositional Resource: 1962-63." In Maximum Clarity and Other Writings on Music, 10-31. University of Illinois Press, 2006. http://www.jstor.org/stable/10.5406/j.ctt1xcqj6.7.

Kolinski, Mieczyslaw. "Mode.” Encyclopaedia Britannica. September 9, 2010. Accessed March 13, 2018. https://www.britannica.com/art/mode-music.

Laederich, Alexandra. "Ibert, Jacques.” Grove Music Online. Accessed February 28, 2018. https://doi.org/10.1093/gmo/9781561592630.article.13675.

Larson, Steve. "The Value of Cognitive Models in Evaluating Solfege Systems." Indiana Theory Review 14, no. 2 (1993): 73-116. http://www.jstor.org.www.libproxy.wvu.edu/stable/24045329. 
Levine, Joseph A. "Toward Defining the Jewish Prayer Modes with Particular Emphasis on the Adonay Malakh Mode.” Music Judaica 3, no. 1 (1980): 13-41. http://www.jstor.org/stable/23687478.

“Mahur, Iran.” Wikipedia. https://en.wikipedia.org/wiki/Mahur,_Iran. Accessed February 12, 2019.

McGuckin, John Anthony. The Encyclopedia of Eastern Orthodox Christianity. Chichester: Wiley-Blackwell, 2011.

Middlebrook, Ron. Scales \& Modes in the Beginning: Created Especially for Guitarists. Anaheim Hills, CA: Centerstream, 1982.

Nauert, Paul. "Field Notes: A Study of Fixed-Pitch Formations." Perspectives of New Music 41, no. 1 (2003): 180-239. http://www.jstor.org/stable/25164511.

Netanel, Deborah Kramer. The Kaddish: A Jewish Prayer in Western Art Music. PhD diss., University of Cincinnati, 2003. Ann Arbor: ProQuest.

Orton, Richard. "Ring Modulator.” Grove Music Online. January 20, 2001. Accessed March 21, 2018.

http://www.oxfordmusiconline.com/grovemusic/view/10.1093/gmo/9781561592630.001. 0001/omo-9781561592630-e-0000023491.

Osmond-Smith, David. Berio. Oxford: Oxford University Press, 1991.

Roccasalvo, Joan L. “The Znamenny Chant.” The Musical Quarterly 74, no. 2 (1990): 217-41. http://www.jstor.org/stable/742190.

Slonimsky, Nicolas. Thesaurus of Scales and Melodic Patterns. New York: Coleman-Ross, 1947. Accessed July 14, 2017. http://hdl.handle.net/2027/uc1.32106007393371.

Spurgeon, Charles Haddon. "Psalm XCIII." The Treasury of David: Containing an Original Exposition of the Book of Psalms; A Collection of Illustrative Extracts from the Whole Range of Literature; A Series of Homiletical Hints upon Almost Every Verse; and Lists of Writers upon Each Psalm, 2nd ed. New York: Funk \& Wagnalls, 1885, 283-291.

Swan, Alfred J. "Russian Liturgical Music and Its Relation to Twentieth-Century Ideals." Music \& Letters 39, no. 3 (1958): 265-274. http://www.jstor.org/stable/730541.

Tarsi, Boaz. "Lower Extension of the Minor Scale in Ashkenazi Prayer Music.” Indiana Theory Review 23 (2002): 153-83. http://www.jstor.org/stable/24046541.

Tarsi, Boaz. "Observations on Practices of 'Nusach' in America." Asian Music 33, no. 2 (2002): 175-219. http://www.jstor.org/stable/834350. 
Toop, Richard. "Stockhausen, Karlheinz." Grove Music Online. January 20, 2001. Accessed March 21, 2018.

http://www.oxfordmusiconline.com/grovemusic/view/10.1093/gmo/9781561592630.001. 0001/omo-9781561592630-e-0000026808.

Wall, Jeffery B. "The Influence of Znamenny Liturgical Chant on the Nineteenth-Century Russian Choral School: A Guide for Performance." The Choral Journal 50, no. 3 (2009): 20-32. http://www.jstor.org/stable/23559804.

Yasser, Joseph. "The Opening Theme of Rachmaninoff's Third Piano Concerto and Its Liturgical Prototype.” The Musical Quarterly 55, no. 3 (1969): 313-28.

http://www.jstor.org/stable/741003. 

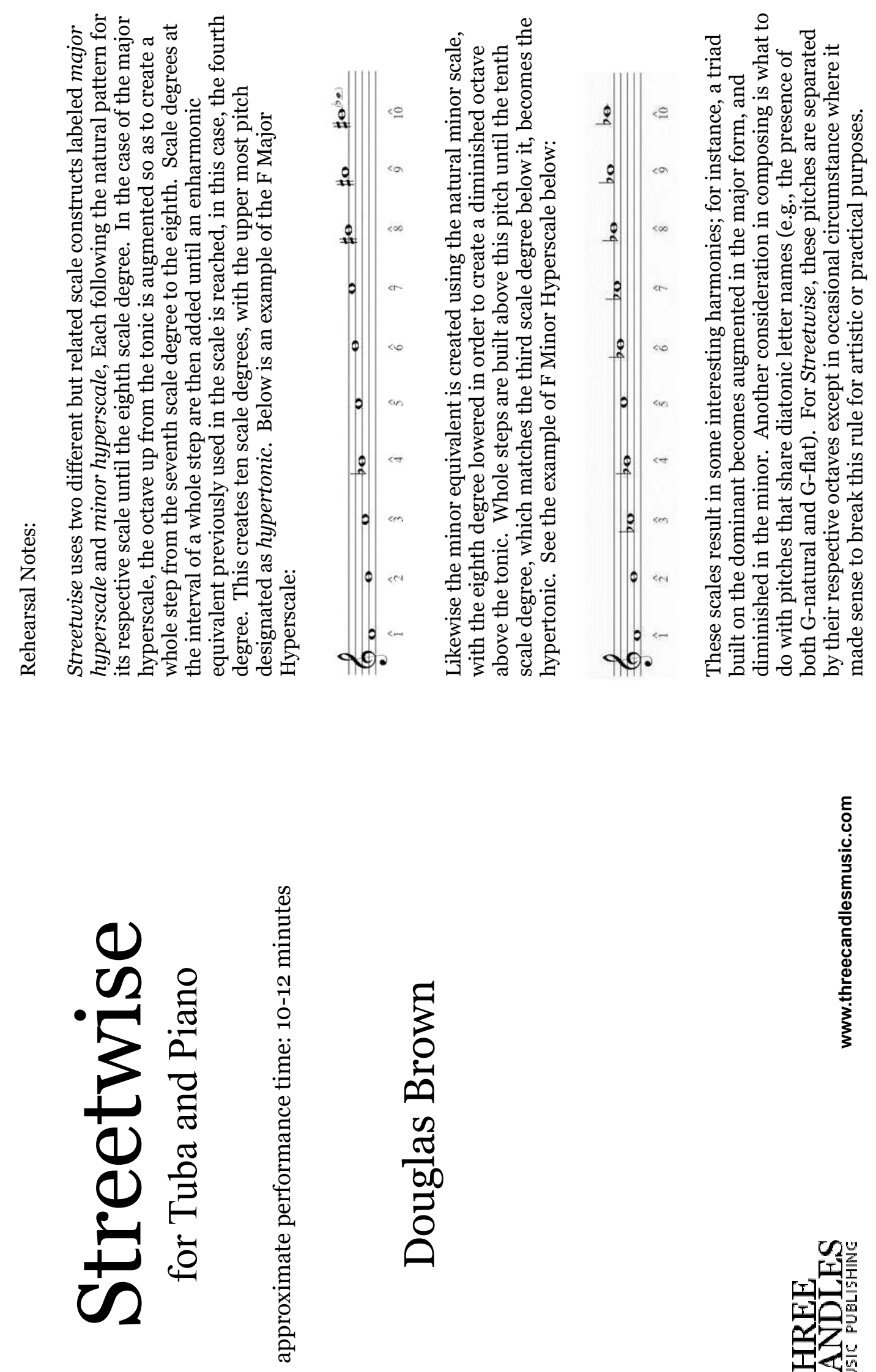

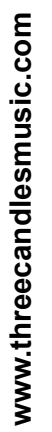

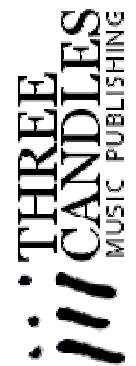




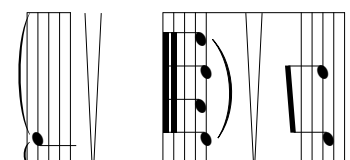

$\because 1$

$\left(\begin{array}{lll}(1) \\ \vdots\end{array}\right)^{-1}$

.

[F: :

I. (

$\therefore(\vdots 1$

- *i so
(1)

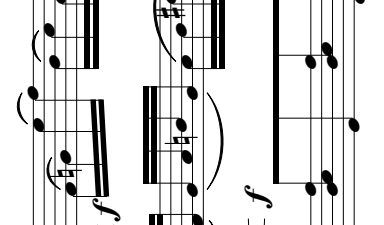

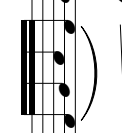

- i,

. I :
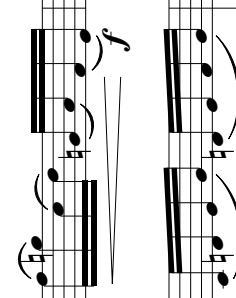

$\overbrace{0}$

I: $:=$

.j I:

(4)

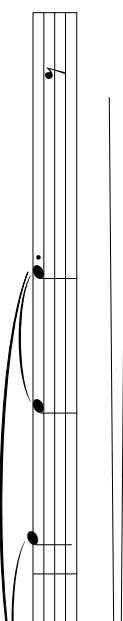

:

$1 \%$

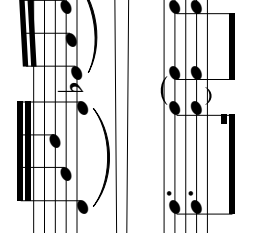

II:

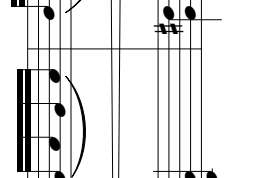

$1:$ :

ii: $[\ddot{0}$

iv

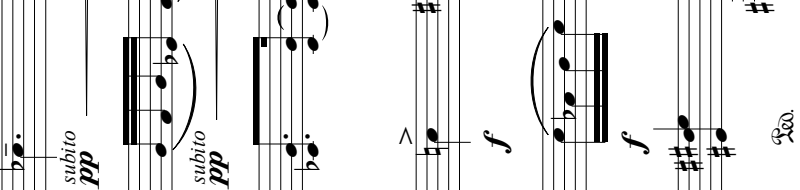

:iो $=\underbrace{200}$
^⿻

(:)
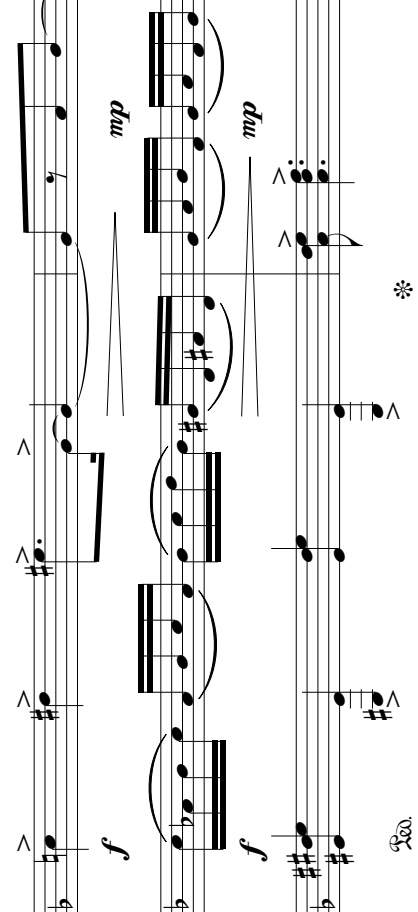

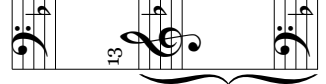

$\therefore: 0$
㕍
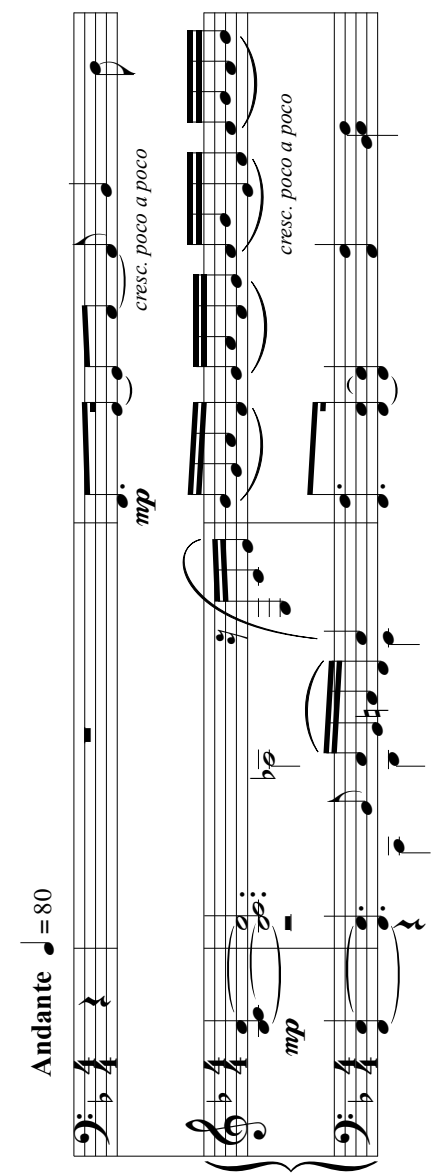

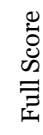
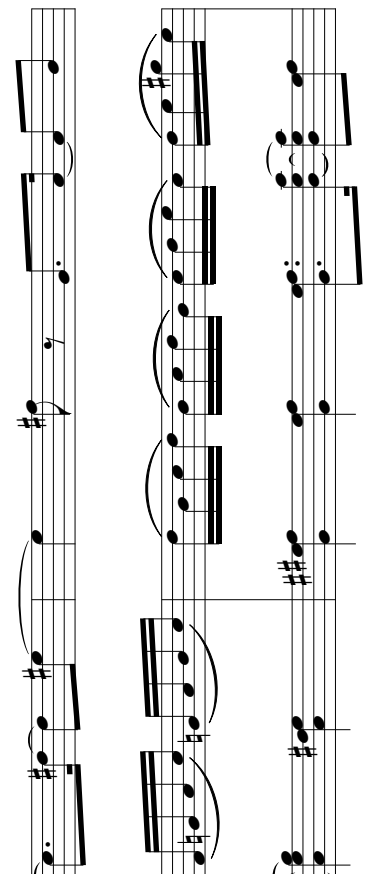

(i)
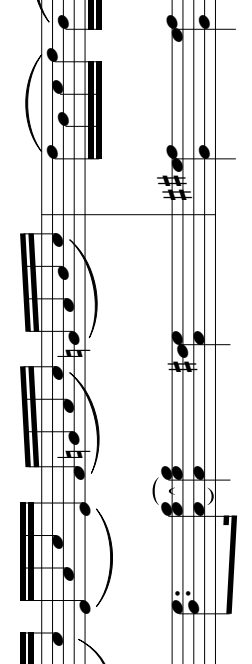

II.)

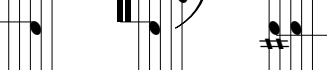

A. 20.
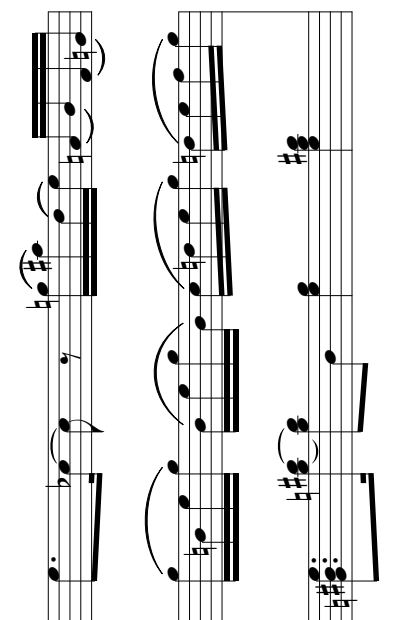

:.

-

- $气$ :

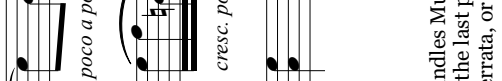

|| || ||

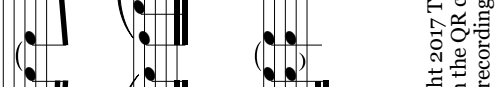

\|U

*1. 


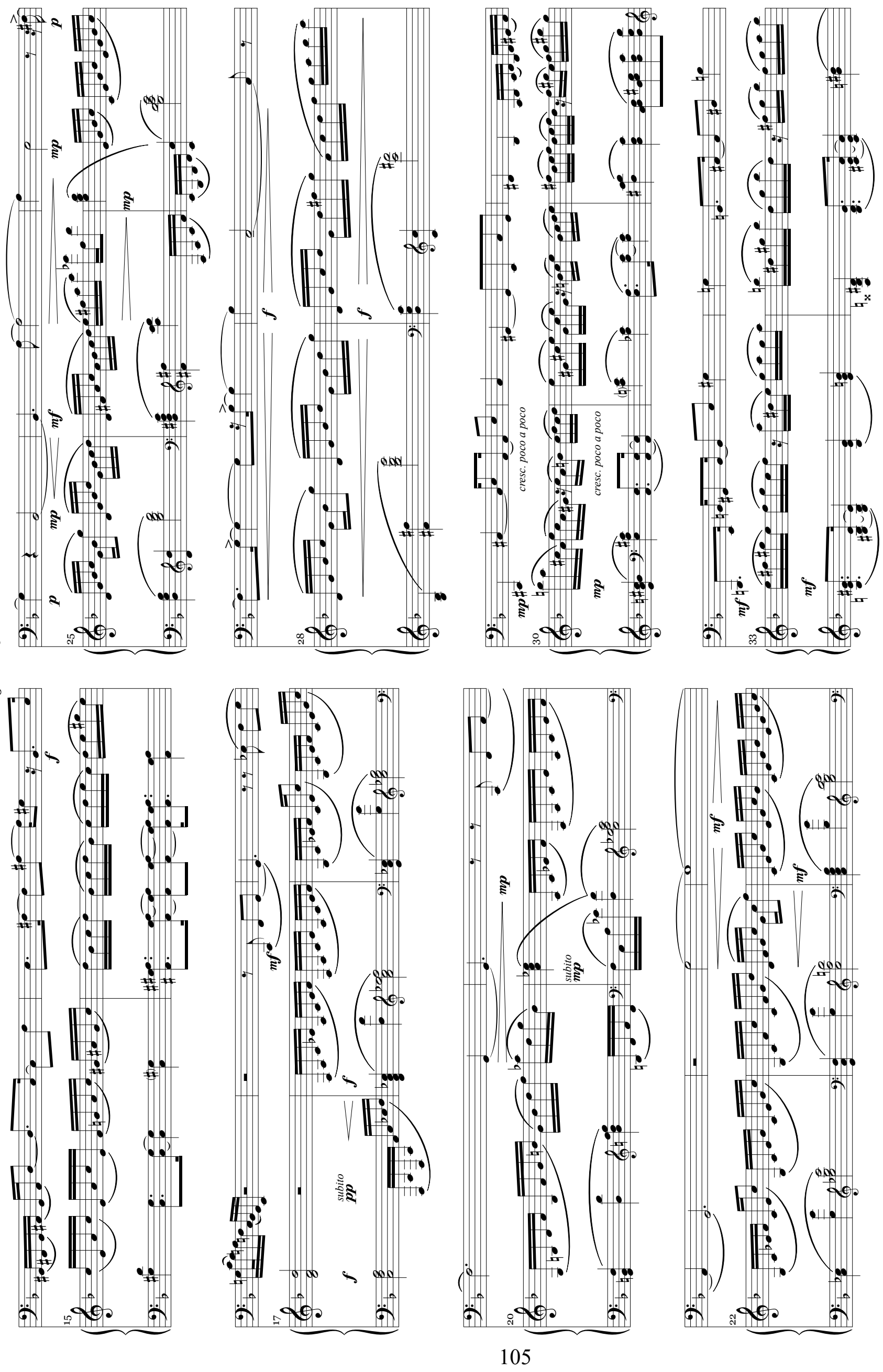




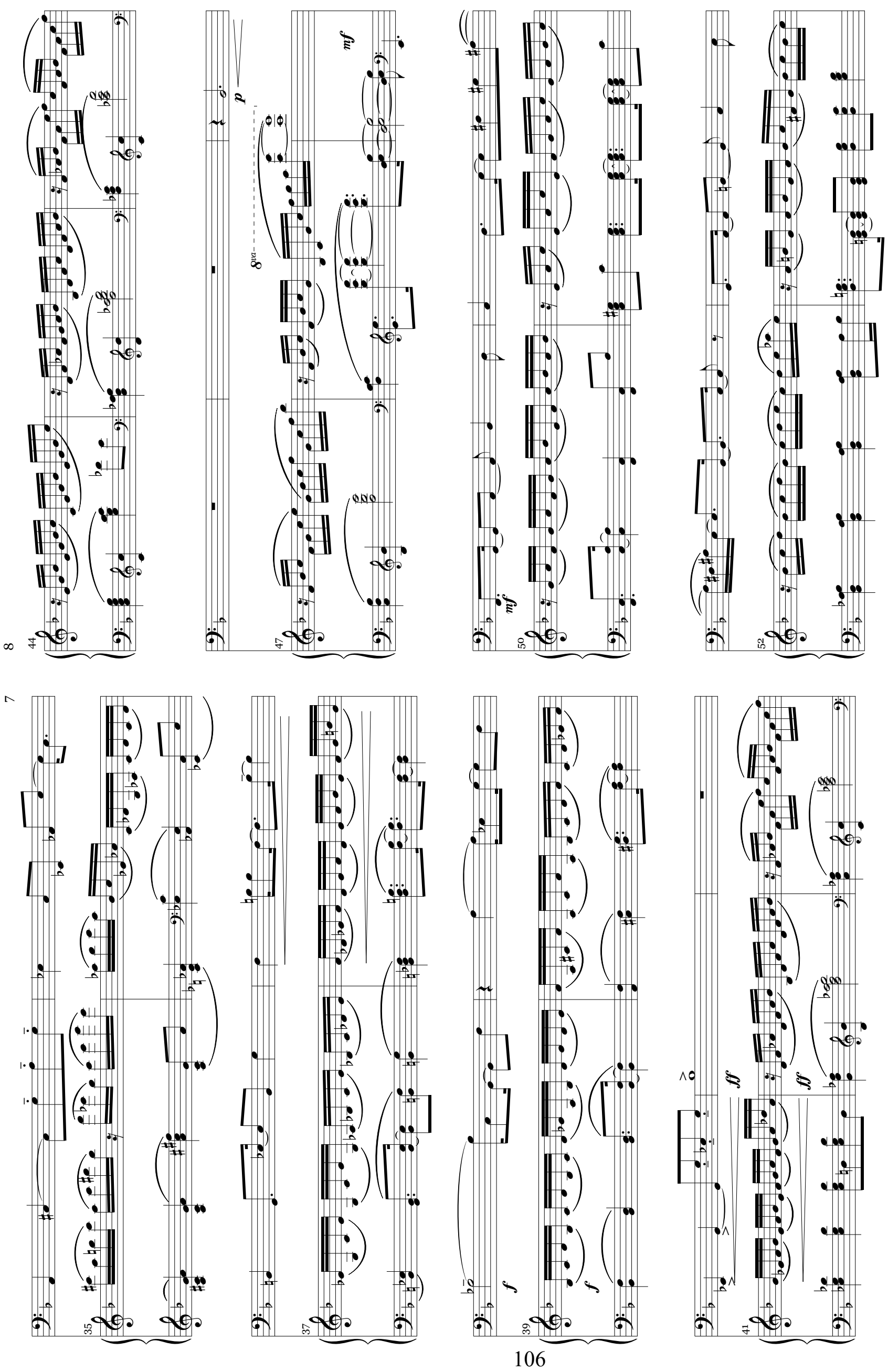




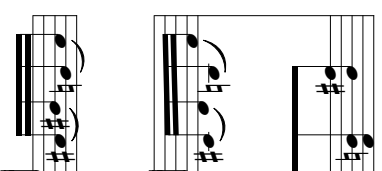

$\|: *^{*}$

(i)

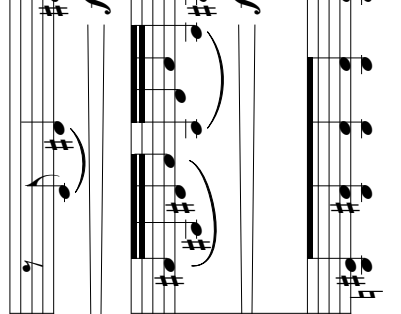

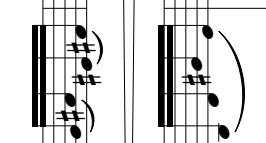

$\because \| \vdots \vdots) \quad \cdots$

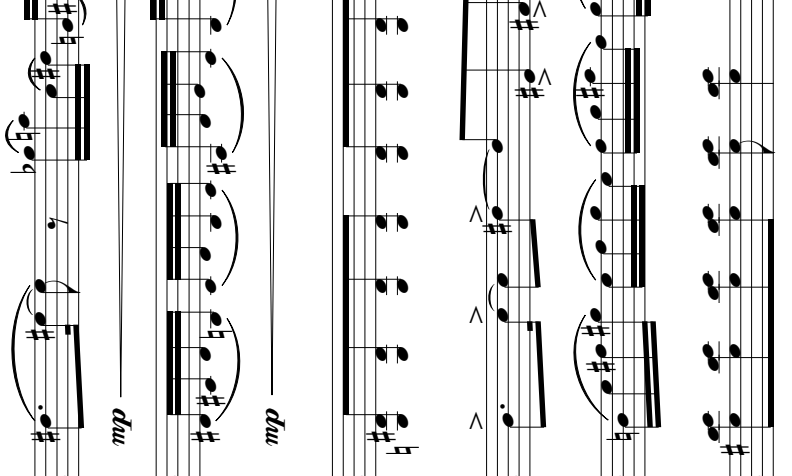

: *ी की

in

(1)

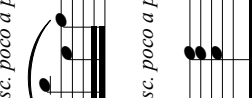

(i)

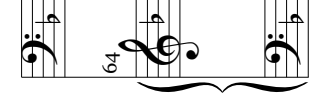

(:)

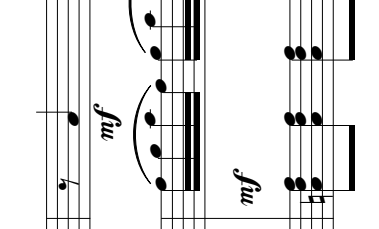

[*

il (i.) ...

7)

;i (i)

(ill

(a)

- $\quad$ il $:$

- 11:

5) 1.:

$\|:$

- F

에

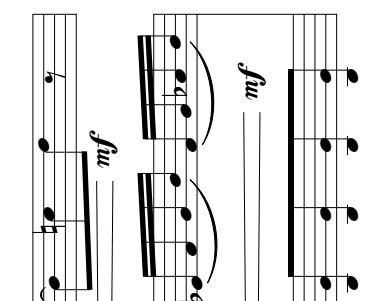

- I:

- $1.8=$

*

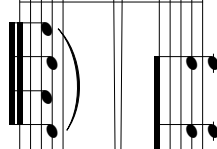

- 1 :

*

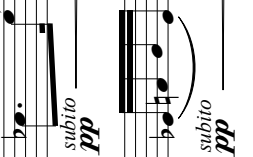

(i) ide
[1: 1:
:|

(:)

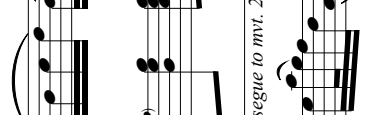

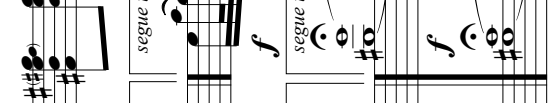

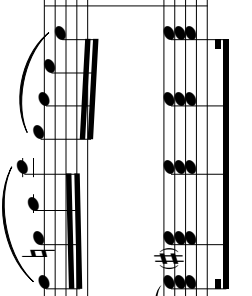

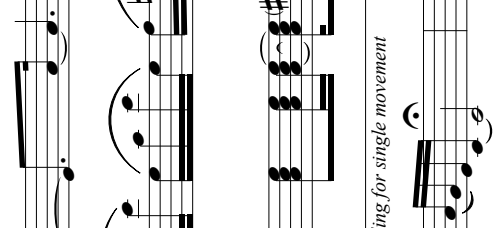

.

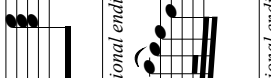

羊

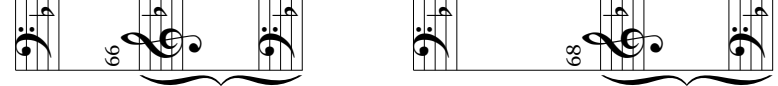

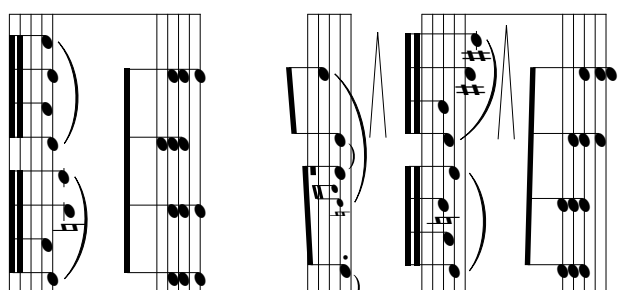

$\mathbb{1}: \vdots$

$(12 \vdots$

;ill

$\operatorname{lin}_{1}$

6) 


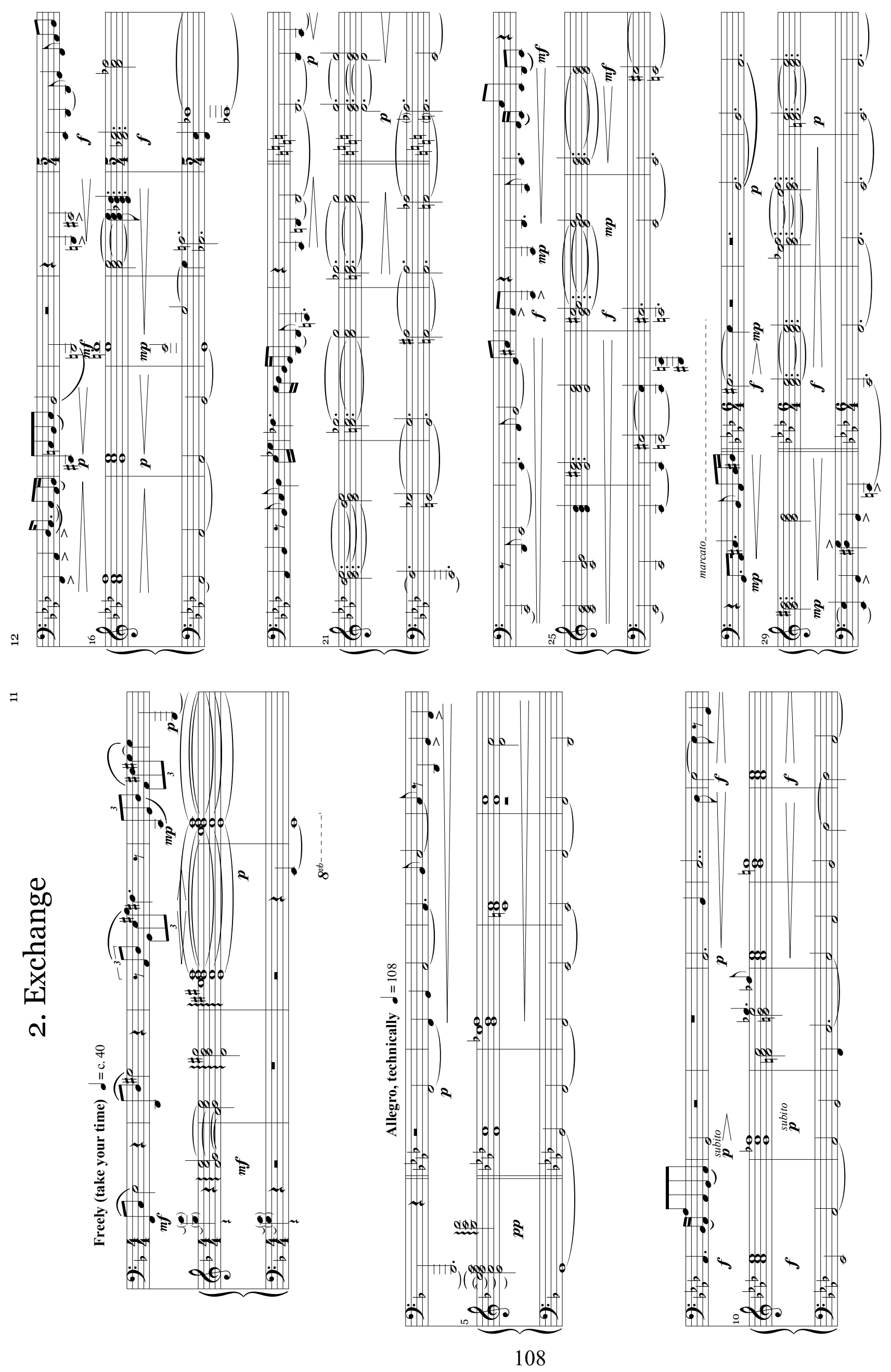




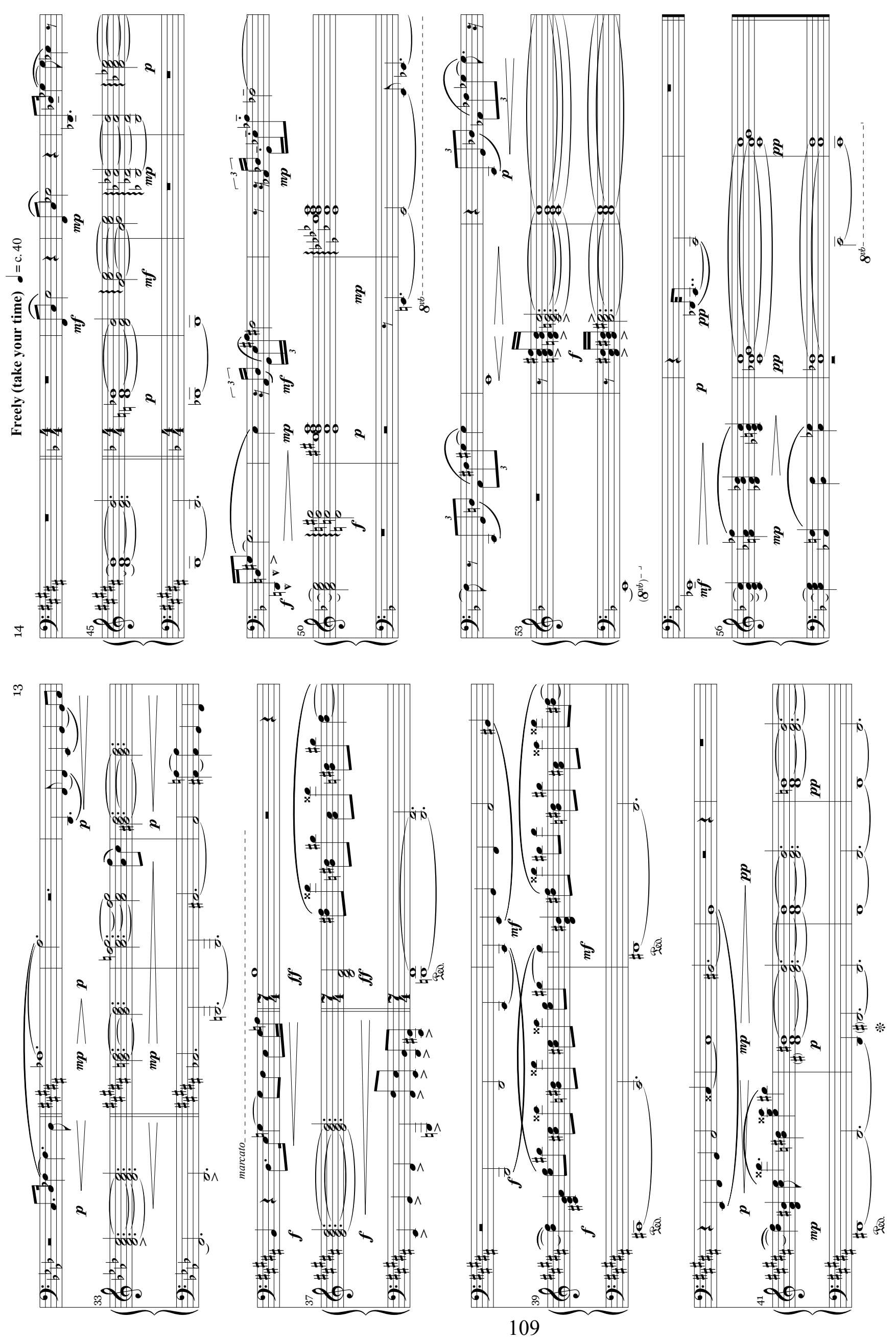



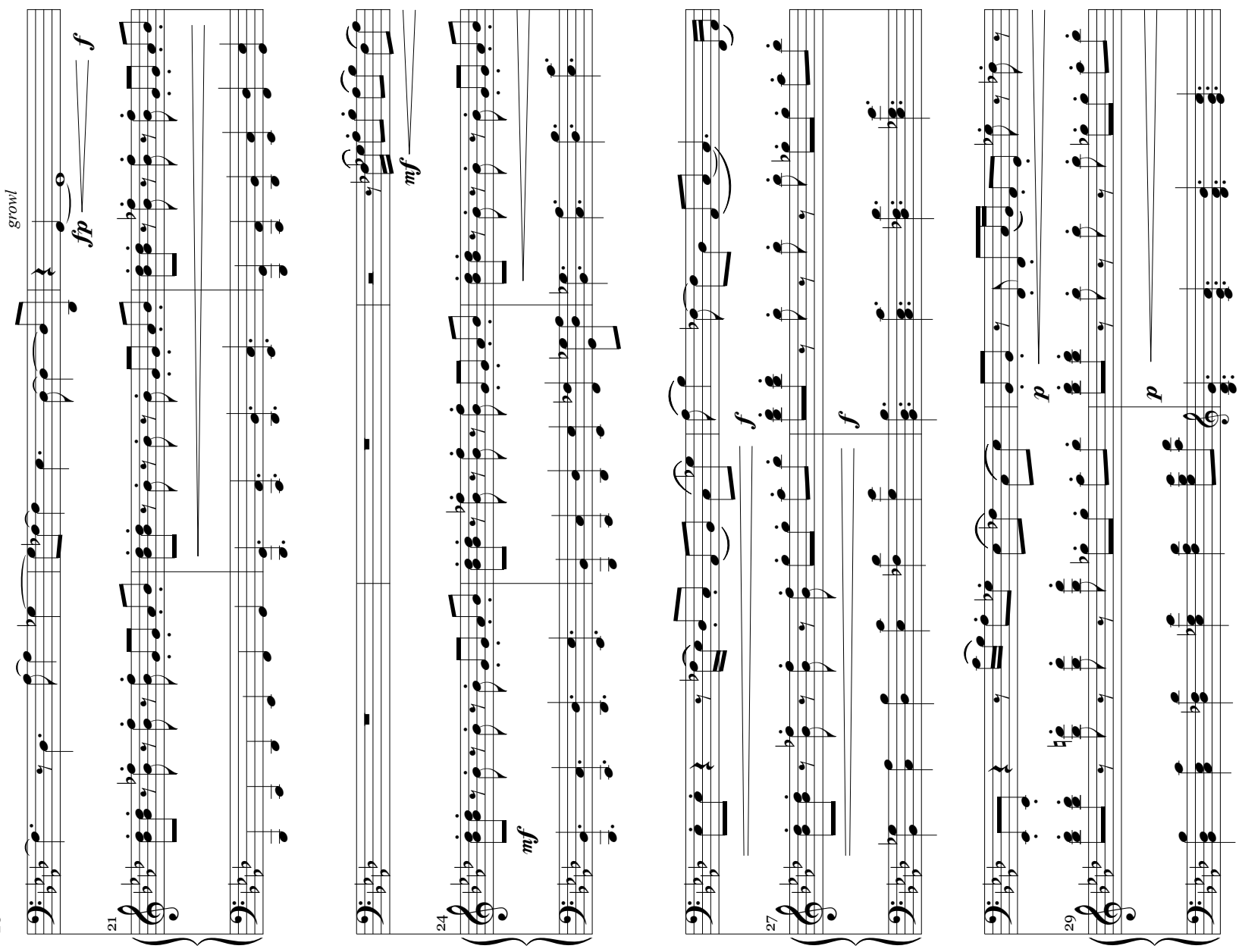

"

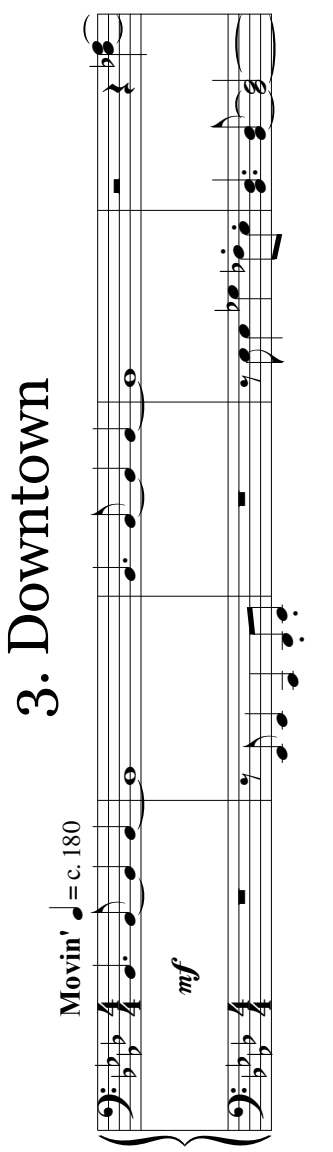

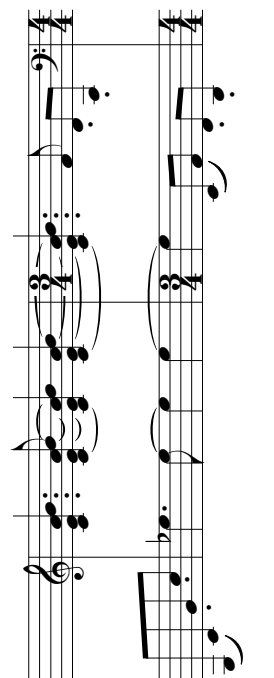
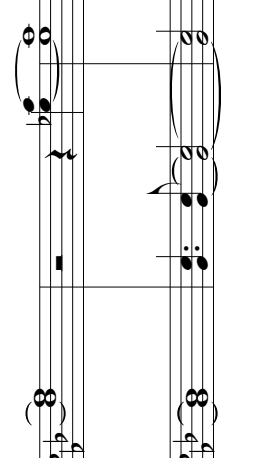

.

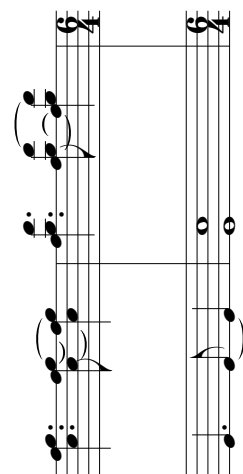

:
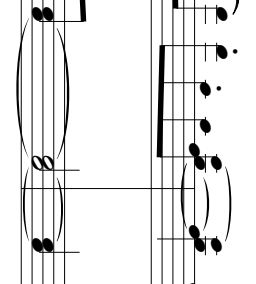

(i)

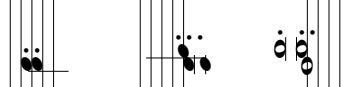

$\ddot{m} \quad \ddot{\theta} \quad \dot{\theta} \ddot{\theta}$

$\therefore 2$

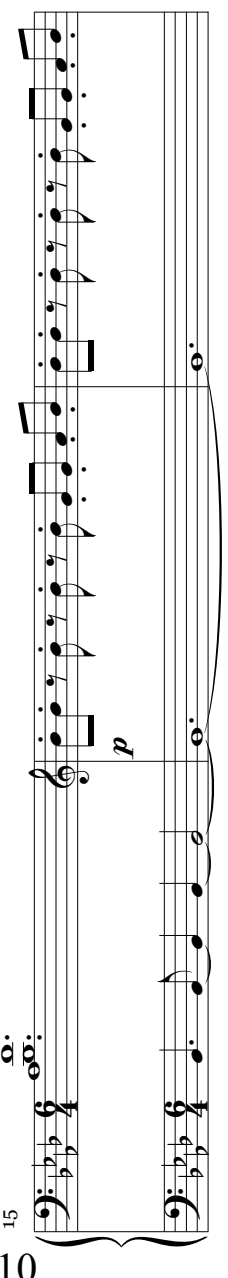

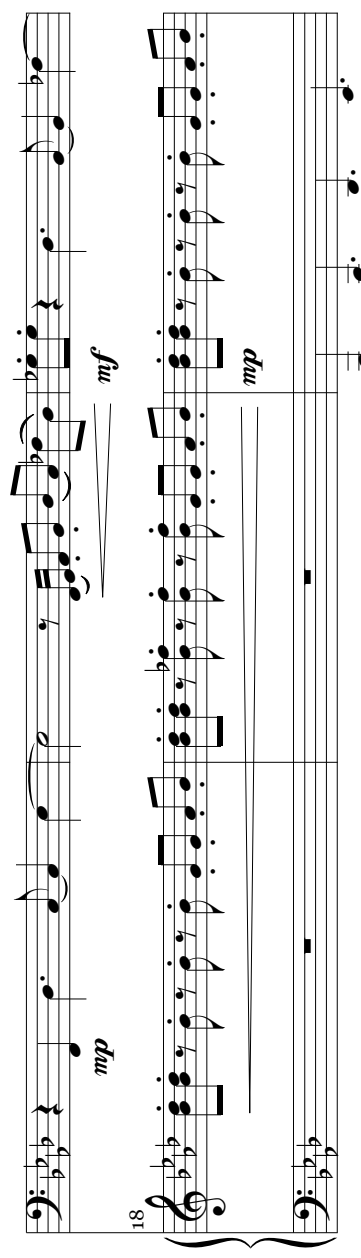



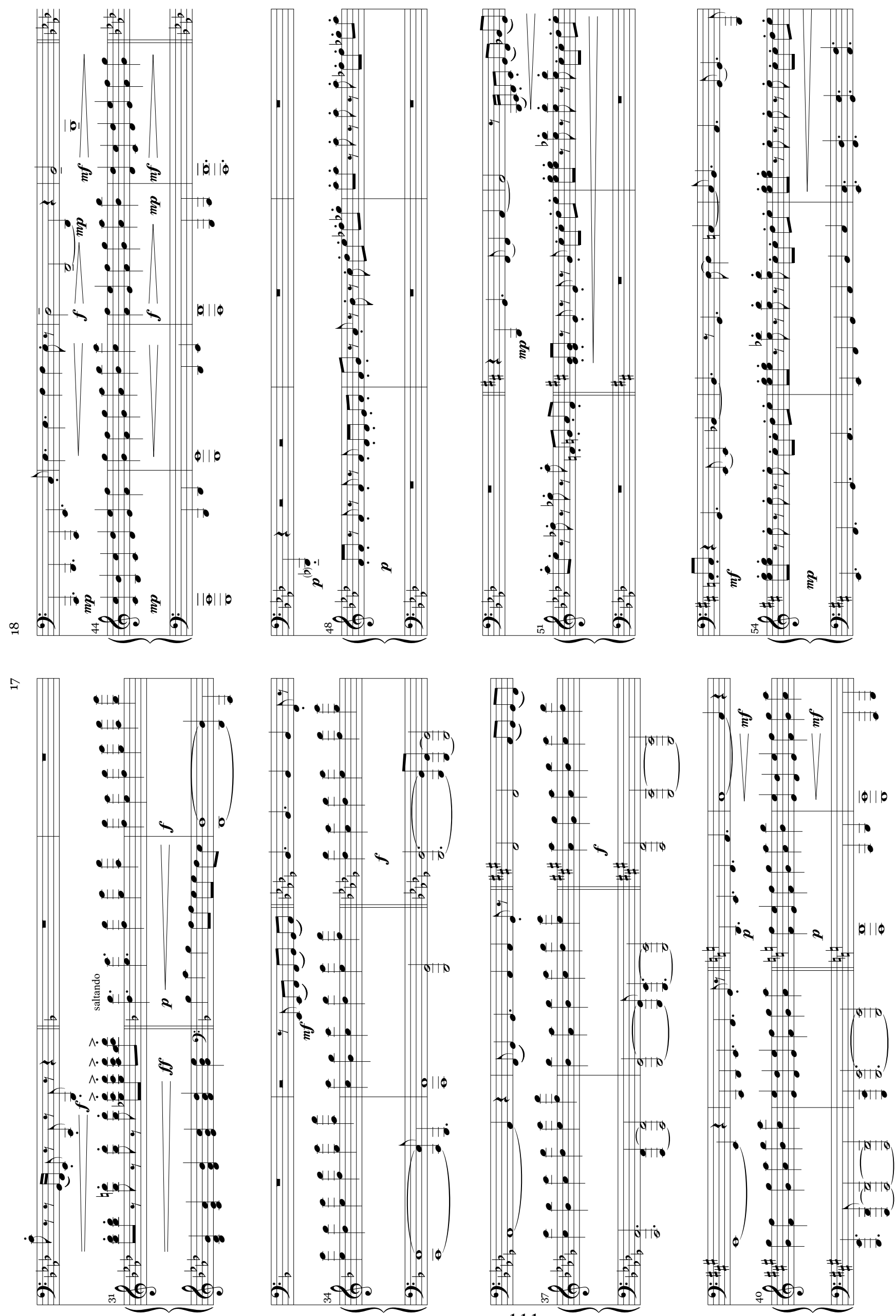


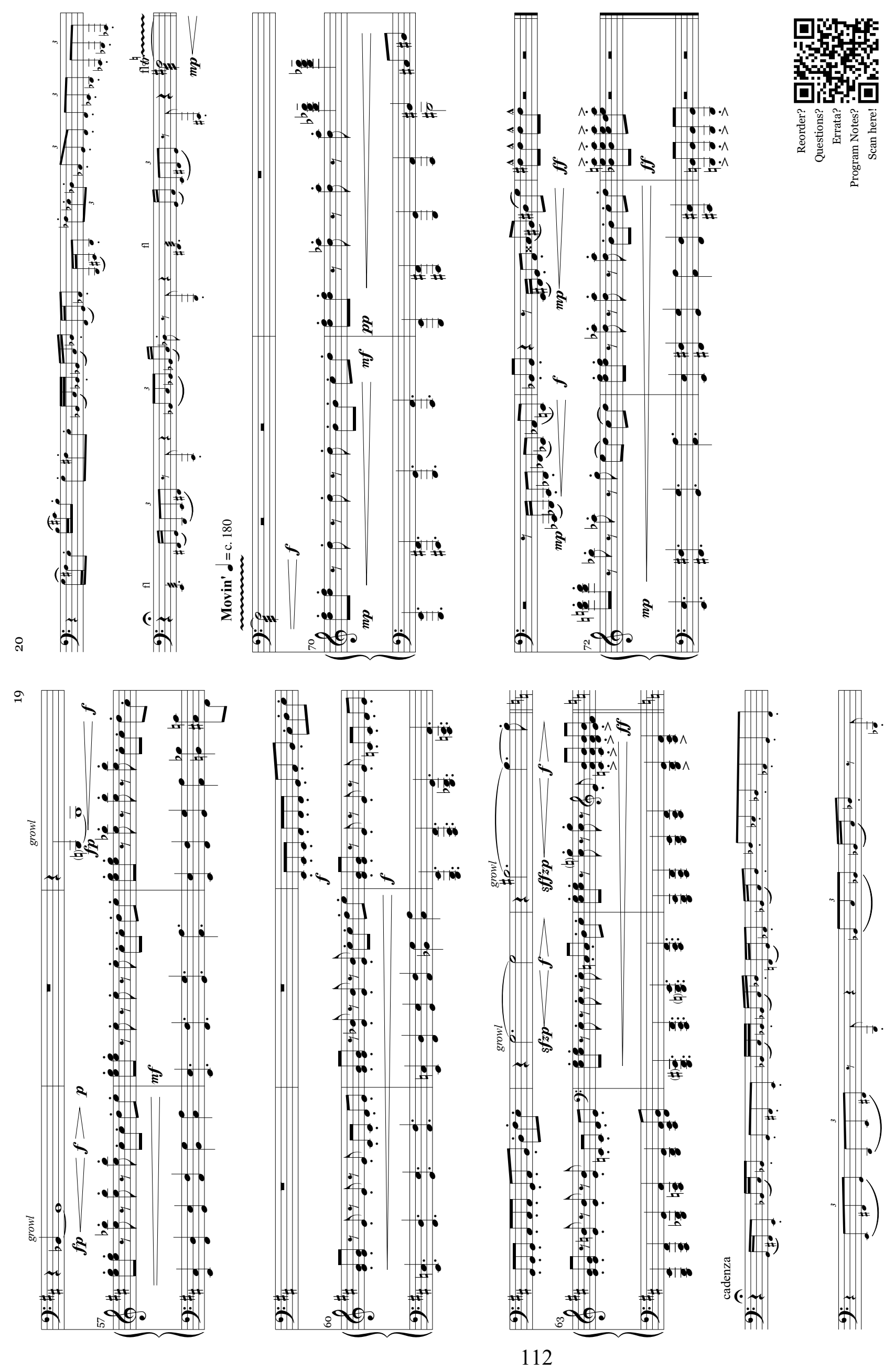

